\title{
WestVirginiaUniversity
}

THE RESEARCH REPOSITORY @ WVU

Graduate Theses, Dissertations, and Problem Reports

2009

\section{Post-transcriptional regulation of RpoS and HemA in Salmonella}

Amy Madeline Jones

West Virginia University

Follow this and additional works at: https://researchrepository.wvu.edu/etd

\section{Recommended Citation}

Jones, Amy Madeline, "Post-transcriptional regulation of RpoS and HemA in Salmonella" (2009). Graduate Theses, Dissertations, and Problem Reports. 2888.

https://researchrepository.wvu.edu/etd/2888

This Dissertation is protected by copyright and/or related rights. It has been brought to you by the The Research Repository @ WVU with permission from the rights-holder(s). You are free to use this Dissertation in any way that is permitted by the copyright and related rights legislation that applies to your use. For other uses you must obtain permission from the rights-holder(s) directly, unless additional rights are indicated by a Creative Commons license in the record and/ or on the work itself. This Dissertation has been accepted for inclusion in WVU Graduate Theses, Dissertations, and Problem Reports collection by an authorized administrator of The Research Repository @ WVU.

For more information, please contact researchrepository@mail.wvu.edu. 


\title{
Post-transcriptional Regulation of RpoS and HemA in Salmonella
}

\author{
Amy Madeline Jones \\ Dissertation submitted to the \\ School of Medicine at West Virginia University \\ In partial fulfillment of the requirements \\ For the degree of \\ Doctor of Philosophy \\ in \\ Microbiology and Immunology
}

Committee members

Thomas Elliott, Ph.D, Chair

Slawomir Lukomski, Ph.D.

Joan Olson, Ph.D.

Lisa Salati, Ph.D.

Andrew Shiemke, Ph.D.

Department of Microbiology and Immunology

Morgantown, WV

2009

Keywords: RpoS, sRNA, HemA, heme, Salmonella, E. coli 


\title{
ABSTRACT \\ Post-transcriptional regulation of RpoS and HemA in Salmonella
}

\begin{abstract}
Amy Madeline Jones
The first part of this thesis is dedicated to translational regulation of rpoS mRNA by the small noncoding RNAs (sRNAs), DsrA and RprA, in two closely related enteric bacteria, Escherichia coli, and Salmonella enterica serovar Typhimurium. The rpoS gene encodes a second vegetative sigma factor for RNA polymerase, which directs the cell's transcriptional response to general stress and entry into stationary phase. The rpoS gene is highly conserved among the $\gamma$-branch of proteobacteria, and sRNAs are highly conserved in related species. In fact, sequence conservation is thought to have predictive value in sRNA discovery and functional conservation is largely assumed. First discovered in E. coli, DsrA and RprA were shown to activate $r p o S$ translation in response to low temperature and osmotic shock respectively. Base pairing between these sRNAs and rpoS mRNA disrupts a hairpin in the untranslated leader region of $r p o S$ that blocks ribosome binding. The function of these sRNAs was tested in $S$. enterica serovar Typhimurium under the same conditions reported to be important for their function in $E$. coli. Neither DsrA nor RprA was required for $r p o S$ regulation in S. enterica. Importantly, this work demonstrates that sRNA function cannot be inferred from sequence conservation.

The second part of this thesis provides evidence for a model in which heme biosynthesis in $S$. enterica is feedback regulated by heme at HemA, the enzyme catalyzing the first committed step of the pathway. HemA is primarily regulated by conditional stability, becoming more stable in response to heme limitation and subject to rapid turnover by $\mathrm{ClpAP}$ and Lon proteases when not limited for heme. The first 18 amino acids of HemA are sufficient for protease recognition, however other regions of the protein are required for heme-responsiveness. Although examples of direct feedback inhibition by heme exist in other organisms, the mechanism by which HemA is targeted for proteolysis in S. enterica is unknown. A model in which heme functions as a proteolytic tag by directly binding HemA is supported by the following: (i) Purified HemA from $S$. enterica contains bound heme, (ii) mutation of a single cysteine residue (C170) results in purified HemA that lacks bound heme, and (iii) the C170A mutant protein is stable in vivo.
\end{abstract}




\section{Acknowledgments}

I would not have made it this far without the support of some really amazing people; Deborah and Donald Jones, my parents, who told me I could do it, but would love me anyway if I didn't, my minion and dear friend, Matt Novotny, who kept me going when I was sometimes sure I couldn't. My heartfelt thanks to Andrew Hiss and Maret Bernard, both of whom never failed to lend me a shoulder, a couch, and a wireless connection. Thanks also to Adrian Larry for providing the soundtrack. 


\section{Table of Contents}

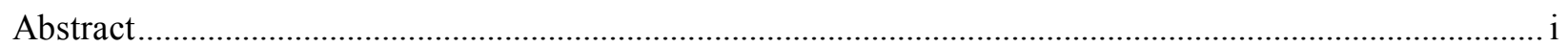

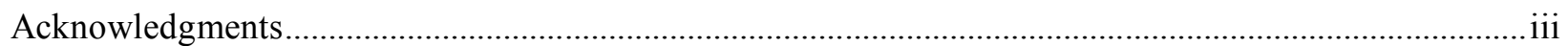

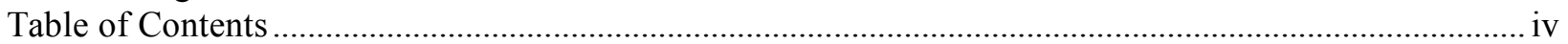

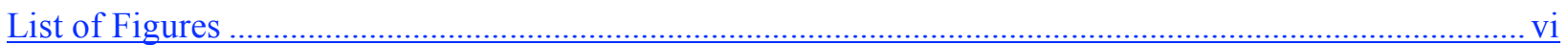

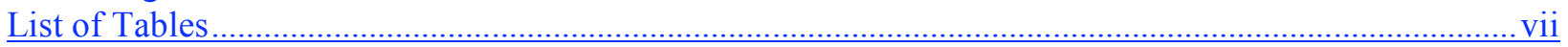

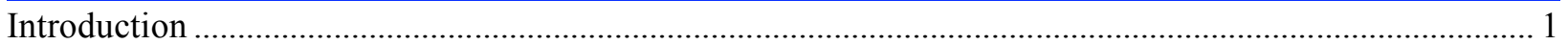

Chapter 1: Literature Review: Small RNA regulators of rpoS translation................................................. 2

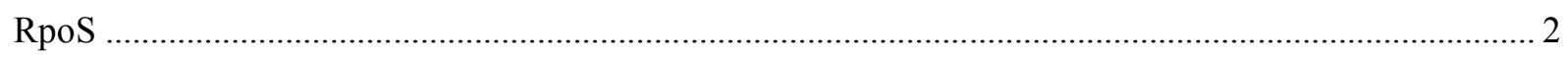

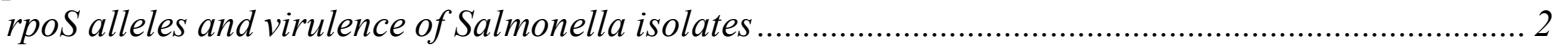

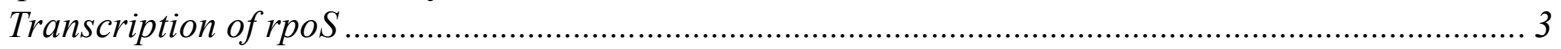

The antisense element model of rpoS regulation.......................................................................... 4

Evidence for the antisense element

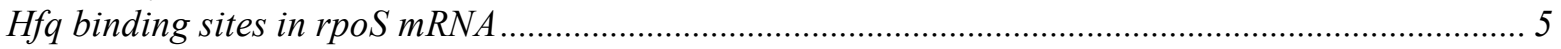

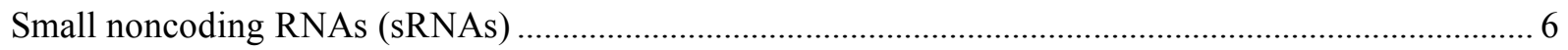

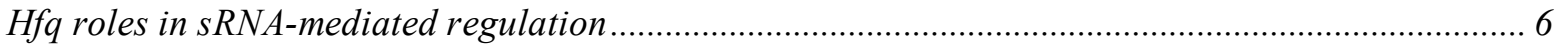

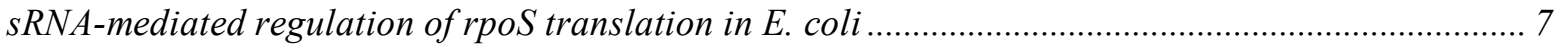

E. coli and S. enterica: conservation of $r p o S$, $d s r A$, and $r p r A$................................................... 8

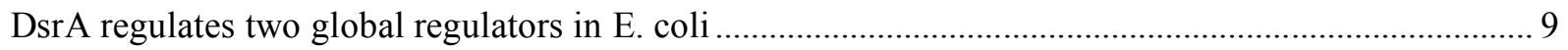

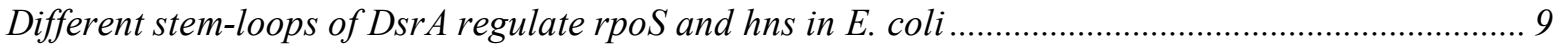

Dsr A regulation of rpoS in E. coli vs. S. enterica .......................................................................... 10

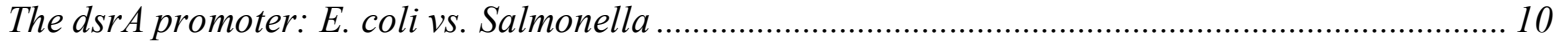

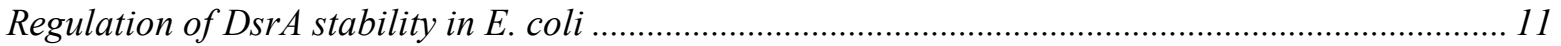

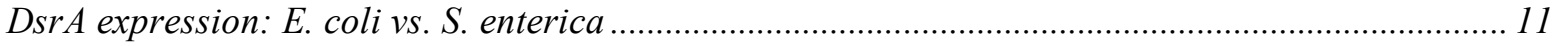

RprA: a second sRNA positively regulating rpoS translation ................................................................ 12

Regulation of rpoS in response to osmotic shock and a constitutive $\mathrm{rcs} C \mathrm{C}$ allele .............................. 12

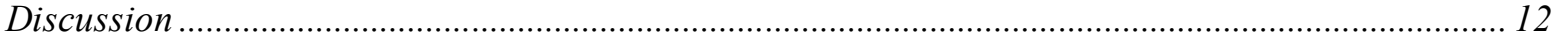

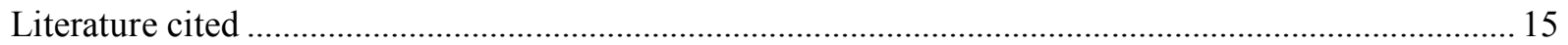

Chapter 2 : Limited role for the DsrA and RprA regulatory RNAs in rpoS regulation in Salmonella

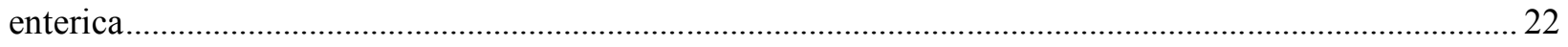

Abstract

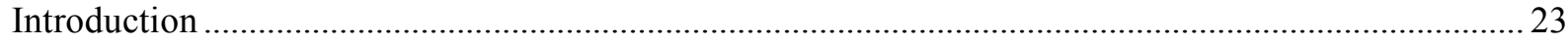

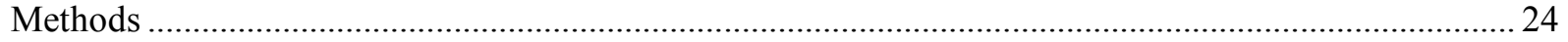

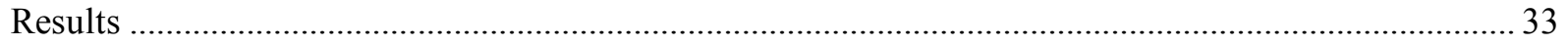

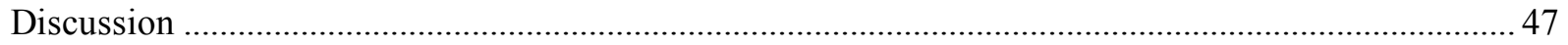

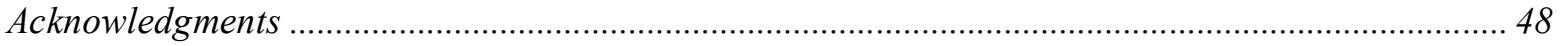

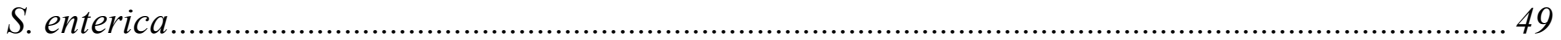

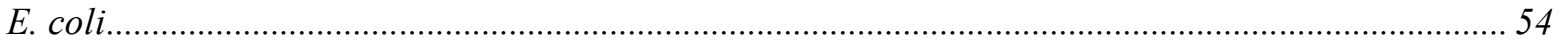

iv 
Heme.

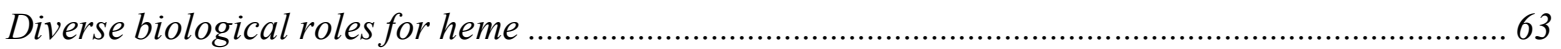

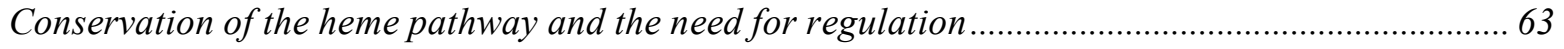

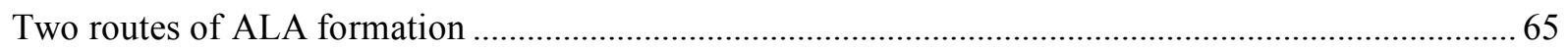

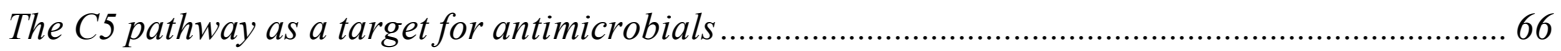

Formation of ALA is the rate-limiting step of heme biosynthesis in eukaryotes ................................ 66

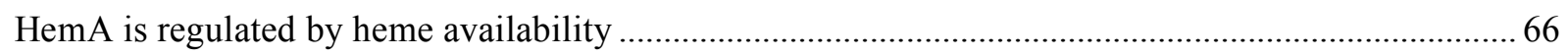

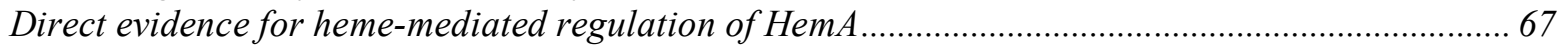

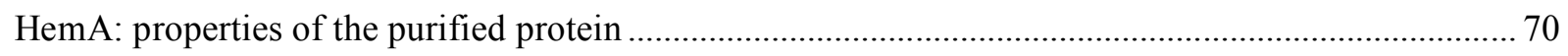

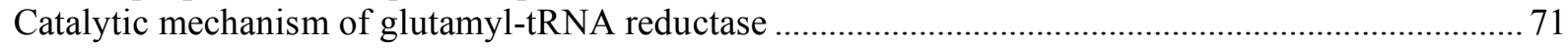

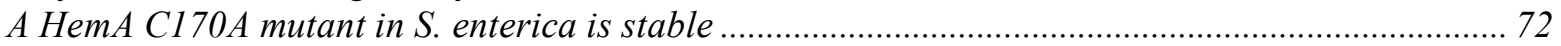

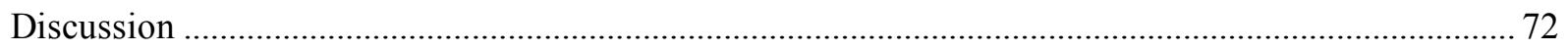

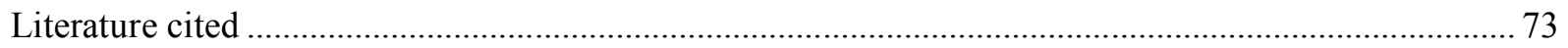

Chapter 4: A purified mutant HemA protein from Salmonella enterica serovar Typhimurium lacks bound heme and is defective for heme-mediated regulation in vivo ................................................................... 78

Abstract

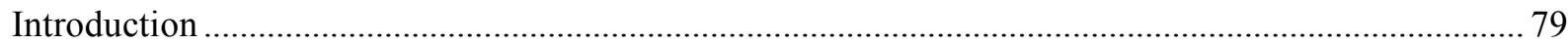

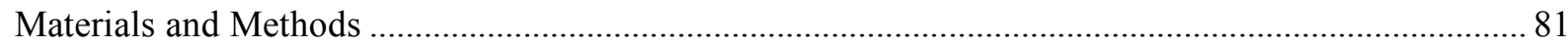

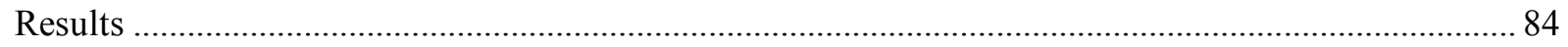

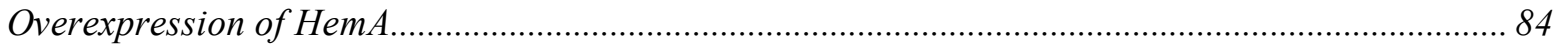

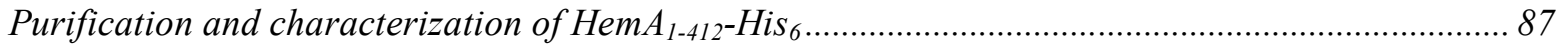

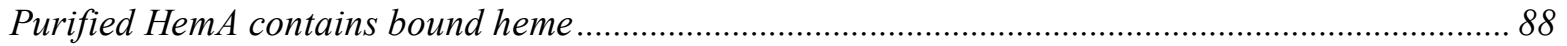

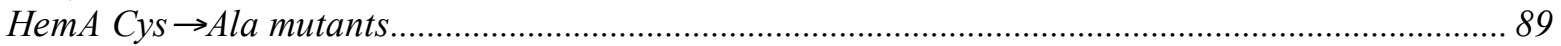

Purification and characterization of His-tagged HemA C170A...................................................... 91

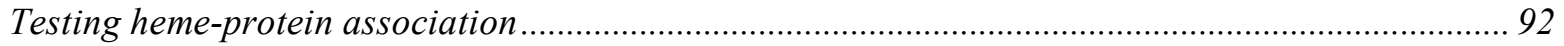

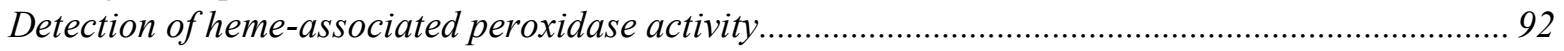

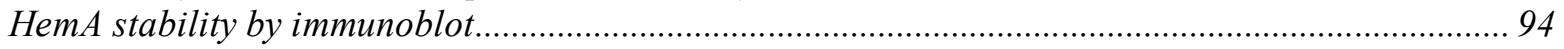

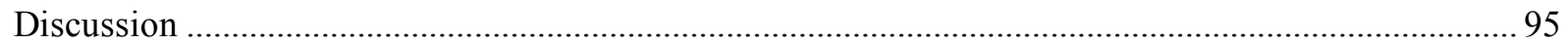

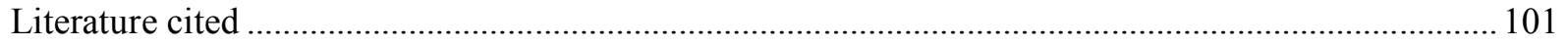




\section{List of Figures}

\section{ChaPTER ONE}

Figure 1. Transcription of $\mathrm{rpoS}$ from PrpoS ………...................................................................................

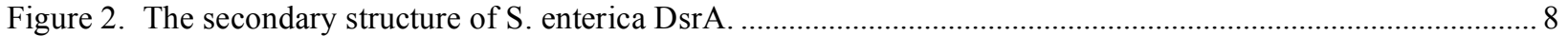

\section{Chapter Two}

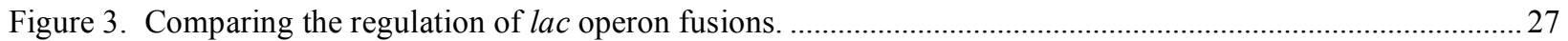

Figure 4. The RNA sequence of a segment of the $565 \mathrm{nt}$ S. enterica rpoS leader RNA ………................................33

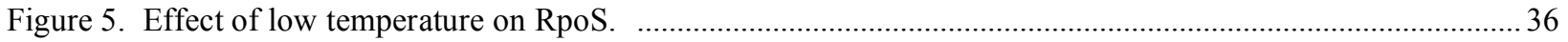

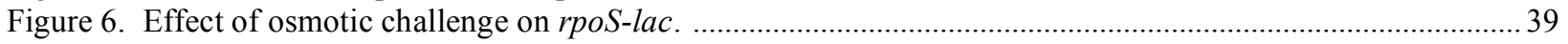

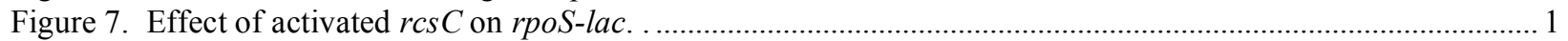

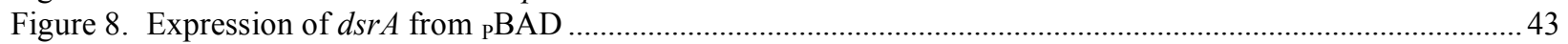

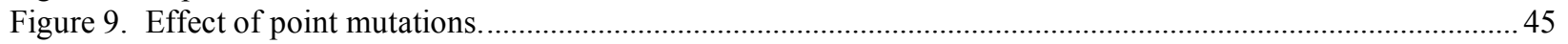

\section{CHAPTER THREe}

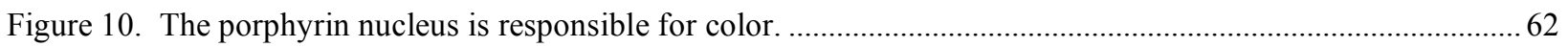

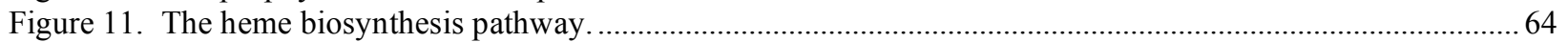

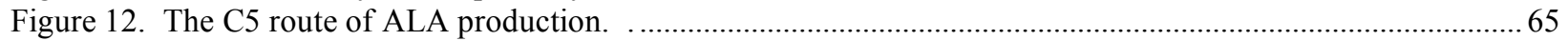

Figure 13. The heme biosynthesis pathway and genes encoding the enzymes ........................................................ 68

\section{CHAPTER FOUR}

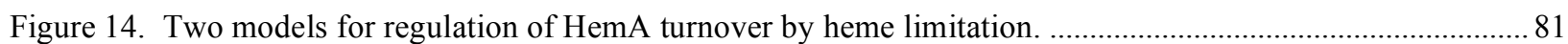

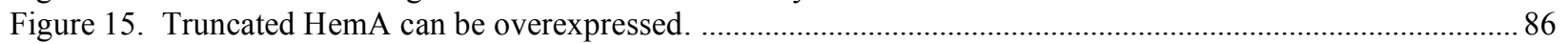

Figure 16. Truncated and FLAG-tagged HemA is correctly regulated by heme. ....................................................... 1

Figure 17. Purified $\mathrm{HemA}_{1-412}-\mathrm{His}_{6}$ has a heme $b$ type spectrum............................................................................ 1

Figure 18. Western blot analysis of HemA Cys $\rightarrow$ Ala mutants in stationary phase.................................................... 1

Figure 19. HemA[C170A] is a regulatory mutant. ........................................................................................... 91

Figure 21. ECL detection of heme-associated peroxidase activity in purified HemA. …………….......................... 93

Figure 20. Characteristic heme b peaks are absent from the HemA[C170A] spectrum............................................. 1

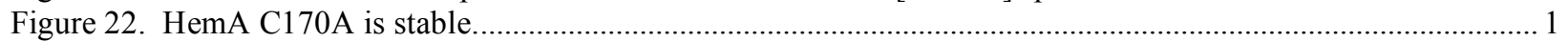




\section{List of Tables}

\section{CHAPTER Two}

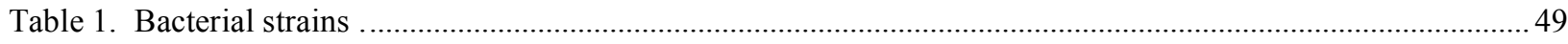

\section{Chapter Three}

Table 2. Heme content and heme inhibition of HemA from various sources... ……….............................................. 71

\section{CHAPTER FOUR}

Table 3. Bacterial strains. 


\section{Introduction}

Theoretically, one can make connections between any two proteins in a given cell if no limit is placed on the number of intermediate steps and no constraints are imposed regarding physiological relevance or experimental evidence. Although the proteins described in this thesis, RpoS and HemA, are important for Salmonella virulence, are primarily post-transcriptionally regulated, and can theoretically be connected by as few as four or five intermediate steps, this would be somewhat contrived. Therefore they will be treated as separate entities since this was the manner in which they were experimentally approached.

If there is an underlying theme that unifies these topics it is that post-transcriptional regulation often involves elaborate schemes, requiring complex coordination of multiple proteins and a diverse group of molecules, which can include RNA, metal ions, gases, and other small molecules. Furthermore,

differential regulation of conserved genes between closely related organisms may be more prevalent than currently recognized. Determining what accounts for reported differences in regulation of homologous genes in E. coli and S. enterica may illuminate pathogen-specific mechanisms. 


\section{Chapter 1: Literature Review: Small RNA regulators of rpoS translation}

\section{RpoS}

Exchangeable proteins called sigma factors are essential for promoter recognition by RNA polymerase in prokaryotes. The "housekeeping" sigma factor, Sigma $\mathrm{D}\left(\mathrm{RpoD}, \sigma^{70}\right)$ is responsible for transcription of most genes during normal growth. Bacteria also employ alternative sigma factors that tailor the cell's transcriptional response to certain stresses or environmental cues. RpoS (sigma S, $\sigma^{S}$,

$\sigma^{38}$ ) is the general stress and stationary phase sigma factor of Escherichia coli, Salmonella spp., and other enteric bacteria, which directs RNA polymerase to transcribe genes belonging to a large regulon, the size of which is second only to that of RpoD; constituting $10 \%$ of genes in E. coli (53). RpoS regulation is complex, occurring at the levels of transcription, translation, proteolysis, and activity; and in response to various stress signals, including low temperature, high osmolarity, carbon starvation, and low $\mathrm{pH}$ (reviewed in 14). This has earned RpoS the title "the master regulator of the stress response."

\section{rpoS alleles and virulence of Salmonella isolates}

Pathogens experience a variety of stresses within the host environment (reviewed in 43). In mice, infection with Salmonella enterica serovar Typhimurium (hereafter referred to as S. enterica), results in a typhoid-like disease, which provides an effective animal model for the human-specific pathogen Salmonella enterica serovar Typhi (9). S. enterica rpoS mutants are attenuated for virulence in mice (9). Attenuation is attributed to the requirement for RpoS in regulation of genes located on the virulence plasmid, and expression of genes necessary for survival within macrophages $(7,9)$. 
S. enterica LT2 has been widely used in genetic studies since its original isolation in the 1940s, however the LT2 strain is attenuated for virulence in mice due to a defective $r p o S$ allele $(50,54)$. The rpoS start codon in LT2 is a non-optimal UUG, as opposed to the AUG start in virulent isolates, such as SL1344 and ATCC 14028s. Virulence can be restored to LT2 by replacement of its rpoS allele with that of a virulent strain, or by mutation of mouse virulence gene A, mviA $(2,50)$. Mutations in $m v i A$ result in increased stability of RpoS due to defective turnover, which partially compensates for the lower expression level (2). These observations illustrate the importance of cellular RpoS levels in S. enterica virulence, indicating a requirement for strict regulation in response to stress.

\section{Transcription of rpos}

The rpoS promoters of E. coli and Salmonella enterica serovars Dublin and Typhimurium have been characterized $(15,21,36)$. The rpoS gene is transcribed from two promoter regions; two closely spaced and relatively weak promoters upstream upstream of the adjacent $n l p D$ gene, and the major rpoS promoter, PrpoS, located approximately in the middle of the $n l p D$ gene (Fig 1A). Transcription from $\operatorname{PrpoS}$ generates a monocistronic rpoS transcript with a 565-nt 5' untranslated leader region (5'UTR). The -35 and -10 hexamers, the length of the 17 bp spacer, and the transcription start site are identical in Salmonella and E. coli $(15,21,36)$. 
A

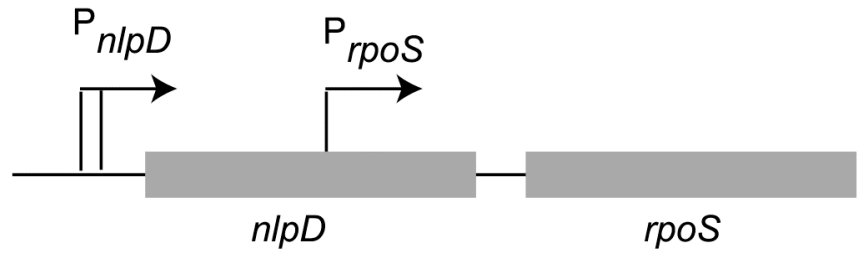

$\mathrm{B}$

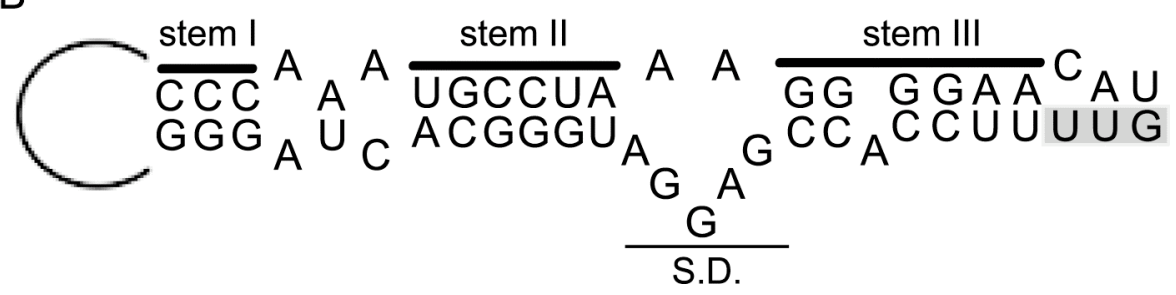

Figure 1. Transcription of rpoS from PrpoS (A), yields a transcript with a long 5 untranslated leader region, which contains an antisense element (B). (A) Two rpoS promoter regions. The PnlpD promoters produce basal levels of rpoS. The major promoter, PrpoS. (B) Nucleotides immediately upstream of the start codon (shaded in grey) base pair with an upstream antisense element (overlined) forming three stems. The Shine-Dalgarno (S.D.) sequence is looped out between stems II and III, which blocks ribosome binding. The open circle represents 63 omitted nts.

\section{The antisense element model of rpoS regulation}

Within the 5'UTR of rpoS mRNA, base pairing between nucleotides immediately upstream of the initiation codon and an upstream antisense element results in the formation of three stems (Fig. 1B). Stems II and III flank the Shine-Dalgarno (S.D.) complementarity to 16S rRNA and ribosome binding is inhibited. Therefore, the default state for translation is 'off'. This model is supported by in silico structural modeling and genetic analyses incorporating point and compensatory mutations of predicted pairing partners within stems $(6,8,18,27)$. With the exception of the start codon, the nucleotides within the hairpin are completely conserved between E. coli and S. enterica. 


\section{Evidence for the antisense element}

The antisense model was first proposed by in silico structural modeling of E. coli rpoS mRNA and recognition of its apparent similarity with rpoH mRNA, which was known to be under antisense control (20). Although the proposed structure was incorrect, subsequent reports by Elliott and coworkers supported an antisense mechanism of regulation. In both E. coli and S. enterica, RpoS levels are dramatically reduced in $h f q$ mutants as a result of inefficient translation $(5,35)$. Authors speculated that Hfq, an RNA binding protein, regulates $r p o S$ translation by altering the proposed antisense structure (5). In S. enterica, suppressor mutations that decrease the in vivo dependence of rpoS-lac expression on Hfq were identified. Most mapped to stems II and III (6).

Further evidence for the structure was obtained by a genetic analysis of the central GC pairs of SII and SIII. The rationale directing this analysis is that if pairing alone is important for Hfq function, then single changes will confer a mutant phenotype, but a double mutant has compensatory changes that allow pairing, and will restore the wild-type phenotype. The single stem II mutants, C126G and G206C, exhibited increased rpoS-lac expression and decreased dependence on Hfq; the C126G/G206C double mutant strongly resembled wild type (6). However, for both E. coli and S. enterica, single mutations within the upper strand of stem III result in a mutant phenotype, but the suppressing effect of the compensatory mutation is incomplete $(6,18)$.

\section{Hfq binding sites in rpoS mRNA}

Hfq preferentially binds A/U-rich sequences, usually flanked by one or more hairpins $(4,55)$. Although the effect of Hfq on rpoS translation is localized to the antisense element, Hfq doesn't directly bind at this site (25). The Hfq-responsive element within the rpoS leader is located $>100$ nts upstream of the antisense element (8). A stretch of 11 single-stranded nts containing AAYA repeats is located 
approximately $100 \mathrm{nts}$ upstream of the antisense element and is necessary for sensitivity to Hfq (48).

Other proposed binding sites include a stretch of unpaired nts (5'UUAUU) within the $63 \mathrm{nt}$ loop adjacent to the antisense element (Fig. 1B), and the sequence 5'AUUUUG just opposite the AUG codon (25). How these sites contribute to $r p o S$ regulation is unclear. However, an important discovery helped bridge the apparent regulatory gap between $r p o S$ and Hfq; the fortuitous identification of small noncoding RNAs (sRNAs) that regulate rpoS in an Hfq-dependent manner.

\section{Small noncoding RNAs (sRNAs)}

Small noncoding RNAs (sRNAs), many of which are expressed in response to a specific environmental cue, function by modulating the translational efficiency and/or stability of their mRNA target(s) $(13,30,40,52)$. An sRNA typically contains a stretch of $\sim 10$ to 25 nucleotides that has the potential to pair with its target, although in some cases it has been experimentally determined that only a core subset of these are necessary for regulation (reviewed in 12). Base pairing between sRNA and mRNA is dependent on Hfq $(12,52)$. Many sRNAs are highly conserved in closely related bacteria, suggesting an important function (12). Most regulation mediated by sRNAs is negative, resulting in inhibited translation, enhanced degradation, or a combination of these.

\section{Hfq roles in sRNA-mediated regulation}

A well-documented role for Hfq is stabilization of sRNAs. Several sRNAs exhibit decreased stability in an $h f q$ mutant background and many accumulate at lower levels $(31,34,47,51,56)$. Like Hfq, RNase E targets $\mathrm{A} / \mathrm{U}$-rich sequences with adjacent secondary structure $(19,26)$. In some cases Hfq stabilizes RNAs by blocking cleavage sites $(31,33,56)$. Hfq also facilitates RNA-RNA interactions. Hfq has two independent RNA-binding surfaces $(1,32)$ and it has been demonstrated that Hfq can form stable ternary complexes with two RNA strands $(48,55)$. Hfq is proposed to promote annealing by increasing the local 
concentration of RNAs $(32,49)$. It has been reported that Hfq effects structural changes in some RNAs and may facilitate RNA-RNA strand exchange $(1,11,33)$. Finally, Hfq is known to associate with many proteins, including components of the ribosome and the degradosome and it has been suggested that Hfq may recruit these as part of its regulatory function (reviewed in 3).

\section{sRNA-mediated regulation of rpoS translation in E. coli}

In E. coli, DsrA and RprA activate rpoS translation in an Hfq-dependent manner in response to low temperature and osmotic shock respectively. A role for RprA in cell envelope stress is suggested by a largely RprA-dependent increase in $r p o S$ expression in response to a constitutive $r c s C$ allele $(39,40)$. These sRNAs function via an anti-antisense mechanism. Both contain short stretches of complementary sequence to the same region of $r p o S$ and activate translation by base pairing with the antisense element. This disrupts the hairpin and opens the translation initiation region to ribosomes $(12,13)$. 
A

\section{SL-2}

$$
\begin{aligned}
& U_{C G}^{C}{ }^{C} \\
& G C
\end{aligned} \quad \text { SL-3 }
$$

SL-1 U A

SL-1

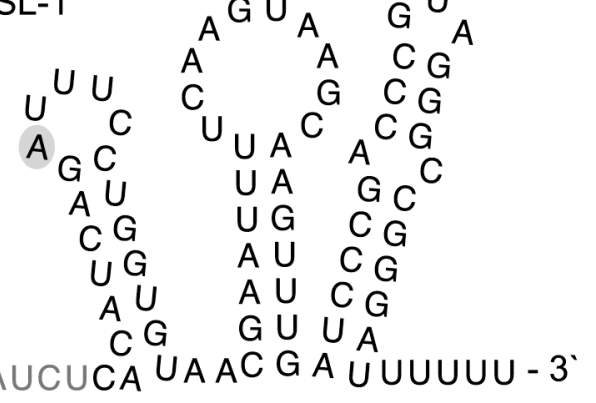

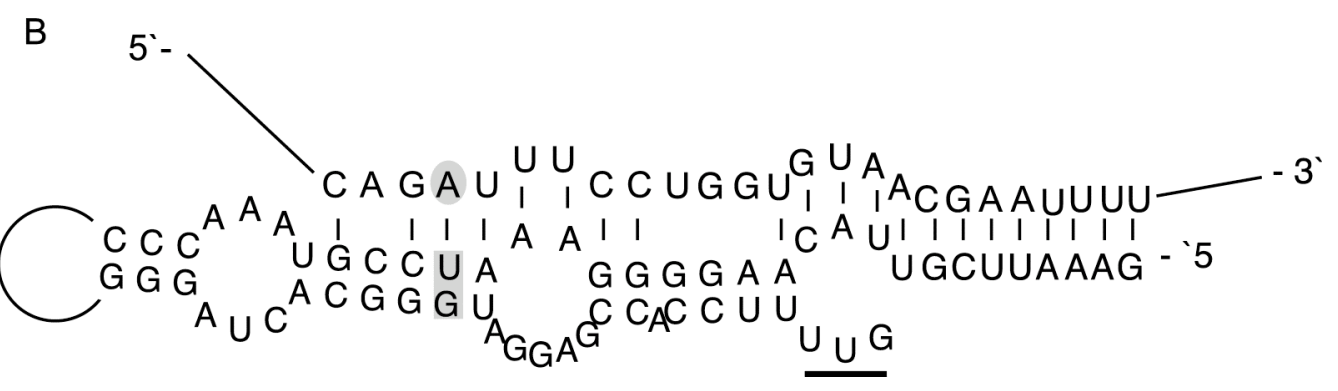

Figure 2. The secondary structure of S. enterica DsrA (A) as modeled by the Vienna RNA server (16). The shaded A in SL- is known to be important for binding rpoS in E. coli (28). (B) DsrA binds rpoS in the region of the antisense element. The U:G pair in stem II is one of several tested by point and compensatory mutation (6).

\section{E. coli and S. enterica: conservation of rpoS, dsrA, and rprA}

It has been suggested that a high degree of sRNA sequence conservation in closely related bacteria indicates conserved function (12). DsrA and RprA functions were initially characterized in E. coli (27, 29). The sequence of $d s r A$ in $S$. enterica shows eight substitutions and three missing nucleotides compared to $E$. coli $(\approx 90 \%$ identity), and these changes do not result in significant alteration of the DsrA structural model $(18,23,35)$. With only three substitutions over $107 \mathrm{nts}$, the $S$. enterica rprA gene 
exhibits even higher identity to its E. coli counterpart (18). The nucleotides of both sRNAs that interface with rpoS are completely conserved between E. coli and S. enterica (18).

\section{DsrA regulates two global regulators in E. coli}

DsrA is the best-characterized sRNA regulating rpoS. DsrA is an 85-nt sRNA initially discovered in E. coli as a multicopy activator of capsule synthesis (cps) genes. Transcription of the $\operatorname{rcs} A$ gene, which encodes an unstable positive regulator of cps genes, is silenced by H-NS (45). H-NS is a global regulator and represses the expression of at least 250 genes (17). DsrA overexpression decreases H-NS levels by inhibiting its translation (22). The discovery that DsrA also regulates rpoS identifies DsrA as a regulator of two global regulators, perhaps serving to fine-tune the response to stress signals in which RpoS and HNS act antagonistically.

\section{Different stem-loops of DsrA regulate rpoS and hns in E. coli}

In vitro structure probing and computer-assisted modeling have predicted no less than three structures for DsrA. In all proposed models, DsrA is configured into three stem-loops (Fig. 2A); the first and third are relatively stable and similar in all models, while the second is unstable and predicted to form alternative structures (42). A mutational dissection of DsrA revealed independent functions for each stemloop. In general, stem-loop 1 (S-L1) regulates rpoS, S-L2 regulates hns, and S-L3 is a transcriptional terminator $(23,24)$. DsrA activates rpoS translation by direct interaction with rpoS mRNA (Fig. 2B; 27, 29). Plasmid-expressed constructs of $d s r A$ either deleted for S-L1 ( $\Delta \mathrm{S}-\mathrm{L} 1)$ or with an NcoI site introduced between S-L1 and S-L2 failed to induce an rpoS-lacZ translational fusion. Activity was restored by compensatory mutations in rpoS. Anti-H-NS activity was maintained in the $\Delta \mathrm{S}-\mathrm{L} 1$ and $N c o I$ DsrA mutants, demonstrating the functional and structural separation of this activity (27). These analyses defined sequence and structural elements necessary for regulation of DsrA's two targets, demonstrated the 
requirement for direct pairing between DsrA and $r p o S$ in activating rpoS translation, and provided further support for the structure of the antisense element.

\section{DsrA regulation of rpoS in E. coli vs. S. enterica}

A link between rpoS and DsrA was discovered in studies directed at determining a role for DsrA when expressed at physiological levels (46). Expression of a $d s r B:: l a c Z$ transcriptional fusion increased in stationary phase, indicative of RpoS regulation, and increased at low temperatures in a $d s r A^{+}$host. Decreased $d s r B:: l a c Z$ expression in a $d s r A$ mutant was determined to be an indirect effect mediated by decreased RpoS synthesis. Using a combination of rpoS::lacZ fusions and Northern and Western blot analyses, it was determined that increased levels of RpoS at low temperature $\left(\leq 30^{\circ} \mathrm{C}\right)$ in exponential phase is dependent on DsrA translational activation of rpoS mRNA (46). In S. enterica, a modest ( $\approx 2-$ fold) induction of RpoS expression at $18^{\circ} \mathrm{C}$ compared to $37^{\circ} \mathrm{C}$ is independent of DsrA and RprA (18).

\section{The dsrA promoter: E. coli vs. Salmonella}

At low temperatures (below $37^{\circ} \mathrm{C}$ ), DsrA levels in E. coli increase due to a combination of increased transcription from the $d s r A$ promoter and increased stability (38). Following the initial discovery that the minimal 36-bp promoter is sufficient for temperature regulation (38), it was determined that an unusual -10 box (TAAGGT) and an AT-rich 17-bp spacer were critical elements within it (39). The $-35,-10$, length of the spacer and sequence of the AT-rich motif are conserved between $E$. coli and $S$. enterica, suggesting that the $d s r A$ promoter in $S$. enterica should exhibit equivalent temperature induction. However, in Salmonella, a $d s r A:: l a c Z$ transcriptional fusion was induced only 2.5 - to 3-fold at $18^{\circ} \mathrm{C}$ versus $37^{\circ} \mathrm{C}(18)$ compared to the 6 -fold increase at $25^{\circ} \mathrm{C}$ versus $42^{\circ} \mathrm{C}$ reported for the E. coli $d s r A$ promoter (38). 


\section{Regulation of DsrA stability in E. coli}

Determination of DsrA levels by Northern analysis revealed two DsrA bands; one corresponds to the full-length sRNA (F form, $\sim 85 \mathrm{nts}$ ), and the second is a truncated species ( $\mathrm{T}$ form) of $\sim 60 \mathrm{nts}$. The T form, which is detected by Northern blot using a probe complementary to S-L2, but not S-L1, is likely a processing product of RNase cleavage (38). Hfq is required for DsrA-mediated regulation of both rpoS and $h n s$ (47). In an $h f q$ mutant background, DsrA is 6-fold less stable than wild type and only the truncated form of DsrA is detected. In vitro, Hfq specifically interacts with DsrA, protecting select nts from RNase cleavage (47). Both RNase E and RNase III have been implicated in DsrA-mediated regulation of $r p o S$. At the non-permissive temperature, the steady-state levels of DsrA in an $r n e^{\text {ts }}$ strain (temperature sensitive RNase E mutant) are increased and the F form is the dominant species (33). In vitro, RNase E cleaves DsrA at nt A28, but only in the absence of Hfq (33). Resch and coworkers proposed a model in which pairing of DsrA with rpoS eliminates detrimental RNase III cleavage at two positions upstream of the S.D. sequence, and creates a new cleavage site $r p o S$ in the strand opposite the intiation codon (41). DsrA itself is cleaved between A28 and A29 dependent on association with rpoS, thus providing a mechanism for DsrA de-activation.

\section{DsrA expression: E. coli vs. S. enterica}

In E. coli, DsrA is easily detected by Northern blot using probes complementary to S-L1 (F form) and S-L2 (T form). Overexpressed DsrA, of either E. coli or S. enterica origin, is detected in an E. coli dsrA mutant by Northern blot using a probe to S-L1. Chromosomal DsrA is also detected in wild type E. coli when samples are prepared from cultures incubated at $18^{\circ} \mathrm{C}$. In contrast, DsrA from either source was undetectable in all conditions tested in S. enterica (18). 


\section{RprA: a second sRNA positively regulating rpoS translation}

RprA was discovered in E. coli as a multicopy suppressor of $d s r A$ mutants (28). RprA levels increase in response to osmotic shock (28) and a constitutive $\operatorname{rcs} C$ allele, indicating a role cell envelope stress (10, 29). RprA has fewer complementary nucleotides when paired with rpoS mRNA than DsrA, with the longest region of complementary sequence (11 out of $13 \mathrm{nt}$ ) lying between A33 and U45 of RprA. Using DsrA as a model, Majdalani and co-workers investigated the role of RprA as an activator of rpoS

translation. RprA directly interacts with $r p o S$ mRNA. This was demonstrated by the mutant phenotype of point mutations in RprA that are restored to wild type by compensatory mutations in rpoS (29). Furthermore, DsrA and RprA bind the same region of the rpoS mRNA to stimulate rpoS translation (29).

\section{Regulation of rpoS in response to osmotic shock and a constitutive rcs C allele}

In an E. coli $d s r A$ mutant, the basal level of rpoS-lac activity was reduced compared to wild type, but induction in response to sucrose challenge was unaffected. Induction was nearly absent in the $d s r A \operatorname{rpr} A$ double mutant $(27,28)$. In contrast, an $S$. enterica $\operatorname{dsr} A \operatorname{rpr} A$ double mutant was no more defective than the single $d s r A$ mutant in response to osmotic shock (18). In E. coli, RprA and RpoS::LacZ levels are increased 50- and 20-fold respectively by a constitutive $r c s C$ allele (29). In $S$. enterica, a modest, 2.5 - to 3-fold increase in $r p o S$-lac expression by an $r c s C$ allele was independent of RprA (18).

\section{Discussion}

Examination of DsrA- and RprA-mediated regulation of rpoS in S. enterica was undertaken to address the general question: Can conservation of sRNA function be inferred from a high degree of sequence conservation? The primary sequences of $d s r A$ and $\operatorname{rpr} A$ in $E$. coli and $S$. enterica are $\geq 90 \%$ identical. Also, the region of $r p o S$ targeted by these sRNAs is, with the exception of the start codon (AUG in E. coli, UUG in $S$. enterica), completely conserved. The function of these sRNAs was tested in 
S. enterica under the same conditions reported to be important for their function in E. coli. Neither DsrA nor RprA was necessary for the relatively modest increases in RpoS expression seen in S. enterica at low temperature $\left(18^{\circ} \mathrm{C}\right)$ in response to osmotic shock, or cell envelope stress as tested in the context of a constitutive $\operatorname{rcs} C$ allele (18). The incongruity of these results begs the question: why are these genes maintained at such fidelity?

It is not uncommon for an sRNA to regulate more than one target (37). Although not required for increased rpoS translation in S. enterica, DsrA has at least one other target, HNS (45). Using a probe specific for stem-loop 1 (S-L1), DsrA was undetectable by Northern blot in S. enterica, suggesting rapid degradation (18). Although untested, Northern analysis of the same samples using a probe specific for SL2 might have yielded a signal corresponding to a truncated form as previously observed for E. coli (47). In E. coli, the truncated form of DsrA is defective for stimulating rpoS translation, but maintains most of its anti-H-NS activity (27). Therefore, it is possible that DsrA function is conserved in S. enterica with regard to H-NS.

An alternative explanation is that DsrA regulates $r p o S$ in $S$. enterica, but perhaps requires an additional stimulus. The demonstration that overexpressed $S$. enterica DsrA is nearly as capable as overexpressed E. coli DsrA in activating rpoS translation in E. coli supports this possibility (18). Furthermore, Sittka and coworkers, attempting to verify predicted sRNAs as well as isolate novel sRNAs, reported that both DsrA and RprA were expressed and associated with Hfq in S. enterica serovar Typhimurium isolate SL1344 (44). Employing anti-Hfq co-IP and high-throughput pyrosequencing, DsrA and RprA were sufficiently enriched to predict detection by Northern blot would be possible, although this was not attempted. The function of these sRNAs regarding rpoS or hns has not yet been tested in SL1344, however association with Hfq indicates they are functional regulators. In conclusion, a 
high level of sequence conservation between sRNAs of related species may indicate an important function, but it does not necessarily follow that it will be the same function in individual species. 


\section{Literature cited}

1. Arluison, V., S. Hohng, R. Roy, O. Pellegrini, P. Regnier, and T. Ha. 2007. Spectroscopic observation of RNA chaperone activities of Hfq in post-transcriptional regulation by a small non-coding RNA. Nucleic Acids Res 35:999-1006.

2. Bearson, S. M., W. H. Benjamin, Jr., W. E. Swords, and J. W. Foster. 1996. Acid shock induction of RpoS is mediated by the mouse virulence gene mviA of Salmonella typhimurium. J Bacteriol $178: 2572-9$

3. Brennan, R. G., and T. M. Link. 2007. Hfq structure, function and ligand binding. Curr Opin Microbiol 10:125-33.

4. Brescia, C. C., P. J. Mikulecky, A. L. Feig, and D. D. Sledjeski. 2003. Identification of the Hfq-binding site on DsrA RNA: Hfq binds without altering DsrA secondary structure. RNA 9:33-43.

5. Brown, L., and T. Elliott. 1996. Efficient translation of the RpoS sigma factor in Salmonella typhimurium requires host factor I, an RNA-binding protein encoded by the hfq gene. J Bacteriol 178:3763-70.

6. Brown, L., and T. Elliott. 1997. Mutations that increase expression of the rpoS gene and decrease its dependence on hfq function in Salmonella typhimurium. J Bacteriol 179:656-62.

7. Chen, C. Y., L. Eckmann, S. J. Libby, F. C. Fang, S. Okamoto, M. F. Kagnoff, J. Fierer, and D. G. Guiney. 1996. Expression of Salmonella typhimurium rpoS and rpoS-dependent genes in the intracellular environment of eukaryotic cells. Infect Immun 64:4739-43. 
8. Cunning, C., L. Brown, and T. Elliott. 1998. Promoter substitution and deletion analysis of upstream region required for rpoS translational regulation. J Bacteriol 180:4564-70.

9. Fang, F. C., S. J. Libby, N. A. Buchmeier, P. C. Loewen, J. Switala, J. Harwood, and D. G. Guiney. 1992. The alternative sigma factor katF (rpoS) regulates Salmonella virulence. Proc Natl Acad Sci USA 89:11978-82.

10. Garcia-Calderon, C. B., M. Garcia-Quintanilla, J. Casadesus, and F. Ramos-Morales. 2005. Virulence attenuation in Salmonella enterica $\operatorname{rcsC}$ mutants with constitutive activation of the Rcs system. Microbiology 151:579-88.

11. Geissmann, T. A., and D. Touati. 2004. Hfq, a new chaperoning role: binding to messenger RNA determines access for small RNA regulator. Embo J 23:396-405.

12. Gottesman, S. 2004. The small RNA regulators of Escherichia coli: roles and mechanisms*. Annu Rev Microbiol 58:303-28.

13. Gottesman, S. 2005. Micros for microbes: non-coding regulatory RNAs in bacteria. Trends Genet 21:399-404.

14. Hengge-Aronis, R. 2002. Signal transduction and regulatory mechanisms involved in control of the sigma(S) (RpoS) subunit of RNA polymerase. Microbiol Mol Biol Rev 66:373-95, table of contents.

15. Hirsch, M., and T. Elliott. 2005. Fis regulates transcriptional induction of RpoS in Salmonella enterica. J Bacteriol 187:1568-80.

16. Hofacker, I. L. 2003. Vienna RNA secondary structure server. Nucleic Acids Res 31:3429-31. 
17. Hommais, F., E. Krin, C. Laurent-Winter, O. Soutourina, A. Malpertuy, J. P. Le Caer, A. Danchin, and P. Bertin. 2001. Large-scale monitoring of pleiotropic regulation of gene expression by the prokaryotic nucleoid-associated protein, H-NS. Mol Microbiol 40:20-36.

18. Jones, A. M., A. Goodwill, and T. Elliott. 2006. Limited role for the DsrA and RprA regulatory RNAs in rpoS regulation in Salmonella enterica. J Bacteriol 188:5077-88.

19. Kaberdin, V. R., A. P. Walsh, T. Jakobsen, K. J. McDowall, and A. von Gabain. 2000. Enhanced cleavage of RNA mediated by an interaction between substrates and the arginine-rich domain of E. coli ribonuclease E. J Mol Biol 301:257-64.

20. Lange, R., and R. Hengge-Aronis. 1994. The cellular concentration of the sigma S subunit of RNA polymerase in Escherichia coli is controlled at the levels of transcription, translation, and protein stability. Genes Dev 8:1600-12.

21. Lange, R., D. Fischer, and R. Hengge-Aronis. 1995. Identification of transcriptional start sites and the role of ppGpp in the expression of rpoS, the structural gene for the sigma S subunit of RNA polymerase in Escherichia coli. J Bacteriol 177:4676-80.

22. Lease, R. A., M. E. Cusick, and M. Belfort. 1998. Riboregulation in Escherichia coli: DsrA RNA acts by RNA:RNA interactions at multiple loci. Proc Natl Acad Sci U S A 95:12456-61.

23. Lease, R. A., and M. Belfort. 2000. A trans-acting RNA as a control switch in Escherichia coli: DsrA modulates function by forming alternative structures. Proc Natl Acad Sci U S A 97:9919-24.

24. Lease, R. A., and M. Belfort. 2000. Riboregulation by DsrA RNA: trans-actions for global economy. Mol Microbiol 38:667-72. 
25. Lease, R. A., and S. A. Woodson. 2004. Cycling of the Sm-like protein Hfq on the DsrA small regulatory RNA. J Mol Biol 344:1211-23.

26. Mackie, G. A. 1998. Ribonuclease E is a 5'-end-dependent endonuclease. Nature 395:720-3.

27. Majdalani, N., C. Cunning, D. Sledjeski, T. Elliott, and S. Gottesman. 1998. DsrA RNA regulates translation of RpoS message by an anti-antisense mechanism, independent of its action as an antisilencer of transcription. Proc Natl Acad Sci U S A 95:12462-7.

28. Majdalani, N., S. Chen, J. Murrow, K. St John, and S. Gottesman. 2001. Regulation of RpoS by a novel small RNA: the characterization of RprA. Mol Microbiol 39:1382-94.

29. Majdalani, N., D. Hernandez, and S. Gottesman. 2002. Regulation and mode of action of the second small RNA activator of RpoS translation, RprA. Mol Microbiol 46:813-26.

30. Majdalani, N., C. K. Vanderpool, and S. Gottesman. 2005. Bacterial small RNA regulators. Crit Rev Biochem Mol Biol 40:93-113.

31. Masse, E., F. E. Escorcia, and S. Gottesman. 2003. Coupled degradation of a small regulatory RNA and its mRNA targets in Escherichia coli. Genes Dev 17:2374-83.

32. Mikulecky, P. J., M. K. Kaw, C. C. Brescia, J. C. Takach, D. D. Sledjeski, and A. L. Feig. 2004. Escherichia coli Hfq has distinct interaction surfaces for DsrA, rpoS and poly(A) RNAs. Nat Struct Mol Biol 11:1206-14.

33. Moll, I., T. Afonyushkin, O. Vytvytska, V. R. Kaberdin, and U. Blasi. 2003. Coincident Hfq binding and RNase E cleavage sites on mRNA and small regulatory RNAs. Rna 9:1308-14. 
34. Moller, T., T. Franch, P. Hojrup, D. R. Keene, H. P. Bachinger, R. G. Brennan, and P. ValentinHansen. 2002. Hfq: a bacterial Sm-like protein that mediates RNA-RNA interaction. Mol Cell 9:23-30.

35. Muffler, A., D. Fischer, S. Altuvia, G. Storz, and R. Hengge-Aronis. 1996. The response regulator RssB controls stability of the sigma(S) subunit of RNA polymerase in Escherichia coli. Embo J $15: 1333-9$

36. Paesold, G., and M. Krause. 1999. Analysis of rpoS mRNA in Salmonella dublin: identification of multiple transcripts with growth-phase-dependent variation in transcript stability. J Bacteriol 181:12648.

37. Papenfort, K., and J. Vogel. 2009. Multiple target regulation by small noncoding RNAs rewires gene expression at the post-transcriptional level. Res Microbiol 160:278-87.

38. Repoila, F., and S. Gottesman. 2001. Signal transduction cascade for regulation of RpoS: temperature regulation of DsrA. J Bacteriol 183:4012-23.

39. Repoila, F., and S. Gottesman. 2003. Temperature sensing by the dsrA promoter. J Bacteriol 185:6609-14.

40. Repoila, F., and F. Darfeuille. 2009. Small regulatory non-coding RNAs in bacteria: physiology and mechanistic aspects. Biol Cell 101:117-31.

\section{Resch, A., T. Afonyushkin, T. B. Lombo, K. J. McDowall, U. Blasi, and V. R. Kaberdin.} 2008. Translational activation by the noncoding RNA DsrA involves alternative RNase III processing in the rpoS 5'-leader. RNA 14:454-9. 
42. Rolle, K., M. Zywicki, E. Wyszko, M. Z. Barciszewska, and J. Barciszewski. 2006.

Evaluation of the dynamic structure of DsrA RNA from E. coli and its functional consequences. J Biochem 139:431-8.

43. Rychlik, I., and P. A. Barrow. 2005. Salmonella stress management and its relevance to behaviour during intestinal colonisation and infection. FEMS Microbiol Rev 29:1021-40.

44. Sittka, A., S. Lucchini, K. Papenfort, C. M. Sharma, K. Rolle, T. T. Binnewies, J. C. Hinton, and J. Vogel. 2008. Deep sequencing analysis of small noncoding RNA and mRNA targets of the global post-transcriptional regulator, Hfq. PLoS Genet 4:e1000163.

45. Sledjeski, D., and S. Gottesman. 1995. A small RNA acts as an antisilencer of the H-NSsilenced rcsA gene of Escherichia coli. Proc Natl Acad Sci U S A 92:2003-7.

46. Sledjeski, D. D., A. Gupta, and S. Gottesman. 1996. The small RNA, DsrA, is essential for the low temperature expression of RpoS during exponential growth in Escherichia coli. Embo J 15:39934000.

47. Sledjeski, D. D., C. Whitman, and A. Zhang. 2001. Hfq is necessary for regulation by the untranslated RNA DsrA. J Bacteriol 183:1997-2005.

48. Soper, T. J., and S. A. Woodson. 2008. The rpoS mRNA leader recruits Hfq to facilitate annealing with DsrA sRNA. RNA 14:1907-17.

49. Sun, X., I. Zhulin, and R. M. Wartell. 2002. Predicted structure and phyletic distribution of the RNA-binding protein Hfq. Nucleic Acids Res 30:3662-71. 
50. Swords, W. E., B. M. Cannon, and W. H. Benjamin, Jr. 1997. Avirulence of LT2 strains of Salmonella typhimurium results from a defective rpoS gene. Infect Immun 65:2451-3.

51. Vytvytska, O., I. Moll, V. R. Kaberdin, A. von Gabain, and U. Blasi. 2000. Hfq (HF1) stimulates ompA mRNA decay by interfering with ribosome binding. Genes Dev 14:1109-18.

52. Waters, L. S., and G. Storz. 2009. Regulatory RNAs in bacteria. Cell 136:615-28.

53. Weber, H., T. Polen, J. Heuveling, V. F. Wendisch, and R. Hengge. 2005. Genome-wide analysis of the general stress response network in Escherichia coli: sigmaS-dependent genes, promoters, and sigma factor selectivity. J Bacteriol 187:1591-603.

54. Wilmes-Riesenberg, M. R., J. W. Foster, and R. Curtiss, 3rd. 1997. An altered rpoS allele contributes to the avirulence of Salmonella typhimurium LT2. Infect Immun 65:203-10.

55. Zhang, A., K. M. Wassarman, J. Ortega, A. C. Steven, and G. Storz. 2002. The Sm-like Hfq protein increases OxyS RNA interaction with target mRNAs. Mol Cell 9:11-22.

56. Zhang, A., K. M. Wassarman, C. Rosenow, B. C. Tjaden, G. Storz, and S. Gottesman. 2003. Global analysis of small RNA and mRNA targets of Hfq. Mol Microbiol 50:1111-24. 


\title{
Chapter 2 : Limited role for the DsrA and RprA regulatory RNAs in rpoS regulation in Salmonella enterica
}

\author{
Morgantown, WV 26506 \\ * corresponding author \\ Phone: 304-293-2676 \\ Fax: 304-293-7823 \\ telliott@hsc.wvu.edu
}

Amy M. Jones, Adam Goodwill and Thomas Elliott*

Department of Microbiology, Immunology and Cell Biology

West Virginia University Health Sciences Center

Running title: sRNA regulation of $r p o S$ in $S$. enterica

\section{Abstract}

RpoS, the sigma factor of enteric bacteria that responds to stress and stationary phase, is subject to complex regulation acting at multiple levels including transcription, translation and proteolysis. Increased translation of rpoS mRNA during growth at low temperature, after osmotic challenge, or with a constitutively activated Rcs phosphorelay, depends on two trans-acting small regulatory RNAs (sRNAs) in Escherichia coli. The DsrA and RprA sRNAs are both highly conserved in Salmonella enterica, as is their target, an inhibitory antisense element within the $r p o S$ untranslated leader. Analysis of $d s r A$ and rprA deletion mutants indicates that while the increased translation of RpoS in response to osmotic challenge is conserved in S. enterica, dependence on these two sRNA regulators is much reduced. Furthermore, low temperature growth or constitutive $\mathrm{RcsC}$ activation had only modest effects on RpoS 
expression and these increases were, respectively, independent of $d s r A$ or $r p r A$ function. This lack of conservation of sRNA function suggests surprising flexibility in RpoS regulation.

\section{Introduction}

RpoS, the general stress and stationary phase sigma factor, is highly conserved among Escherichia coli, Salmonella enterica, and other related enteric bacteria. The diverse and often harsh conditions encountered by these bacteria, whether residing as pathogens in the gut or as saprophytes in the environment, require the ability to integrate multiple stress signals and initiate the appropriate cellular responses in order to survive. RpoS serves in this capacity as the master regulator of the general stress response. Its levels increase in response to a number of stress signals, including osmotic shock, nutrient depletion, low temperature, and growth into stationary phase (reviewed in reference 19). As RpoS becomes more abundant, it effectively competes with the vegetative sigma factor in binding RNA polymerase, leading to increased transcription of genes necessary for mediating the stress response (48).

Regulation of RpoS is complex, with a large post-transcriptional component, and involves transacting factors (19). These factors include several small regulatory RNAs $(27,38)$, which target a cisacting antisense element within the rpoS mRNA untranslated leader (7). In E. coli, two such small RNAs (sRNAs), DsrA and RprA, activate $r p o S$ translation by pairing with $r p o S$ mRNA and disrupting the antisense element (reviewed in reference 28). DsrA is necessary for activation of $\operatorname{rpoS}$ translation in response to low temperature and osmotic shock (30), while RprA increases RpoS both in response to osmotic shock (29) and to a constitutively active $\operatorname{rcs} C$ allele, indicating a role in cell envelope stress (15, 29).

These sRNAs were initially discovered and characterized in E. coli, and their gene sequences are $\approx$ 90\% identical in S. enterica. The high degree of sequence conservation shared by E. coli and S. enterica, 
in both rpoS and the sRNAs, suggests that their regulatory function is likely to be conserved as well. Here we describe the results of experiments undertaken to characterize the roles of DsrA and RprA in $S$. enterica, specifically their effect on rpoS regulation. Our findings strongly suggest that, under the conditions tested, neither of these sRNAs is required for optimal RpoS synthesis in S. enterica. Mutational analysis of the rpoS antisense element in S. enterica was also performed to further characterize the role of secondary structure in RpoS synthesis. The results of this analysis are broadly comparable to those in E. coli.

\section{Methods}

Bacterial strains and growth conditions.

The bacterial strains used in this study are listed in Table 1. The katE-lac operon [op] fusion used in this work has been described previously and is a reporter of RpoS activity $(6,10,21)$. Isolation of Mud insertions and construction of site-specific mutations is described below. The high-frequency generalized transducing bacteriophage P22 mutant HT105/1 int-201 was used for transduction in S. enterica by standard methods (12). Phage P1 vir was used for transduction in E. coli, also by standard methods (40). Bacteria were grown in media and at temperatures which are described for each individual experiment. LB was used as rich medium (40), and the minimal medium was MOPS (morpholinepropanesulfonic acid; 34) as modified (4). Plates were prepared by using nutrient agar (Difco) with $5 \mathrm{~g}$ of NaCl per liter. Antibiotics were added to rich medium to final concentrations as follows: $20 \mu \mathrm{g}$ of tetracycline hydrochloride per ml, $20 \mu \mathrm{g}$ of chloramphenicol per ml, $50 \mu \mathrm{g}$ of kanamycin sulfate per $\mathrm{ml}, 200 \mu \mathrm{g}$ of streptomycin sulfate per $\mathrm{ml}$, and either $100 \mu \mathrm{g}$ of sodium ampicillin per $\mathrm{ml}$ for high copy plasmids, or 30 $\mu \mathrm{g}$ per $\mathrm{ml}$ for low copy plasmids. In minimal medium, kanamycin sulfate was added to a final concentration of $100 \mu \mathrm{g}$ per $\mathrm{ml}$. 
Isolation and analysis of rpoS-lac fusions formed by insertion of Mud transposons.

Insertions of MudJ (MudI 1734) to form operon fusions and MudK to form protein fusions $(1,8)$ were obtained by screening large pools of insertions $\left(>10^{5}\right.$ clones) for linkage to the $r p o S$ region. Since rpoS is very close to $c y s C$ (6 kb separate the two genes), a phage $\mathrm{P} 22$ transducing lysate grown on each insertion pool was used to transduce TE8607 ( $\Delta$ cysC::tet) to $\mathrm{Kan}^{\mathrm{R}} \mathrm{Cys}^{+}$on plates containing X-gal. Blue colonies were picked, purified once on selective medium, patched onto NB agar containing kanamycin, and tested for an rpoS mutant phenotype by scoring formation of bubbles when spotted with 5 $\mu l$ of $3 \%$ hydrogen peroxide. Insertions were mapped by PCR, and the precise joint with the Mud element was located by DNA sequencing. The starting insertion pools were isolated by mutagenesis of $S$. enterica LT2 using the method of Hughes and Roth (22). The original host for MudK insertions carried a plasmid unrelated to the current project $(\mathrm{pRF} 1 ; 14)$, therefore, backcrossed candidate insertions were checked to confirm that this plasmid had been lost as expected.

Preliminary characterization showed both expected and unexpected properties for strains carrying these fusions. Fusions were recovered within $\operatorname{rpoS}$ but also in the upstream region encoding the Cterminal part of $n l p D$. Polarity of the insertions lying within this part of $n l p D$ on expression of $r p o S$ is consistent with the location of the major rpoS promoter roughly in the middle of the $n l p D$ gene $(21,23$, 45). Also as expected, all lac protein fusions to $\operatorname{rpoS}$ tested were found to be substantially ( $\approx 4$ - to 5-fold) dependent on function of the $h f q$ and $d k s A$ genes, known from previous studies to affect rpoS translation but not transcription $(6,33,47)$. Sensitivity to $\operatorname{clp} X$ and $m v i A$ mutations was tested in the LT2A background (9). The effect of mutations blocking the protein turnover pathway was variable depending on the location of the insertion site within rpoS. The MudK insertion at $r p o S$ codon 22 was unaffected by loss of $\operatorname{clp} X$ or $m v i A$, whereas expression of the insertion at codon 250 was increased 5- to 6-fold in both 
$c l p X$ and $m v i A$ mutant backgrounds during exponential phase in LB medium. This behavior is consistent with identification of K173 as a critical residue in the RpoS "turnover element" in E. coli (2). In stationary phase, expression of sensitive rpoS-lac protein fusions became independent of $c l p X$ and $m v i A$. Other results in S. enterica (21) show that this behavior is not characteristic of the RpoS protein itself or of RpoS-dependent reporters. We can explain this result by postulating that the rpoS-dependence of $m v i A$ ( $r s s B / s p r E$ ) expression during stationary phase found in E. coli (39) is conserved in S. enterica.

One unexpected result was that several MudK insertions in $\operatorname{rpoS}$ (screened as dark blue $\mathrm{Lac}^{+}$colonies on X-gal plates) were found to be out-of-frame but express lac as strongly as in-frame fusions. Remarkably, an insertion in the +1 frame at codon 36 expressed lac at a 3 -fold higher level during exponential phase than any in-frame fusion recovered. Several high-expressing out-of-frame fusions were confirmed to have the predicted sequence across $\mathrm{Mu}$ and into the first $300 \mathrm{bp}$ of lacZ. The explanation for this unusual situation is likely that: (i) exponential-phase expression of in-frame rpoS-lac protein fusions is quite low ( $\approx 10$-fold lower than any rpoS-lac operon fusion), due at least in part to the action of the antisense element; and (ii) the sequence at the joint with MudK consists of the in-frame codon XTG, where $\mathrm{X}$ is contributed by rpoS and TG is from Mu. The sequences of all high-expressing out-of-frame insertions contained a plausible ribosome-binding site (RBS) upstream from an initiation codon. This suggests that the high relative expression of out-of-frame fusions is an artifact due to the novel sequence at the insertion joint.

A second puzzling and cautionary result comes from comparison of MudJ (operon) fusions upstream and downstream of the rpoS initiation codon. We found that two early fusions, one within $n l p D$ at +9 with respect to the $\operatorname{rpoS}$ transcriptional start, and the other at +276 , showed no stationary phase induction in LB medium, whereas later fusions at codon 36 and codon 222 showed normal induction. This behavior indicated that normal regulation depends on sequences substantially downstream of the promoter. 
However, leader-dependent regulation is not consistent with our previous study of SP induction (21), which showed that a short segment surrounding the promoter region displayed the full range of SP regulation of transcription.

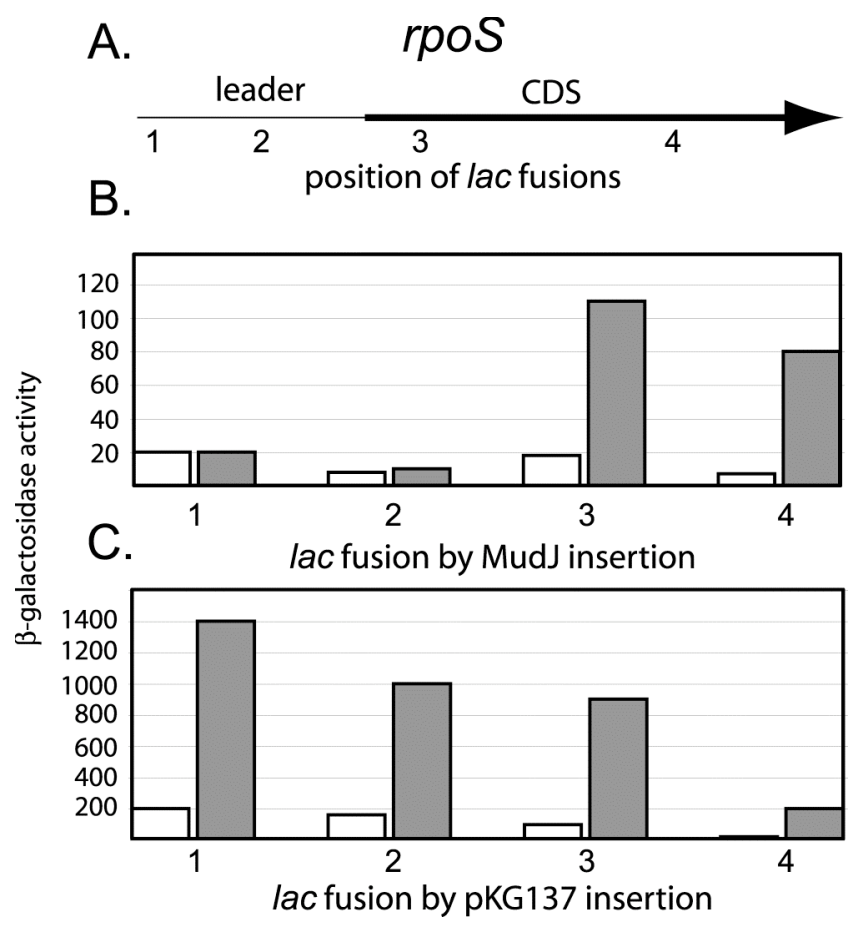

Figure 3. Comparing the regulation of lac operon fusions formed by MudJ insertion or plasmid integration. Panel A. The rpoS coding sequence (bold line) and upstream leader are indicated, with labels indicating four sites at which fusions were isolated or constructed as described in the text. These positions are: 1 ( +9 of the leader), 2 ( +276 of the leader), 3 (codon 36 of rpoS) and 4 (codon 222 of rpoS). Panel B. Analysis of lac expression from MudJ insertions at sites 1-4. Open bars indicate exponential phase cultures and filled bars indicate stationary phase (SP) cultures, as defined in the text. SP induction of $r p o S$ transcription is measured as the ratio of the value from the filled bars to open bars. Panel $\mathrm{C}$. The same as panel B, except that each fusion was made by integration of plasmid pKG137, as described in the Methods. Strains for panel B were: TE8804, TE8935, TE8936, and TE8794. Strains for panel C were: TE9052, TE9049, TE9050, and TE9051. Each bar represents the average of at least three experiments. Standard deviations were within $15 \%$ of the mean. 
To resolve this issue and map the apparent discontinuity, a number of precisely targeted lac operon fusions were constructed using the method of Ellermeier et al. (13). In this method, the $\lambda$ Red recombination system is used to direct insertion of a drug resistance marker flanked by directly repeated FRT sites into the bacterial chromosome. The insertions are then resolved to leave a single unmarked FRT site, which is targeted for Flp / FRT-mediated integration of a replication-defective Kan ${ }^{\mathrm{R}}$ plasmid to provide the lac genes and form either an operon or a protein fusion. The lac fusions used here were constructed with pKG137 (M. Garsha and J. Slauch, personal communication), a plasmid that forms lac operon fusions including a strong RBS for lacZ. As shown in Fig 3, the fusions made by this method at +9 and +276 with respect to the transcriptional start were regulated, in contrast to the behavior of MudJ fusions inserted at exactly the same sites. The different behavior of MudJ insertions is currently unexplained, but presumably depends on the nature of the extra sequences present at the attR end of MudJ, including about $400 \mathrm{bp}$ from $\mathrm{Mu}$ as well as a substantial segment of the E. coli trp operon.

Plasmid pTE780 (PBD-S. enterica dsrA $)$ was constructed by PCR using the following primers: 5' GCGGGATCCTACCTGACGCTTTTTATCGCAACTCTCTACTGTTTCT CCATCACATCAGATTTCCTGGTGT-3', and 5'-GCGTCTAGAACCG TTAAAAAGGC CGAAA-3' on LT2 DNA as template. Sequences from $d s r A$ are shown in italics. The PCR product was purified, digested with BamHI and XbaI and cloned into pBAD18 (18).

Construction of insertion and point mutations using $\lambda$ Red recombination. Other point mutations and insertion / deletions were made by direct transformation of S. enterica, either with oligonucleotides or with DNA segments amplified by PCR, utilizing the $\lambda$ Red recombination system as provided on plasmid pKD46 (11). Exponential-phase recipient cells carrying pKD46, grown at $30^{\circ} \mathrm{C}$ with selection for ampicillin resistance (Amp ${ }^{\mathrm{R}}$ ), were induced by treatment with $0.2 \%$ arabinose for one hour 
before electroporation, after which transformants were grown out in liquid medium before plating and selection at $37^{\circ} \mathrm{C}$. A few experiments utilized pSIM5, a plasmid for mutant construction based on the method of Yu et al (50) and obtained from D. Court.

Most of the unmarked point mutations were obtained as follows. First, an insertion of tetAR near or at the target site was isolated. Subsequently a recipient bearing that insertion and induced for $\lambda$ Red was transformed with a mutated oligo and selection applied for loss of Tet ${ }^{\mathrm{R}}$ (Bochner selection; 5,31). For unknown reasons, this selection has a high background for insertions at certain sites. For insertion within the rpoS RBS, it was important that the recipient strain also contained katE-lac [op], an RpoSdependent reporter fusion. Replacement of the tetAR cassette restored a Lac ${ }^{+}$phenotype, visualized by subsequent single colony isolation on MacConkey lactose agar. Some double mutants with lesions affecting both the antisense element and the RBS region were constructed by an iterative procedure in which a tet insertion derivative of an existing point mutant was constructed as an intermediate. A second, more rapid method used a singly mutant DNA template (lesion in the RBS) for PCR to introduce the second mutation, which was recovered by transformation of a recipient deleted for the region between the antisense element and the RBS. This deletion, marked with tetAR, was from strain TE8701 ( $\triangle$ rpoS1080::tetAR).

A mutation changing the rpoS TTG start codon to ATG was obtained by oligo transformation as described above, but a second mutation changing the TTG to TCG could not be screened in the same way since it does not confer a Lac ${ }^{+}$phenotype. To make this change, we designed and constructed a different counter-selectable insertion in the RBS region of $r p o S$, based on the known dominance of wild type $r p s L$ $\left(\mathrm{Str}^{\mathrm{S}}\right)$ in merodiploids containing one $\mathrm{Str}^{\mathrm{S}}$ and one $\mathrm{Str}^{\mathrm{R}}$ allele, as exploited by others (41). First tetAR 
was inserted just upstream of the $r p s L^{+}$gene of an $\operatorname{Str}^{\mathrm{S}}$ E. coli strain. Chromosomal DNA from this strain (TE9062) was used as template to amplify a tetAR-rpsL ${ }^{+}$cassette and this DNA segment was then inserted at the RBS of S. enterica rpoS. TE9179, carrying both the $\operatorname{rpoS}::\left[\operatorname{tetAR}\right.$-rps $\left.L^{+}\right]$insertion and the strAl (Str ${ }^{\mathrm{R}}$ ) allele, was found to be $\mathrm{Str}^{\mathrm{S}}$ as expected. For unknown reasons the strain forms small colonies on NB agar lacking streptomycin, but this slow growth phenotype appears to be stable. Transformants were easily obtained by selecting $\operatorname{Str}^{\mathrm{R}}$ in this background, again using $\lambda$ Red recombination. The vast majority of these were Tet ${ }^{\mathrm{S}}$ when mutated oligonucleotide DNA was added to the transformation; three candidate transformants were sequenced and all contained the TTG to TCG change.

Point mutations were backcrossed by transduction of recipient strain TE8607 ( $\triangle$ cysC::tetAR $\Delta$ rpoS1076::cat), selecting Cys ${ }^{+}$and screening for loss of the Cam ${ }^{\mathrm{R}}$ marker in the $\operatorname{rpoS}$ leader. Double mutants carrying both a lac fusion and linked point mutation were constructed by transduction using a

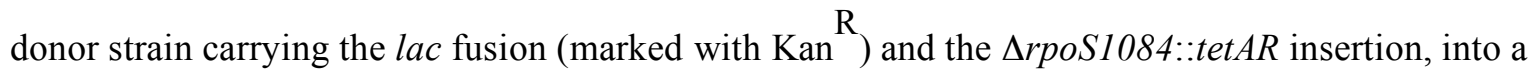
recipient bearing the desired point mutation. The desired class of transductants was Kan ${ }^{\mathrm{R}} \mathrm{Lac}^{+} \mathrm{Tet}^{\mathrm{S}}$. The rpoS leader genotype of each recombinant strain was confirmed by DNA sequencing.

Targeted insertion / deletions of several genes were made by the $\lambda$ Red method. The extent of deletion for each construct is as follows: $\triangle c y s C$ deletes $11 \mathrm{bp}$ of the leader including the RBS precisely to the stop codon; $\Delta d s r A$ deletes from the -35 hexamer of the promoter through the terminal polyU sequence (2068766-2068651 of Genbank NC_003197); $\Delta r p r A$ also deletes from the -35 hexamer of the 30 
promoter through the terminal polyU sequence (1444972-1444822 of Genbank NC_003197). For reference, the rpoS leader extends from 3067051-3066487 of Genbank NC_003197.

$\boldsymbol{\beta}$-galactosidase assays. Cells were centrifuged, resuspended in $\mathrm{Z}$ buffer (100 $\mathrm{mM} \mathrm{KPO}_{4}[\mathrm{pH} 7.0]$, $10 \mathrm{mM} \mathrm{KCl}, 1 \mathrm{mM} \mathrm{MgSO}_{4}$ ), and then permeabilized by treatment with sodium dodecyl sulfate (SDS) and chloroform (32). Assays were performed in Z buffer containing $50 \mathrm{mM} \beta$-mercaptoethanol. Usually, reactions were carried out in microtiter (96 well) plates and read in a Molecular Devices plate reader. Activities (change in optical density per minute at $420 \mathrm{~nm}$ ) were normalized to cell density $\left(\mathrm{OD}_{650}\right)$ and were always compared with activities of appropriate controls assayed at the same time. For experiments involving cultures grown to different densities, the number of cells harvested was adjusted to provide approximately equal cell densities in the assay. One unit of activity, as determined by this method, is equivalent to $\approx 23$ units as measured by the Miller assay (32). The latter assay is much more sensitive, and was employed in selected experiments for this reason.

Immunological detection of proteins. Cultures were grown as described in the figure legends. Exponential phase samples were taken at an $\mathrm{OD}_{600} \approx 0.13$, and stationary phase (SP) samples were taken after 24 hours or 48 hours for cultures growing at $37^{\circ} \mathrm{C}$ or $18^{\circ} \mathrm{C}$ respectively. Protein samples were prepared from 1-ml culture volumes by centrifugation and resuspension in $100 \mu 1$ Tris / SDS buffer (5 $\mathrm{mM}$ Tris-HCl, 2\% SDS). Samples were vortexed and then boiled for 10 minutes, centrifuged for 30 minutes, and the supernatants collected and stored at $-20^{\circ} \mathrm{C}$. The total protein concentration of each sample was determined using a Lowry-based protein assay (Bio-Rad) according to the manufacturer's protocol. For each gel, protein samples were diluted in sample buffer to an equal concentration then boiled for 5 minutes prior to loading onto 10 or $12 \%$ polyacrylamide mini-gels. Gels were loaded with 
either $10 \mu \mathrm{g}$ of total protein per well (SP protein samples) or $50 \mu \mathrm{g}$ per well (exponential phase samples). Electrophoresis was carried out at $75 \mathrm{~V}$ for 2.5 hours and resolved proteins were transferred to a Sequiblot PVDF membrane (Bio-Rad) at 100V for 50 minutes using Bio-Rad's Mini Trans-Blot Transfer Cell. Subsequent steps and RpoS detection, using the R12 monoclonal antibody (6), were carried out as previously described (21) with the following exception. Membranes prepared from stationary phase protein samples, containing relatively higher levels of RpoS, were incubated for 2-3 hours with a secondary antibody directly conjugated to HRP.

Northern blots. To detect DsrA, a probe (designated SL1) specific for the first stem loop of DsrA was designed based on a probe used to study DsrA in E. coli (27). The SL1 probe is a single-stranded biotinylated DNA oligo and has the following sequence: 5' biotinAATCGTTACACCAGGAAATCTGATGTG.

Cultures were grown overnight, diluted 1:1000 into LB containing ampicillin and 0.02\% L-arabinose, and incubated at either 18 or $32^{\circ} \mathrm{C}$. Total RNA was isolated from $1 \mathrm{ml}$ of cultures grown to mid-log phase using an RNeasy mini kit (Qiagen) according to the manufacturer's protocol. RNA samples were diluted to $1 \mu \mathrm{g}$ in a final volume of $15 \mu \mathrm{l}$ in glyoxal load dye (Ambion) and incubated at $50-55^{\circ} \mathrm{C}$ for at least one hour prior to loading onto $6 \%$ urea/polyacrylamide mini gels. Electrophoresis was carried out at $100 \mathrm{~V}$ for $80 \mathrm{~min}$ in 1xTBE buffer.

Gels were assembled into a Bio-Rad mini trans blot unit and RNA was transferred to a Brightstar membrane (Ambion) at $100 \mathrm{~V}$ for 50 minutes in 1xTBE. The RNA was cross-linked with a UV crosslinker (Stratagene) using the autocrosslink function. Cross-linked membranes were incubated at $37^{\circ} \mathrm{C}$ in $10 \mathrm{ml}$ of Ultrahyb-Oligo buffer (Ambion) for 2-4 hours, and then with the same buffer containing the SL1 probe at a concentration of $185 \mathrm{ng} / \mathrm{ml}$. Hybridization was carried out overnight at $37^{\circ} \mathrm{C}$. The blots were 
washed and developed using the BrightStar Biodetect non-isotopic kit (Ambion) according to the manufacturer's protocol.

\section{Results}

Conservation of $d \operatorname{sr} A$ and $\operatorname{rpr} A$ gene sequences between $E$. coli and $S$. enterica. As noted

previously by the authors who first reported the functions of the $d s r A$ and $\operatorname{rpr} A$ genes in $E$. coli $(27,30)$,

these genes are highly conserved between $E$. coli K-12 and S. enterica LT2 as well as in certain other

enteric species. In fact, conservation of sequence is thought to have predictive value in the search for new

small regulatory RNA genes $(16,46)$. Both the $d s r A$ and $r p r A$ genes reside at similar positions in the two

bacterial chromosomes. Each gene is flanked by the same neighboring genes.
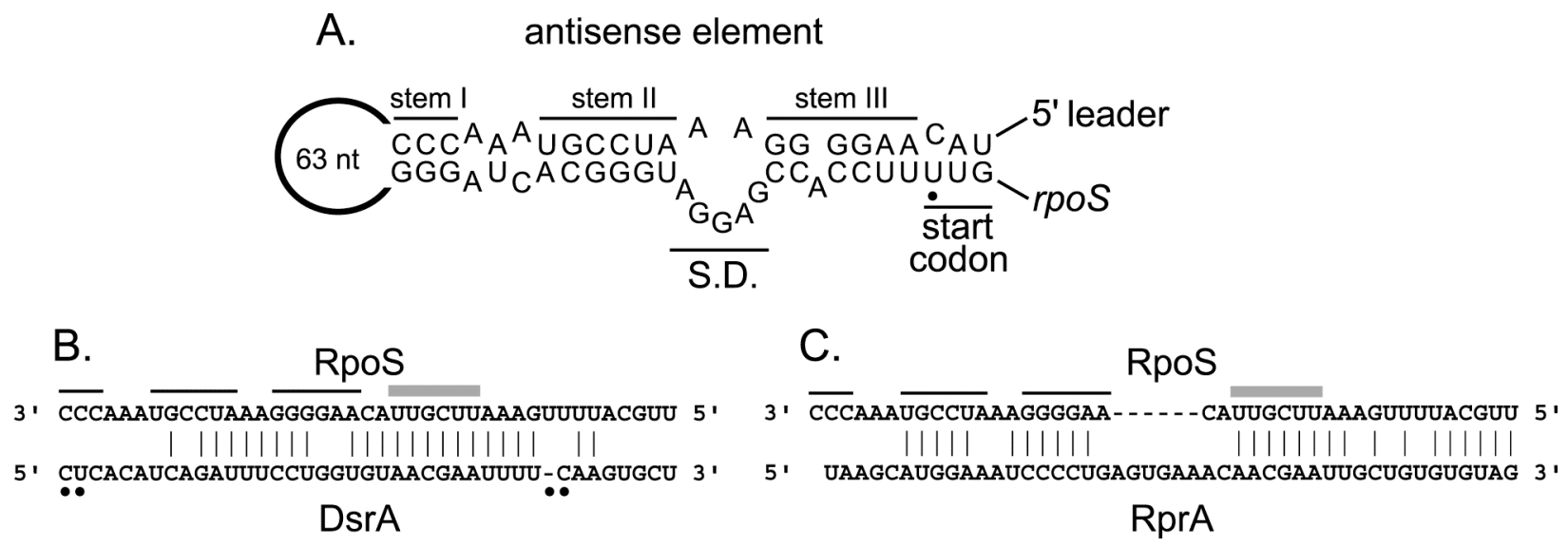

Figure 4 Panel A. The RNA sequence of a segment of the $565 \mathrm{nt}$ S. enterica rpoS leader RNA, starting at nt 456 (110 nt upstream from the start codon), and folded to show pairing between the antisense element and the rpoS RBS region (stems I, II, and III). Paired regions flank the Shine-Dalgarno (S.D.) complementarity to 16S rRNA and extend to the start codon (UUG in S. enterica, AUG in E. coli). Nucleotides that differ between S. enterica and E. coli are marked by filled circles. The antisense element and the RBS region are connected by $63 \mathrm{nt}$, which are not shown but indicated by the oval. Panel B. Pairing is shown between the antisense element (extended by an additional 18 nt on the upstream side) and two different sRNA regulators of RpoS: DsrA and RprA. Paired nucleotides are indicated by vertical lines, and spaces have been introduced where needed to facilitate the alignment. The stems of the antisense element are overlined for reference. The gray boxes indicate a hexameric sequence whose complementarity with the target RpoS RNA is essential for sRNA function, as shown in E. coli (Majdalani 98, Majdalani 02). The DsrA sequence shown starts at +1 , the RprA sequence starts at +28 . 
The primary sequence of $S$. enterica $d s r A$ shows eight substitutions and three missing nucleotides compared to its $E$. coli counterpart $(\approx 90 \%$ identity), and these changes can be accommodated with limited effect on the folded structure $(42,24)$. Furthermore, the nucleotides of DsrA RNA that are predicted to pair with rpoS mRNA are completely conserved, as shown in Figure 4. The S. enterica rprA gene shows even higher identity to its E. coli counterpart (three substitutions in $107 \mathrm{nts}$ ) and its interface with rpoS mRNA is highly conserved as well. The promoter sequences of the two genes are also nearly identical.

This conservation of sequence suggests that the functions of these two genes are important and also implies these functions should be conserved between the two species. Therefore, we investigated the role of these two sRNAs in regulation of $S$. enterica rpoS under three conditions shown to activate $r p o S$ expression in E. coli: low temperature (DsrA), osmotic shock (DsrA and RprA) and activation by RcsC (RprA).

Effect of low temperature. Sledjeski et al. reported that growth at low temperature $\left(20^{\circ} \mathrm{C}\right)$ has a dramatic effect on rpoS in E. coli. Expression in exponential phase was reported to increase by $\approx 100$-fold compared to $42^{\circ} \mathrm{C}$ (43). This increase specifically required DsrA (43) and was a post-transcriptional effect on synthesis, consistent with the known mode of action of overexpressed DsrA on RpoS at $37^{\circ} \mathrm{C}$ (27). The effect of a $d s r A$ mutation was less dramatic in stationary phase but still significant (8- to 10fold).

To study the role of $d s r A$ and $r p r A$ in $S$. enterica, we characterized the effect of the deletion of each gene separately, or both genes together, on expression of the RpoS-dependent reporter, katE-lac [op]. This reporter was used because the level of expression of rpoS-lac [pr] fusions is very low in exponential phase, particularly since the rpoS gene has a TTG start codon in S. enterica (see below). Results obtained by assay of katE-lac were confirmed by Western blot of RpoS itself. As a positive 34 
control, we used the katE-lac reporter fusion in an E. coli MC4100 derivative that was either wild type for $d s r A$ or carried the $d s r A 1:: c a t$ mutation (43). As expected, little effect of $d s r A$ loss was seen for cells in exponential phase at $37^{\circ} \mathrm{C}$, either in E. coli or in S. enterica (Fig 5, panel B). For $d s r A^{+} E$. coli cells in exponential phase at $18^{\circ} \mathrm{C}$, expression of katE-lac [op] was about 10 -fold higher than at $37^{\circ} \mathrm{C}$, and the $d s r A$ mutant showed $\approx 6.5$-fold lower expression compared to wild type at $18^{\circ} \mathrm{C}$ (Fig 5, panel A). A modest increase in reporter expression at low temperature was also seen in $S$. enterica $(\approx 2$-fold $)$, but there was no effect of deleting $d s r A$ or $\operatorname{rpr} A$, either singly or together. Western blot analysis using a monoclonal antibody specific for RpoS confirmed this finding (Fig 5, panels C and D). A $d s r A$ mutation has a large effect on RpoS levels and expression of katE-lac [op] at $18^{\circ} \mathrm{C}$ in E. coli, but not in S. enterica. Additionally, the effect of the $d s r A 1:: c a t$ on $r p o S-l a c Z$ [pr] activity was assessed in E. coli as performed previously by Sledjeski et al (43). In exponential phase at $18^{\circ} \mathrm{C}$, the $r p o S$-lac $Z$ activity of the $d s r A^{+}$ cells was $\approx 12$-fold higher than at $37^{\circ} \mathrm{C}$, and the activity of the $d s r A 1::$ cat cells was $\sim 14$-fold less than wild type at $18^{\circ} \mathrm{C}$.

The temperature response in $E$. coli results from a combination of $\approx 6$-fold increased expression from the $d s r A$ promoter at $25^{\circ} \mathrm{C}$ compared to $37^{\circ} \mathrm{C}$, as well as stabilization of the RNA at low temperature (37). A lac operon fusion to the chromosomal S. enterica $d s r A$ gene was constructed to test whether there was a response similar to that of E. coli. We observed 2.5- to 3-fold higher expression at $18^{\circ} \mathrm{C}$ compared to $37^{\circ} \mathrm{C}$ (Fig 5, panel E). 

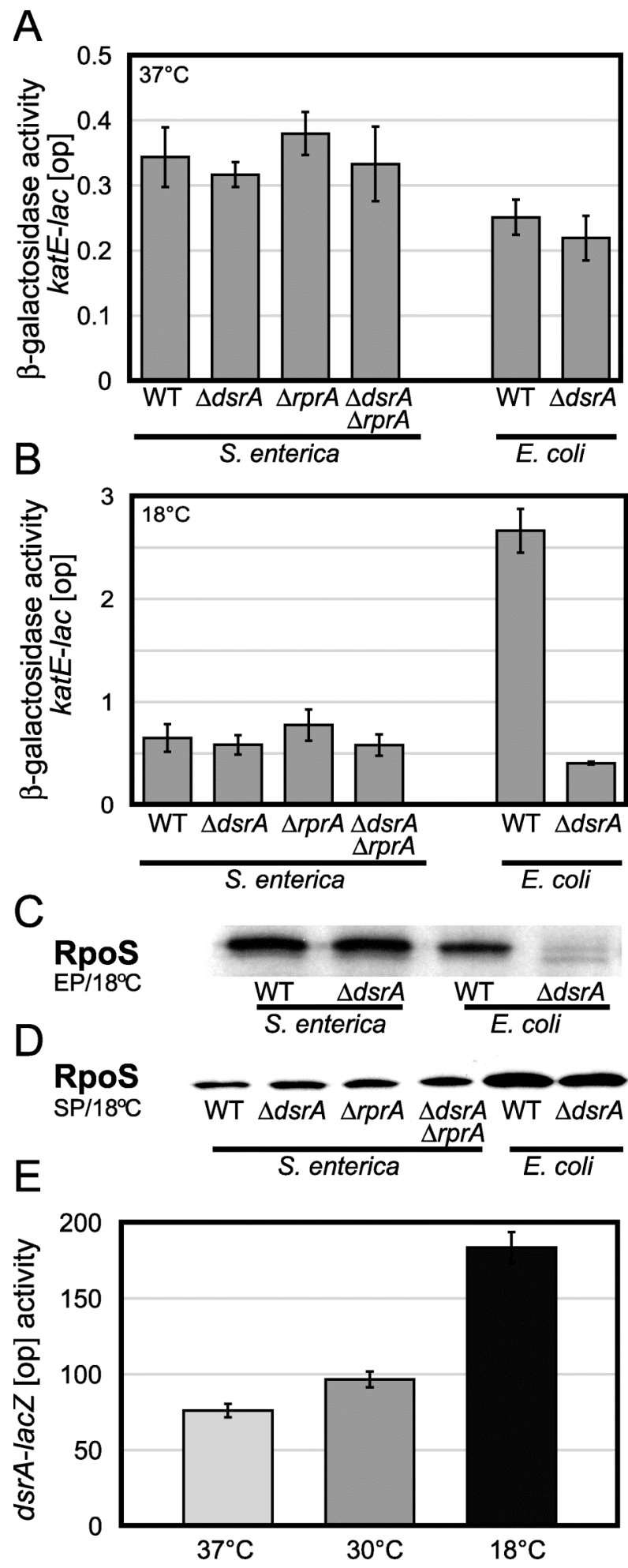

TTG start codon for rpoS. Expression of $S$.

enterica rpoS is particularly low because the gene starts with a TTG initiation codon (26), compared to the ATG start found in E. coli. This is partially compensated at the level of RpoS protein and reporters such as katE-lac [op] by the mviA V102G mutation which eliminates regulated RpoS protein turnover $(3,9)$. We are not aware of any protein sequence analysis that would confirm the assignment of the initiation codon in either E. coli or S. enterica. 
The origin of this difference between E. coli and S. enterica lineages is not clear. The DNA sequences of several LT2 isolates (stored frozen for many years) all show the TTG start (unpublished data). On the other hand, rpoS from virulent Salmonella strains has an ATG start (49). Since it has recently been found that $\mathrm{N}$-terminal deletions of $\operatorname{rpoS}$ may retain substantial function $(17,36)$, we tested the function of the $S$. enterica TTG initiation codon. Site-directed mutations changing the start codon were substituted at the native rpoS locus in the bacterial chromosome as described in the Methods. Substitution of TTG by ATG increased expression of an rpoS-lac protein fusion (codon 250) by $\approx 10$ fold, whereas substitution of TTG by TCG decreased expression by more than 50 -fold. This genetic test confirms that the predicted TTG start codon carries out this role for rpoS in S. enterica.

Osmotic shock. Sucrose challenge experiments were carried out following the protocol described by Majdalani et al. (30). Cells with a single-copy rpoS-lac [pr] fusion were grown in LB medium at $30^{\circ} \mathrm{C}$ and challenged with sucrose during early exponential phase. The lac fusion used for this experiment was formed by insertion of MudK at codon 250 of the rpoS gene. In other backgrounds, this fusion can be subject to the protein turnover control exerted by mviA / rss / sprE and the ClpXP protease (data not shown), but the "wild type" LT2 strain employed for this experiment is defective for this pathway $(3,9)$. The signal from this lac fusion was increased by substituting an ATG start codon, as found in E. coli. This change should not affect pairing with the antisense element and also did not affect induction of rpoS by osmotic shock (data not shown).

Addition of sucrose causes cells to plasmolyse, reducing their cross-section for light scattering and thereby resulting in decreased turbidity. Even without a change in lac expression, this decrease in turbidity would result in an artifactual increase in $\beta$-galactosidase activity, if it were normalized to $\mathrm{OD}_{650}$ as is typically done. For this reason, following Majdalani et al., we plot the total $\beta$-galactosidase activity from a fixed volume of cells versus the amount of protein in the same sample, as determined at various 37 
times after challenge. In Fig 6, panel A, the results from a representative experiment are given for osmotic challenge of a $d s r A$ single mutant, compared to wild type. In panel $\mathrm{B}$, the same experiment was carried out with a $d s r A \operatorname{rpr} A$ double mutant, also compared to wild type. It can be seen that the response to sucrose was reduced in the $d s r A$ single mutant, but did not appear to be further reduced in the $d s r A$ rprA double mutant. Growth of the double mutant was apparently sensitive to sucrose, based on decreased protein accumulation in the challenged culture, and this observation was reproducible.

The incomplete effect in the S. enterica double mutant contrasts with the results obtained for E. coli. There, a $d s r A$ knockout reduced basal rpoS-lac expression by about 7 -fold (at $32^{\circ} \mathrm{C}$ ), but the relative induction of rpoS by osmotic shock was still nearly as high as in wild type (27). In contrast, induction was almost eliminated for the $\operatorname{sr} A \operatorname{rpr} A$ double mutant (data shown in Fig 6 of reference 30, estimated in part). Combined data from a set of trials in S. enterica is shown in Fig 6, panel C. Each bar represents the ratio of enzyme activity normalized to protein, comparing values from $45 \mathrm{~min}$ post-challenge to timezero. It can be seen that the double mutant retained substantial induction by osmotic shock although it was noticeably decreased from the wild type level. The normalization to protein levels employed here is technically demanding because of limited sensitivity of the small-scale protein assay as well as high background (data not shown), and because the comparison made is between ratios of ratios (activity divided by protein, at two different times).

Therefore we also analyzed the data in a simpler fashion, by calculating the ratio of total $\beta$ galactosidase activity in sucrose-challenged and control cultures at 45 minutes post-challenge. This alternative approach confirms that the double mutant retained about two-thirds the induction seen in wild type (data not shown). 


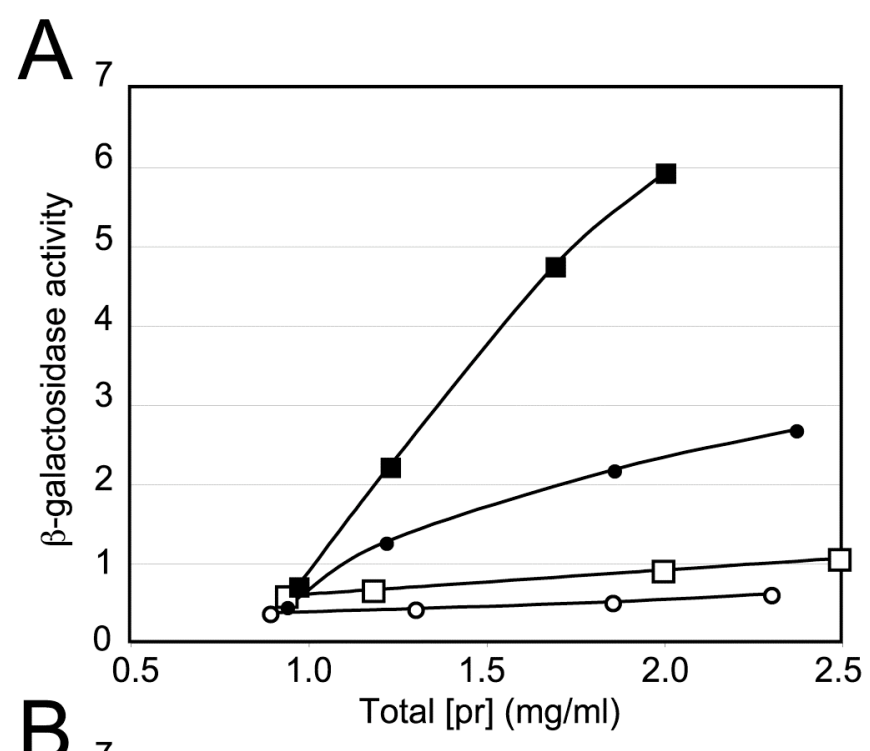

B

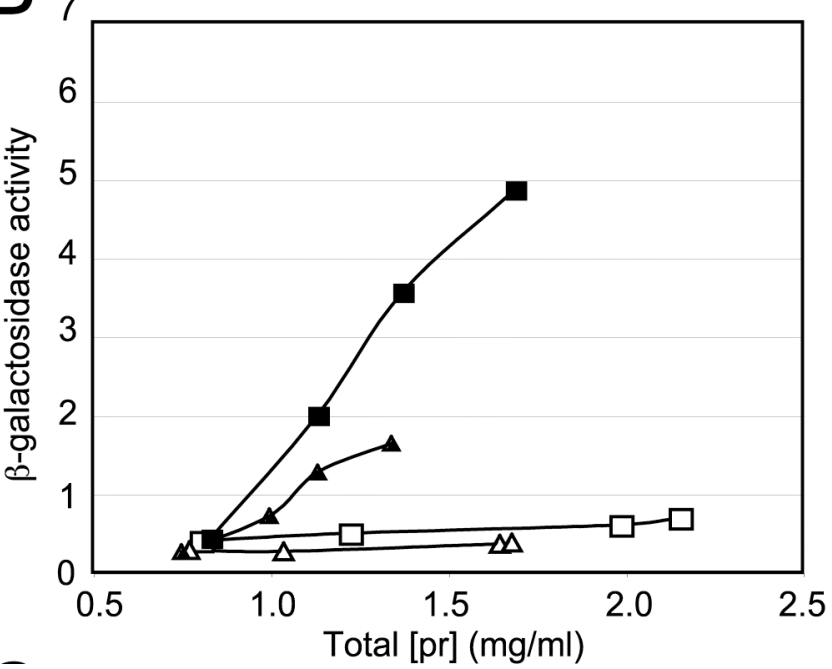

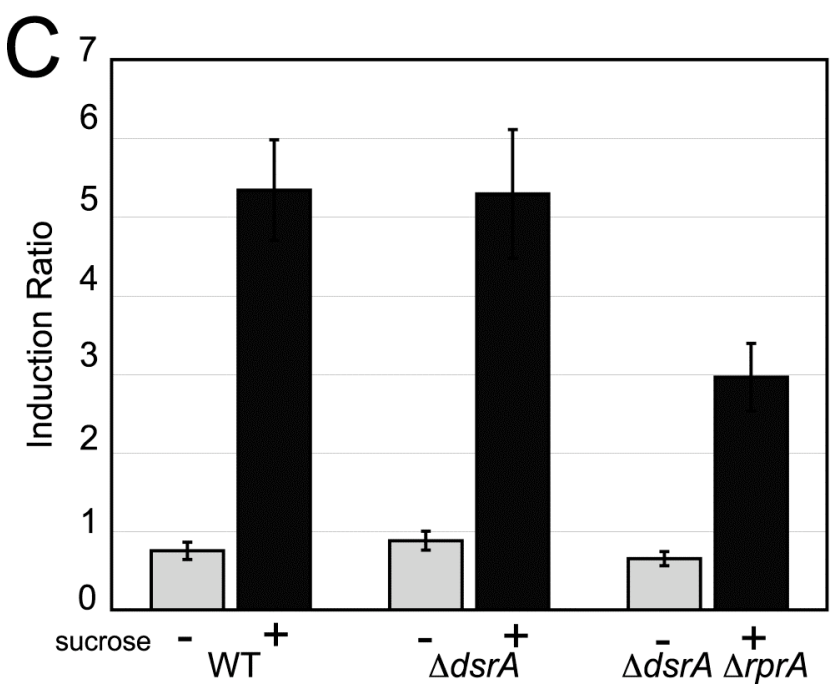

Figure 6 Effect of osmotic challenge on rpoS-lac. The lac protein fusion employed was formed by insertion of the transposon MudK at codon 250 of the $S$. enterica $r p o S$ gene (see Methods for details). Cultures were grown in LB medium at $30^{\circ} \mathrm{C}$ to early exponential phase, split into duplicate cultures, and grown to $\mathrm{OD}_{600}=0.12$. Cultures were challenged with prewarmed aliquots of either sucrose dissolved in LB medium (addition of $\approx 1 / 5$ volume of $2 \mathrm{M}$ sucrose to give $0.464 \mathrm{M}$ final concentration, $\approx 16 \%$ ), or $\mathrm{LB}$ alone. Samples were removed at time-zero and at 15,30 and 45 min after challenge. Cells were concentrated and assayed for total protein and for $\beta$-galactosidase activity. Panel $A$ shows a comparison of wild type cells (squares) to a $d s r A$ mutant (circles); sucrose-challenged cells are represented by filled symbols. Panel B shows a comparison of wild type to the $\Delta d s r A \Delta r p r A$ double mutant under the same conditions. Panel $C$ shows data from a set of such experiments. Each bar represents the ratio of enzyme activities from the 45 min and time-zero samples, where both values have been normalized to the corresponding protein concentration. Dark bars represent sucrose-challenged cultures, and light bars are untreated controls. The strains used were wild type (TE9160), $\triangle d s r A$ (TE9213), and $\triangle d s r A \Delta r p r A$ (TE9219). 
Since growth of this mutant appears somewhat more sensitive to osmotic shock than wild type, the value of two-thirds is actually a lower limit for the relative inducibility of the mutant. In summary, our results indicate that in S. enterica osmotic induction of $r p o S$ was decreased by about one-third in a $d s r A$ rprA double mutant, while the defect in the E. coli double mutant was nearly complete.

Effect of constitutive ResC. The third characterized small RNA-mediated regulation of rpoS in $E$. coli involves induction of RprA via the rcs phosphorelay system, which also regulates capsule synthesis. As described by Majdalani et al. (29), in E. coli RprA RNA levels are increased about 50-fold by the constitutive $\operatorname{rcsC} 137$ allele of the gene encoding the transmembrane sensor kinase RcsC. The recessive nature of this allele $(\mathrm{A} 904 \mathrm{~V})$ suggests that it affects a negative regulatory activity contributed by the response regulator domain of this hybrid sensor kinase. RpoS-LacZ levels are increased more than 20fold by the same mutation and most of this increase is rprA-dependent. We tested two similar constitutively active alleles of $r c s C$ in $S$. enterica, $r c s C 55$ (T903A) and $r c s C 64$ (F473I), described by Garcia-Calderon et al. (15). Otherwise isogenic strains were constructed carrying an $\operatorname{rpoS}::$ MudK insertion (lac protein fusion at codon 22 of rpoS) and either wild type for $\operatorname{rcs} C$ or carrying one of the two constitutive $r c s C$ alleles. Subsequently, a deletion of $r p r A$ was introduced into each strain. Expression of rpoS-lac was elevated 2.5- to 3-fold by both $r c s C$ alleles (Fig 7), however deletion of $r p r A$ had almost no effect on the activation. As a positive control for the effect of constitutive $\operatorname{rcs} C^{*}$ mutations, similar strains were constructed substituting the lac fusion with an insertion of MudJ (forms operon fusions) in the $\mathrm{gmm} / \mathrm{wcaH}$ gene, to monitor transcription of the capsule biosynthesis cluster. Activation of $w c a H$ by the mutant alleles of $\operatorname{rcs} C$ was at least 50-fold (expression in the wild type $\operatorname{rcs} C^{+}$strain was below the limit of detection for this assay). Although RprA was not previously observed to regulate capsule synthesis, introduction of the rprA deletion reduced expression of wcaH-lac to about $60 \%$ of the level 40 
seen with wild type $r p r A$. In summary, we do find $\approx 3$-fold activation of $r p o S$ expression by both of these constitutive $\operatorname{rcs} C$ alleles, but there is no evidence for involvement of the RprA RNA in this response.

\section{Testing the effect of overexpression of}

DsrA on rpoS-lac. The experiments presented in this paper do not support a significant role for the DsrA and RprA RNAs in the regulation of rpoS in S. enterica. One possible explanation is that the few sequence differences between the $d s r A$ and rprA genes of $S$. enterica and E. coli are responsible for this unexpected result.

Therefore, we tested the function of $S$. enterica $d s r A$ more extensively by using the

overexpression phenotype described by Majdalani et al. (27). The $d s r A$ gene from $S$. enterica was expressed from the $\mathrm{pBAD}$ promoter in plasmid pTE780, and a similar plasmid, pNM3, carrying the E. coli $d s r A$ gene was tested in parallel (27). These plasmids together with vector controls were introduced

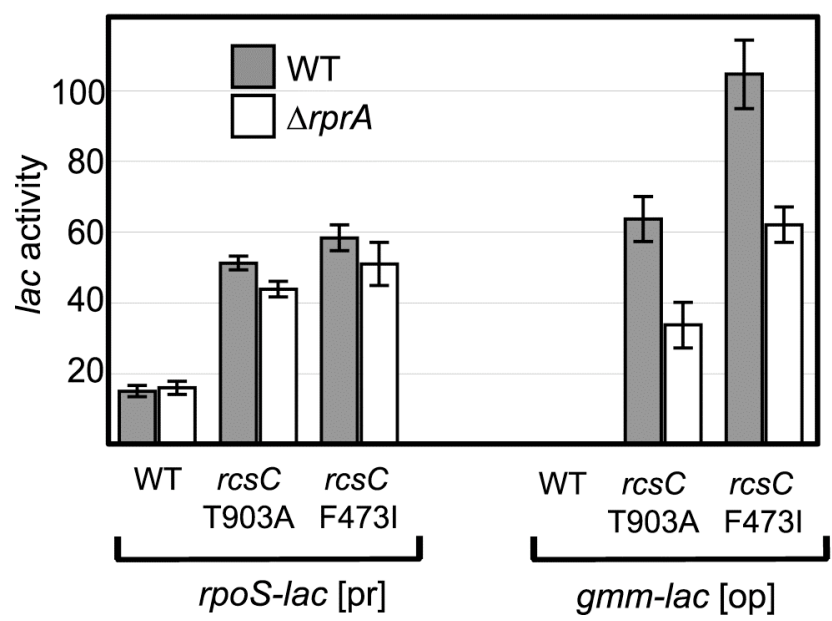

Figure 7 Effect of activated $r c s C$ on $r p o S$-lac. In the left half of the figure, the lac protein fusion was formed by insertion of the transposon MudK at codon 22 of the S. enterica rpoS gene. In the right half, the lac fusion was the gmm-21::MudJ insertion (also called wcaH; 15). Two activated alleles of $\operatorname{rcsC}$ were compared to wild type, and each set consisted of strains either wild type or mutant for rprA. Cells were grown overnight to stationary phase in $\mathrm{LB}$ medium at room temperature $\left(23-25^{\circ} \mathrm{C}\right)$ and assayed for $\beta$-galactosidase activity, normalized to OD600 as described in Methods. Results shown are the average and standard deviation for at least 7 independent experiments. Strains for rpoS-lac were $\operatorname{resC}+\operatorname{rprA}+(\mathrm{TE9317}), \operatorname{rcsC}+\Delta \operatorname{rprA}$ (TE9353), resC55 rprA+ (TE9316), resC55 $\triangle$ rprA (TE9352), resC64 rprA+ (TE9318), and resC64 $\Delta$ rprA (TE9354). The corresponding strains with the gmm-21::MudJ insertion were: TE9334, TE9394, TE9333, TE9395, TE9368, and TE9396. into E. coli and S. enterica strains bearing appropriate rpoS-lac [pr] fusions. Cultures were grown overnight at $32^{\circ} \mathrm{C}$ in LB medium with ampicillin, then diluted into the same medium containing arabinose as the inducer and grown overnight to stationary phase. Preliminary experiments testing various levels of 
inducer showed that at high levels $(0.2 \%$ arabinose $)$ the empty vector controls displayed a significant negative effect on rpoS expression. Because of this, the experiments described here were performed with intermediate levels of arabinose $(0.02 \%)$.

The results are shown in Fig 8, panel A. Expression of either E. coli or S. enterica dsrA in E. coli resulted in significant induction of $r p o S$. There was an $\approx 8$-fold increase in activity of rpoS-lac [pr] with overexpression of the $E$. coli $d s r A$ gene; for $S$. enterica $d s r A$ the increase was slightly less, $\approx 6$-fold. In contrast, neither gene was able to activate $r p o S$ expression in the $S$. enterica strain background. This negative result in S. enterica, obtained using a MudK insertion in the native rpoS locus as the reporter, was confirmed using a fusion construct identical to the reporter tested in E. coli: E. coli rpoS fused to lac (8; data not shown). These results show that $S$. enterica $d s r A$ is capable of activating $r p o S$ expression in E. coli.

Northern blot analysis of RNA purified from the induced cultures showed that DsrA RNA expressed from $\mathrm{P}_{\mathrm{BAD}}$ was clearly visible in E. coli, but no signal could be detected in S. enterica (Fig 8, panel B). The pattern of ribosomal RNA in all samples was normal (data not shown, 35). Furthermore, arabinose induction of a $\mathrm{P}_{\mathrm{BAD}}-l a c Z$ construct was observed in $S$. enterica, to approximately the level of a fully induced single copy lac operon (data not shown). Failure to overexpress DsrA RNA of either type in S. enterica suggests that the defect lies with DsrA RNA turnover, but allows the formal possibility that S. enterica rpoS also fails to respond. 


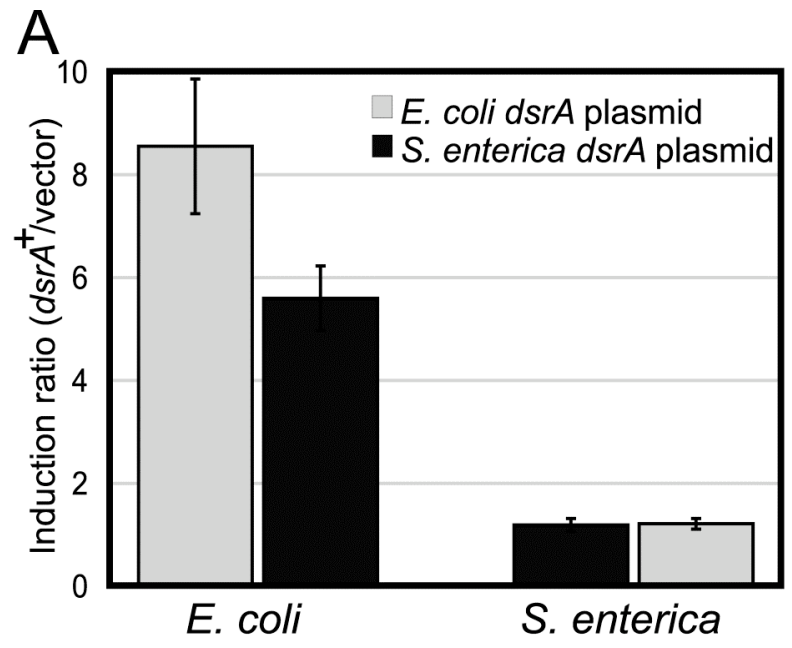

B

Chromosomal dsrA $\frac{\text { E. coli }}{+--_{-}} \frac{\text { S. enterica }}{+--_{-}}$

S. enterica dsrA plasmid , $-{ }_{-}+{ }_{-}+{ }_{-}+$

$18^{\circ} \mathrm{C}$

$32^{\circ} \mathrm{C}$

C

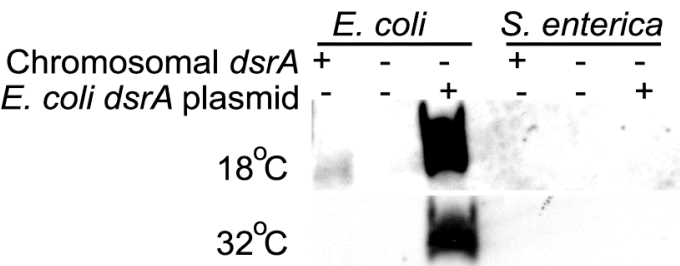

Figure 8 Expression of $d s r A$ from ${ }_{\text {PBAD. Panel A. Strains }}$ of $E$. coli or $S$. enterica with an rpoS-lac [pr] fusion in the bacterial chromosome, deleted for $d \operatorname{sr} A$, and also carrying a plasmid ${ }_{\mathrm{P}} \mathrm{BAD}-d s r A$ construct from the species indicated, were induced with $0.02 \%$ arabinose and grown overnight to stationary phase in $\mathrm{LB}$ Amp medium at $32^{\circ} \mathrm{C}$. Activity of $\beta$-galactosidase is plotted for each strain, normalized to the expression seen with a vector control. Panel B. RNA purified from cultures grown as in $A$ was analyzed by Northern blot as described in Methods, using a $\operatorname{dsr} A-$ specific oligonucleotide probe. Strains were: TE9418, TE9419, TE9424, TE9425, TE9427, TE9428, TE9430, and TE9431.

\section{Mutations affecting the antisense element} and its RBS target in S. enterica rpoS. Our previous studies on function of the antisense element employed a lac fusion to the E. coli rpoS gene and its upstream sequences (6). The effect of point mutations on rpoS expression was studied

primarily in the $S$. enterica background (7), while the effect of deletion and overexpression of small RNA genes has been studied in E. coli $(43,27,51,29)$. Therefore, we tested the effect of mutations changing either the antisense element or the rpoS RBS in S. enterica. As described above, the sequence of the rpoS leader is highly conserved in S. enterica compared to E. coli, particularly in the region between the antisense element and the start codon (Fig 4). Even in the 63-nt connector region, which is predicted to form two stem-loops (20), the eight substitutions found in S. enterica would affect loop nucleotides rather than paired stem nucleotides (data not shown).

A number of point mutations were constructed directly on the bacterial chromosome using the $\lambda$ Red recombination system and selection for Tet ${ }^{\mathrm{S}}$ transformants as described in the Methods, and combined 
with a MudK insertion in the $r p o S$ gene to measure their effect on expression. Mutations in the rpoS leader were studied in a strain carrying an insertion in the $h f q$ gene for several reasons. First, an $h f q$ mutation is known to sensitize E. coli to the effect of similar mutations (7). This may be due to the existence of other, as yet uncharacterized Hfq-dependent activating sRNAs, or it may be due to far upstream elements of the rpoS leader which also have Hfq-dependent effects (10). A second reason to use an $h f q$ mutant is that interactions with other molecules might confound the interpretation of phenotypes for strains with compensatory mutations. 
A.
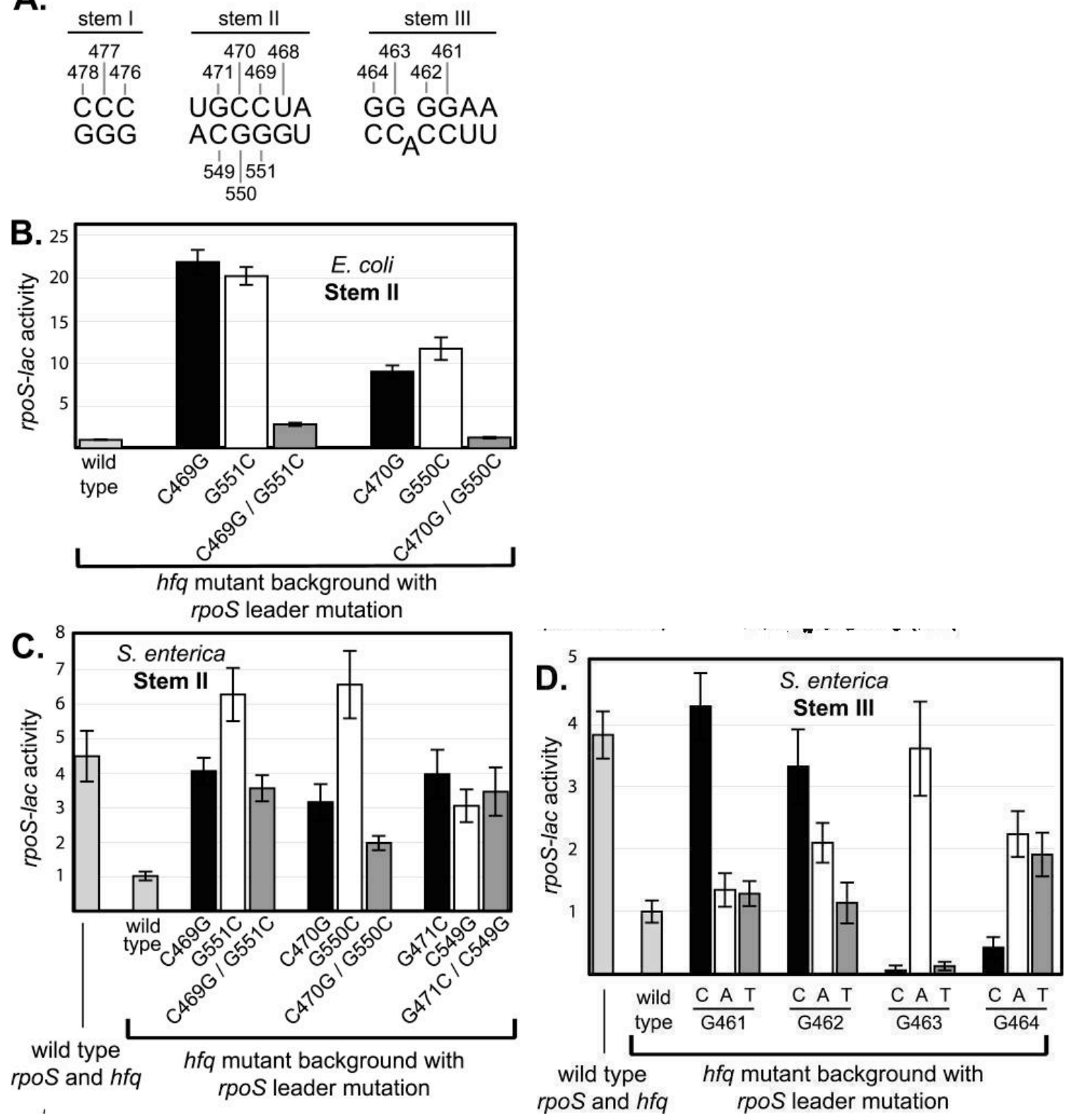

Figure 9. Effect of point mutations in the antisense element and RBS region on expression of rpoS in $E$. coli and $S$. enterica. S. enterica strains with mutations in the $r p o S$ leader on the bacterial chromosome were constructed as described in Methods. The rpoS::MudK (codon 216) fusion and an $h f q$ ::Mud-Cam insertion were introduced by P22 transduction. $E$. coli fusion strains have been described or were made in the same way (7). Cultures were grown overnight in LB medium at $23-25^{\circ} \mathrm{C}$ to SP and assayed for $\beta$-galactosidase activity. Panel A shows the location of point mutations within the antisense element. Strains used in panel B: TE6266, TE6557, TE6558, TE6590, TE6369-2, TE6369-3, and TE6382. Strains for panel C were TE8808, TE8815, and TE8852-TE8860. Strains for panel D were TE8808, TE8815, and TE9236TE9247. 
The results of these experiments are shown in Fig 9. The effects observed for mutations in S. enterica are broadly, but not completely, compatible with what was reported previously in E. coli. For three positions of stem II lying within the antisense element and the corresponding three positions in the RBS region, each mutation tested showed a mutant phenotype, with elevated $r p o S$ expression (Fig 9, panel C). Two differences from E. coli were noted. First, the magnitude of the effect on expression in the mutants was somewhat lower in S. enterica than in E. coli. Second, the effect of compensatory mutations was not as complete or dramatic as observed in E. coli. (Compare panel C with panel B).

A comprehensive set of mutations in the top strand of stem III was also constructed (Fig 9, panel D). The pattern for this set is complex: of 12 mutations, three have a strong mutant phenotype with elevated expression, three are weakly mutant with elevated expression, three are mutant but show decreased expression (as much as 10-fold decreased), while three are wild type (Fig 9, panel D). We do not currently have an explanation for this complex pattern. However, we emphasize that precisely the same pattern was observed in a similar panel of mutations affecting E. coli rpoS at positions 461-464 (Cunning and Elliott, unpublished data). The sole exception was G461A, which is mutant in E. coli and normal in S. enterica.

The conservation of all nucleotides involved in the folded structure, as well as the phenotypes of single mutations affecting paired nucleotides, are both consistent with a similar function for the antisense element in S. enterica as in E. coli. As a final support for this interpretation, we sought and obtained additional mutations, including some that have a down phenotype - decreased expression of rpoS. These include a double mutation in stem I (C476G C477G, 7-fold elevated) and T468C (4-fold down). Phenotypes for both of these mutants are consistent with the model. 


\section{Discussion}

Working with S. enterica, we examined the roles of DsrA and RprA regulatory RNAs in rpoS expression under three specific conditions: growth at low temperature, after osmotic shock, and with constitutive activation of the Rcs phosphorelay by an $\mathrm{Rcs}^{*}$ mutation. Only osmotic shock revealed a significant requirement for the two RNAs. The competence of $S$. enterica DsrA for $r p o S$ regulation was tested in an E. coli host and found nearly to be as effective as E. coli DsrA. Conservation of the ability to stimulate RpoS expression is not surprising given the high sequence identity of the sRNAs and their targets within the antisense element. The reciprocal test, of E. coli DsrA in an S. enterica host, showed no stimulation of RpoS, but was inconclusive since Northern blots did not show any accumulation of the small RNA. A variety of mutations affecting the antisense element of $S$. enterica rpoS and its RBS are consistent with results seen with E. coli, except that the phenotype of predicted compensatory double mutants was not clearly wild type. The reason for this difference from E. coli is not known. In summary, sRNA regulation of rpoS is not conserved in S. enterica, despite sequence conservation of the sRNA regulators and their target. The most likely explanation for this is RNA instability, though this was not demonstrated directly.

How can the apparent non-conservation of DsrA and RprA function with respect to RpoS regulation be reconciled with clear sequence conservation of the $d s r A$ and rprA genes between E. coli, S. enterica and other enterics? One idea would be that $S$. enterica uses other, or additional, sRNAs to regulate rpoS translation. A role for sRNAs in mediating regulation of $r p o S$ in $S$. enterica is suggested by the following lines of evidence: (i) E. coli and S. enterica share a common pattern of $r p o S$ translational regulation by the antisense element (results), (ii) translation of $r p o S$ depends on $\mathrm{Hfq}(44,6)$, and (iii) many trans-acting sRNA regulators require Hfq for activity (28). 
In addition to DsrA and RprA, other potential sRNA regulators of $r p o S$ have been identified in E. coli (46), although the relevant physiological conditions under which they regulate have not yet been determined. It is not clear whether these are conserved in S. enterica, and to our knowledge a search for unique sRNAs in S. enterica has not been done. This presents the possibility that sRNA regulators, in addition to DsrA and RprA and having a synergistic or antagonistic role in regulating rpoS translation in E. coli, are not conserved in S. enterica. The goal of this study was to determine the rpoS-specific effects of these sRNAs, but it cannot be ruled out that perhaps DsrA and RprA regulate other targets in $S$.

enterica. In E. coli, multicopy $d s r A$ has been shown to negatively regulate $h n s$ translation (42) and has a modest effect on acid resistance (25). However, lack of sRNA accumulation is the simplest explanation although the mechanism for this is unknown. In summary, although the sequences of these sRNAs are conserved between E. coli and S. enterica, their function is not conserved.

\section{Acknowledgments}

We are grateful to individuals cited in the text for bacterial strains. This study was supported by Public Health Service grant GM63616. 
Table 2. Bacterial Strains.

\section{S. enterica}

TE6134 $h f q-1::$ Mud-Cam

(Brown 96)

TE6153 putPA1303::Kan ${ }^{\mathrm{r}}$-katE-lac [op]

(Brown 96)

TE6266 $h f q-1::$ Mud-Cam putPA1303:: Kan ${ }^{\mathrm{r}}$-rpoS-lac [pr]

(Brown 97)

TE6369-2 hfq-1::Mud-Cam putPA1303:: Kan ${ }^{\mathrm{r}}$-rpoS-lac [pr] (C470G)

(Brown 97)

TE6369-3

hfq-1::Mud-Cam putPA1303:: Kan ${ }^{\mathrm{r}}$-rpoS-lac [pr] (G550C)

(Brown 97)

TE6382

hfq-1::Mud-Cam putPA1303:: Kan $\stackrel{\mathrm{r}}{-}$ rpoS-lac [pr] (C470G) (G550C)

(Brown 97)

TE6557

hfq-1::Mud-Cam putPA1303:: Kan ${ }^{\mathrm{r}}$-rpoS-lac [pr] (C469G)

TE6558

hfq-1::Mud-Cam putPA1303:: Kan ${ }^{\mathrm{r}}$-rpoS-lac [pr] (G551C)

TE6590

hfq-1::Mud-Cam putPA1303:: Kan ${ }^{\mathrm{r}}$-rpoS-lac [pr] (C469G) (G551C)

TE6850

clpX1::Tn10d-Cam

(Cunning 99)

TE6851 mviA22::Tn10d-Cam

(Cunning 99)

TE8007 JF3490 dksA4::Tn10d-Tet

(J. Foster)

TE8012 TE8007 LT2A putPA1303::Kanr-katE-lac [op]

TE8544 putPA::katE-lac [op] rpoS1074::tetAR (A.S., deletes nt 461-464 of rpoS leader) 
TE8546 putPA::katE-lac [op] rpoS1076::cat (deletes from 110 bp upstream to 469 of rpoS leader)

TE8566 putPA::katE-lac [op] $\Delta$ dsrA::tetAR

TE8567 putPA::katE-lac [op] $\Delta$ rprA::tetAR

TE8587 putPA::katE-lac [op] $\Delta$ dsrA::cat

TE8588 putPA::katE-lac [op] $\Delta$ cysC::tetAR

TE8589 putPA::katE-lac [op] rpoS1084::tetAR (AGGA, deletes nt 554-557

of rpoS leader)

TE8607 $\Delta$ cysC::tetAR

TE8608 putPA1303::Kan ${ }^{\mathrm{r}}$-katE-lac [op] $\Delta$ dsrA::cam

TE8610 putPA1303::Kan ${ }^{\mathrm{r}}$-katE-lac [op] $\Delta$ rprA::tetAR

TE8613 putPA1303::Kan ${ }^{\mathrm{r}}$-katE-lac [op] $\Delta$ dsrA::cam $\Delta$ rprA::tetAR

TE8622 $\Delta$ cysC::tetAR rpoS1076::cat (deletes from 110 bp upstream to 469

of rpoS leader)

TE8701 putPA::katE-lac [op] rpoS1080::tetAR (DA.S.-AGGA, deletes nt 461557)

TE8737 rpoS1082::MudJ (codon 66) 


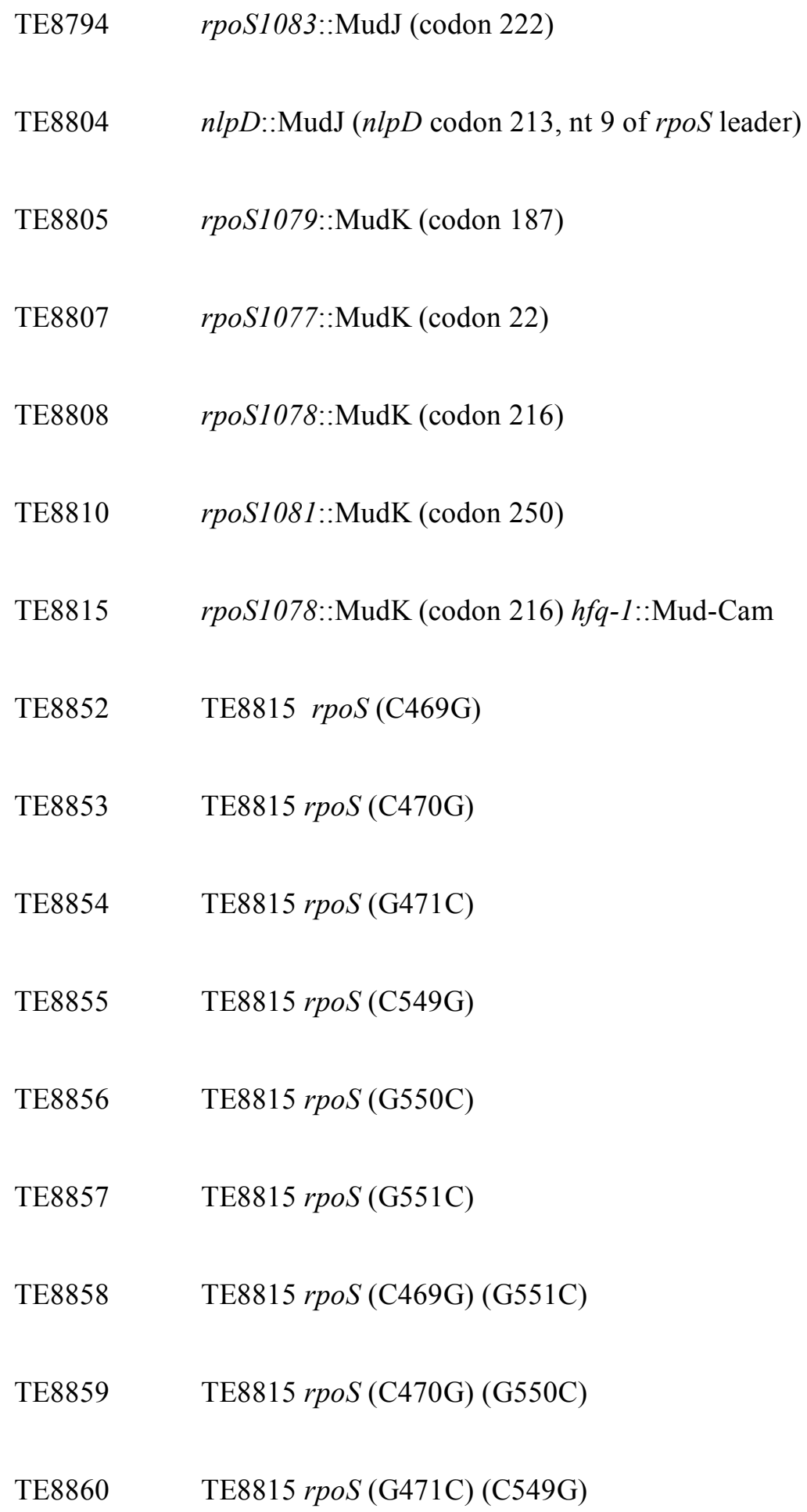




\begin{tabular}{|c|c|c|}
\hline TE8935 & $n l p D::$ MudJ ( $n l p D$ codon 302, nt 276 of rpoS leader) & \\
\hline TE8936 & rpoS:::MudJ (codon 36) & \\
\hline TE8983 & rpoS1077::MudK (codon 22) $\Delta d s r A:: c a t$ & \\
\hline TE9049 & $\begin{array}{l}n l p D::\left[\text { FRT-lacZY pKG137 Kan }{ }^{\mathrm{R}} \text { (nlpD codon } 302 \text {, nt } 276 \text { of rpoS }\right. \\
\text { leader) }\end{array}$ & \\
\hline TE9050 & $r p o S::\left[\right.$ FRT-lacZY pKG137 Kan ${ }^{\mathrm{R}}$ (rpoS codon 36) & \\
\hline TE9051 & rpoS::[FRT-lacZY pKG137 Kan ${ }^{\mathrm{R}}$ ] (rpoS codon 222) & \\
\hline TE9052 & $\begin{array}{l}n l p D::\left[\text { FRT-lacZY pKG137 Kan }{ }^{\mathrm{R}}\right] \text { (nlpD codon } 213, \text { nt } 9 \text { of } r p o S \\
\text { leader) }\end{array}$ & \\
\hline TE9053 & $r p o S::\left[\right.$ FRT-lacZY pKG137 Kan $\left.{ }^{\mathrm{R}}\right](r p o S$ codon 4$)$ & \\
\hline TE9160 & rpoS1081::MudK (codon 250) (TTG -> ATG start codon) & \\
\hline TE9179 & MS1868 StrA1 rpoS::[tetAR rpsL $\left.{ }^{+}\right]$(AGGA) & (S. Maloy) \\
\hline TE9213 & rpoS1081::MudK (codon 250) (TTG -> ATG start codon) $\Delta d s r A:: c a t$ & \\
\hline TE9219 & $\begin{array}{l}\text { rpoS1081::MudK (codon 250) (TTG -> ATG start codon) } \Delta d s r A:: c a t \\
\Delta \operatorname{rpr} A:: t e t A R\end{array}$ & \\
\hline TE9236 & TE8815 rpoS (G461C) & \\
\hline TE9237 & TE8815 rpoS (G461A) & \\
\hline TE9238 & $\mathrm{TE} 8815 \operatorname{rpoS}(\mathrm{G} 461 \mathrm{~T})$ & \\
\hline TE9239 & TE8815 rpoS (G462C) & \\
\hline
\end{tabular}


TE9241 TE8815 rpos (G462T)

TE9242 TE8815 rpoS (G463C)

TE9243 TE8815 rpoS (G463A)

TE9244 TE8815 rpos (G463T)

TE9245 TE8815 rpos (G464C)

TE9246 TE8815 rpoS (G464A)

TE9247 TE8815 rpos (G464T)

TE9316 rpoS1077::MudK (codon 22) zef-6829::tetAR rcsC55 (T903A)

TE9317 rpoS1077::MudK (codon 22) zef-6829::tetAR rcsC ${ }^{+}$

TE9318 rpoS1077::MudK (codon 22) zef-6829::tetAR rcsC64 (F473I)

TE9333 gmm-21::MudJ zef-6829::tetAR rcsC55 (T903A)

TE9334 gmm-21::MudJ zef-6829::tetAR rcsC+

TE9352 rpoS1077::MudK (codon 22) zef-6829::tetAR rcsC55 (T903A) $\operatorname{rpr} A:: c a m$

TE9353 rpoS1077::MudK (codon 22) zef-6829::tetAR $\operatorname{rcs} C^{+} \Delta$ rprA::cam

TE9354 rpoS1077::MudK (codon 22) zef-6829::tetAR rcsC64 (F473I) $\triangle$ rprA::cam 
TE9428

\section{TE8983 / pNM3 (PBD-E. coli $\left.d s r A^{+}\right)$}

TE9430

TE8983 / pBAD18 (vector)

TE9431

$$
\text { TE8983 / pTE780 (PBD-S. enterica dsrA } \left.{ }^{+}\right)
$$

TE9452 TE8815 rpoS (T468C)

TE9453 TE8815 rpos (C476A) (C477A)

\section{E. coli}

SG22182 MC4100 ara mal::lacI ${ }^{\mathrm{Q}}$

(D. Sledjeski)

DDS1365 MC4100 ara mal::lacI ${ }^{\mathrm{Q}}$ dsrA1::cat

(D. Sledjeski)

TE6897 MC4100 ara mal::lacI ${ }^{\mathrm{Q}}$ trpDC700:: putPA1303::Kan -katE-lac [op]

TE6898 MC4100 ara mal::lacI ${ }^{\mathrm{Q}}$ trpDC700:: putPA1303::Kan ${ }^{\mathrm{r}}$-rpoS-lac [pr]

TE6913 MC4100 ara mal::lacI ${ }^{\mathrm{Q}}$ trpDC700:: putPA1303::Kan -katE-lac [op] dsrA1::cat

TE6914 MC4100 ara mal::lacI ${ }^{\mathrm{Q}}{ }_{\text {trpDC700:: }}$ putPA1303::Kan ${ }^{\mathrm{r}}$-rpoS-lac [pr] dsrA1::cat 


\begin{tabular}{|c|c|c|}
\hline TE8096 & $\begin{array}{l}\text { BW26678 E. coli K-12 / pKD46 (AmpR, pSC101 rep(Ts) araC }{ }^{+} \mathrm{P}_{\mathrm{BAD}^{-}} \\
\lambda \text { red })\end{array}$ & (B. Wanner) \\
\hline TE9062 & $z g d:: t e t A R$ (just upstream of $r p s L^{+}$) & \\
\hline TE9418 & TE6914 / pBAD18 (vector) & \\
\hline TE9419 & TE6914 / pTE780 (PBAD-S. enterica $\left.d s r A^{+}\right)$ & \\
\hline TE9424 & TE6914 / pNM12 (vector) & D. Sledjeski \\
\hline TE9425 & TE6914 / pNM3 (PBAD-E. coli $\left.d s r A^{+}\right)$ & D. Sledjeski \\
\hline
\end{tabular}

Numbering corresponds to the position of the last nucleotide retained from the rpoS leader or the codon within which the fusion occurs (i.e. the last intact codon is one previous). 


\section{Literature cited}

1. Altman, E., J. R. Roth, A. Hessel, and K. E. Sanderson. 1996. Transposons currently in use in genetic analysis of Salmonella species. pp. 2613-2626. . In F. C. Neidhardt, R. Curtiss III, J. L. Ingraham, E. C. C. Lin, K. B. Low, B. Magasanik, W. S. Reznikoff, M. Riley, M. Schaechter, and H. E. Umbarger (ed.), Escherichia coli and Salmonella: cellular and molecular biology, 2nd ed., vol. 2. American Society for Microbiology, Washington, D.C.

2. Becker, G., E. Klauck, and R. Hengge-Aronis. 1999. Regulation of RpoS proteolysis in Escherichia coli: the response regulator RssB is a recognition factor that interacts with the turnover element in RpoS. Proc. Natl. Acad. Sci. USA 96:6439-6444.

3. Benjamin, W. H., Jr., X. Wu, and W. E. Swords. 1996. The predicted amino acid sequence of the Salmonella typhimurium virulence gene vviA $^{+}$strongly indicates that MviA is a regulator protein of a previously unknown S. typhimurium response regulator family. Infect. Immun. 64:2365-2367.

4. Bochner, B. R. and B. N. Ames. 1982. Complete analysis of cellular nucleotides by twodimensional thin layer chromatography. J. Biol. Chem. 257:9759-9769.

5. Bochner, B. R., H. C. Huang, G. L. Schieven, and B. N. Ames. 1980. Positive selection for loss of tetracycline resistance. J. Bacteriol. 143:926-933.

6. Brown, L., and T. Elliott. 1996. Efficient translation of the RpoS sigma factor in Salmonella typhimurium requires host factor I, an RNA-binding protein encoded by the $h f q$ gene. J. Bacteriol. 178:3763-3770. 
7. Brown, L. and T. Elliott. 1997. Mutations that increase expression of the rpoS gene and decrease its dependence on $h f q$ function in Salmonella typhimurium. J. Bacteriol. 179:656-662.

8. Castilho, B. A., P. Olfson, and M. J. Casadaban. 1984. Plasmid insertion mutagenesis and lac gene fusion with mini-Mu bacteriophage transposons. J. Bacteriol. 158:488-495.

9. Cunning, C. and T. Elliott. 1999. RpoS synthesis is growth rate regulated in Salmonella typhimurium, but its turnover is not dependent on acetyl phosphate synthesis or PTS function. J. Bacteriol. 181:4853-4862.

10. Cunning, C., L. Brown, and T. Elliott. 1998. Promoter substitution and deletion analysis of upstream region required for $r p o S$ translational regulation. J. Bacteriol. 180:4564-4570.

11. Datsenko, K. A. and B. L. Wanner. 2000. One-step inactivation of chromosomal genes in Escherichia coli K-12 using PCR products. Proc. Natl. Acad. Sci. USA 97:6640-6645.

12. Davis, R. W., D. Botstein and J. Roth. 1980. Advanced bacterial genetics. Cold Spring Harbor Laboratory Press, Cold Spring Harbor, N.Y.

13. Ellermeier, C. D., and J. M. Slauch. 2002. Construction of targeted single copy lac fusions using lambda Red and FLP-mediated site-specific recombination in bacteria. Gene 290:153-161.

14. Elliott, T., and X. Wang. 1991. Salmonella typhimurium prfA mutants defective in release factor 1. J. Bacteriol. 173:4144-4154.

15. Garcia-Calderon, C. B., M. Garcia-Quintanilla, J. Casadesus, and F. Ramos-Morales. 2005. Virulence attenuation in Salmonella enterica rcs C mutants with constitutive activation of the Rcs system. Microbiology 151:579-588.

16. Gottesman, S. 2004. The small RNA regulators of Escherichia coli: roles and mechanisms. Annu. Rev. Microbiol. 58:303-328. 
17. Gowrishankar, J., K. Yamamoto, P. R. Subbarayan, and A. Ishihama. 2003. In vitro properties of RpoS (sigma(S)) mutants of Escherichia coli with postulated N-terminal subregion 1.1 or C-terminal region 4 deleted. J. Bacteriol. 185:2673-2679.

18. Guzman, L., Belin, D., Carson, M., and J. Beckwith. 1995. Tight regulation, modulation, and high-level expression by vectors containing the arabinose $\mathrm{P}_{\mathrm{BAD}}$ promoter. J. Bacteriol. $177: 4121-4130$

19. Hengge-Aronis, R. 2002. Signal transduction and regulatory mechanisms involved in control of the $\sigma^{S}$ (RpoS) subunit of RNA polymerase. Microbiol. Mol. Biol. Rev. 66:373-395.

20. Hirsch, M. and T. Elliott. 2002. Role of ppGpp in rpoS stationary-phase regulation in Escherichia coli. J. Bacteriol. 184:5077-5087.

21. Hirsch, M., and T. Elliott. 2005. Fis regulates transcriptional induction of RpoS in Salmonella enterica. J. Bacteriol. 187:1568-1580.

22. Hughes, K. T., and J. R. Roth. 1988. Transitory cis complementation: a method for providing transposition functions to defective transposons. Genetics 119:9-12.

23. Lange, R., D. Fischer, and R. Hengge-Aronis. 1995. Identification of transcriptional start sites and the role of ppGpp in the expression of $r p o S$, the structural gene for the sigma $\mathrm{S}$ subunit of RNA polymerase in Escherichia coli. J. Bacteriol. 177:4676-4680.

24. Lease, R. A. and M. Belfort. 2000. A trans-acting RNA as a control switch in Escherichia coli: DsrA modulates function by forming alternative structures. Proc. Natl. Acad. Sci. USA 97:99199924.

25. Lease, R.A., Smith, D., K. McDonough and M. Belfort. 2004. The small noncoding DsrA RNA is an acid resistance regulator in Escherichia coli. J. Bacteriol. 186:6179-6185. 
26. Lee, I. S., J. Lin, H. K. Hall, B. Bearson, and J. W. Foster. 1995. The stationary-phase sigma factor sigma $\mathrm{S}(\mathrm{RpoS})$ is required for a sustained acid tolerance response in virulent Salmonella typhimurium. Mol. Microbiol. 17:155-167.

27. Majdalani, N., C. Cunning, D. Sledjeski, T. Elliott and S. Gottesman. 1998. DsrA RNA regulates translation of RpoS message by an anti-antisense mechanism, independent of its action as an antisilencer of transcription. Proc. Natl. Acad. Sci. USA 95:12462-12467.

28. Majdalani, N., C. Vanderpool, and S. Gottesman. 2005. Bacterial Small RNA Regulators. Crit. Rev Biochem Mol Biol. 40:93-113.

29. Majdalani, N., D. Hernandez, and S. Gottesman. 2002. Regulation and mode of action of the second small RNA activator of RpoS translation, RprA. Mol. Microbiol. 46:813-826.

30. Majdalani, N., S. Chen, J. Murrow, K. St. John and S. Gottesman. 2001. Regulation of RpoS by a novel small RNA: the characterization of RprA. Mol. Microbiol. 39:1382-1394.

31. Maloy, S. R. and W. D. Nunn. 1981. Selection for loss of tetracycline resistance by Escherichia coli. J. Bacteriol. 145:1110-1111.

32. Miller, J. H. 1972. Experiments in molecular genetics. Cold Spring Harbor Laboratory. Cold Spring Harbor, N.Y.

33. Muffler, A., D. Fischer, and R. Hengge-Aronis. 1996. The RNA-binding protein HF-I, known as a host factor for phage Qbeta RNA replication, is essential for $r p o S$ translation in Escherichia coli. Genes Dev. 10:1143-1151.

34. Neidhardt, F. C., P. L. Bloch, and D. F. Smith. 1974. Culture medium for enterobacteria. J. Bacteriol. 119:736-747.

35. Pronk, L., and K. Sanderson. 2001. Intervening sequences in $r r l$ genes and fragmentation of 23S rRNA in genera of the family Enterobacteriaceae. J. Bacteriol. 183:5782-5787. 
36. Rajkumari, K., and J. Gowrishankar. 2002. An N-terminally truncated RpoS (sigma(S)) protein in Escherichia coli is active in vivo and exhibits normal environmental regulation even in the absence of rpoS transcriptional and translational control signals. J. Bacteriol. 184:3167-3175.

37. Repoila, F., and S. Gottesman. 2001. Signal transduction cascade for regulation of RpoS: temperature regulation of DsrA. J. Bacteriol. 183:4012-4023.

38. Repoila, F., N. Majdalani and S. Gottesman. 2003. Small non-coding RNAs, co-ordinators of adaptation processes in Escherichia coli: the RpoS paradigm. Mol. Microbiol. 48:855-861.

39. Ruiz, N., C. N. Peterson, and T. J. Silhavy. 2001. RpoS-dependent transcriptional control of sprE: regulatory feedback loop. J. Bacteriol. 183:5974-5981.

40. Silhavy, T. J., M. L. Berman, and L. W. Enquist. 1984. Experiments with gene fusions. Cold Spring Harbor Laboratory Press, Cold Spring Harbor, N.Y.

41. Skorupski, K., and R. K. Taylor. 1996. Positive selection vectors for allelic exchange. Gene 169:47-52.

42. Sledjeski, D.D. and S. Gottesman. 1995. A small RNA acts as an antisilencer of the H-NSsilenced rcsA gene of Escherichia coli. Proc. Natl. Acad. Sci. USA 92:2003-2007.

43. Sledjeski, D. D., A. Gupta and S. Gottesman. 1996. The small RNA, DsrA, is essential for the low temperature expression of RpoS during exponential growth in Escherichia coli. EMBO J. 15:3993-4000.

44. Sledjeski D.D., C. Whitman and A. Zhang. 2001. Hfq is necessary for regulation by the untranslated RNA DsrA. J. Bacteriol. 183:1997-2005.

45. Takayanagi, Y., K. Tanaka, and H. Takahashi. 1994. Structure of the $5^{\prime}$ upstream region and the regulation of the rpoS gene of Escherichia coli. Mol. Gen. Genet. 243:525-531. 
46. Wassarman, K. M., F. Repoila, C. Rosenow, G. Storz and S. Gottesman. 2001. Identification of novel small RNAs using comparative genomics and microarrays. Genes Dev. 15:1637-1651.

47. Webb, C., M. Moreno, M. Wilmes-Riesenberg, R. Curtiss $3^{\text {rd }}$, and J. W. Foster. 1999. Effects of DksA and ClpP protease on sigma S production and virulence in Salmonella typhimurium. Mol. Microbiol. 34:112-123.

48. Weber, H., T. Polen, J. Heuveling, V. F. Wendisch, and R. Hengge. 2005. Genome-wide analysis of the general stress response network in Escherichia coli: $\sigma^{S}$-dependent genes, promoters, and sigma factor selectivity. J. Bacteriol. 187:1591-1603.

49. Wilmes-Riesenberg, M. R., J. W. Foster, and R. Curtiss, $3^{\text {rd }} .1997$. An altered $r p o S$ allele contributes to the avirulence of Salmonella typhimurium LT2. J. Bacteriol. 65:203-210.

50. Yu, D., H. M. Ellis, E. C. Lee, N. A. Jenkins, N. G. Copeland, and D. L. Court. 2000. An efficient recombination system for chromosome engineering in Escherichia coli. Proc. Natl. Acad. Sci. USA 97:5978-5983.

51. Zhang, A., S. Altuvia, A. Tiwari, L. Argaman, R. Hengge-Aronis and G. Storz. 1998. The OxyS regulatory RNA represses rpoS translation and binds the Hfq (HF-1) protein. EMBO J. 17:6061-6068. 


\section{Chapter 3: Literature review: Heme-mediated regulation of HemA}

\section{Heme}

Porphyrins are a colorful group of organic compounds. Famous representatives include hemes and chlorophylls, responsible for the red color of blood and the green pigment of plants, respectively. The porphyrin nucleus is a highly conjugated ring, consisting of four pyrrole subunits interconnected via methine bridges (Fig. 1). The double bonds joining the pyrrole rings are responsible for a characteristic absorption peak around $400 \mathrm{~nm}$, the Soret band, as well as a strong red fluorescence when viewed under UV light. These properties are independent of the various groups attached to the periphery of the macrocycle, which are used to classify different hemes (Fig, 10). The nitrogen atoms of the four pyrroles are used to chelate divalent cations, including $\mathrm{Fe}^{2+}$ for the formation of hemes, and $\mathrm{Mg}^{2+}$ for chlorophylls (reviewed in 7,9).
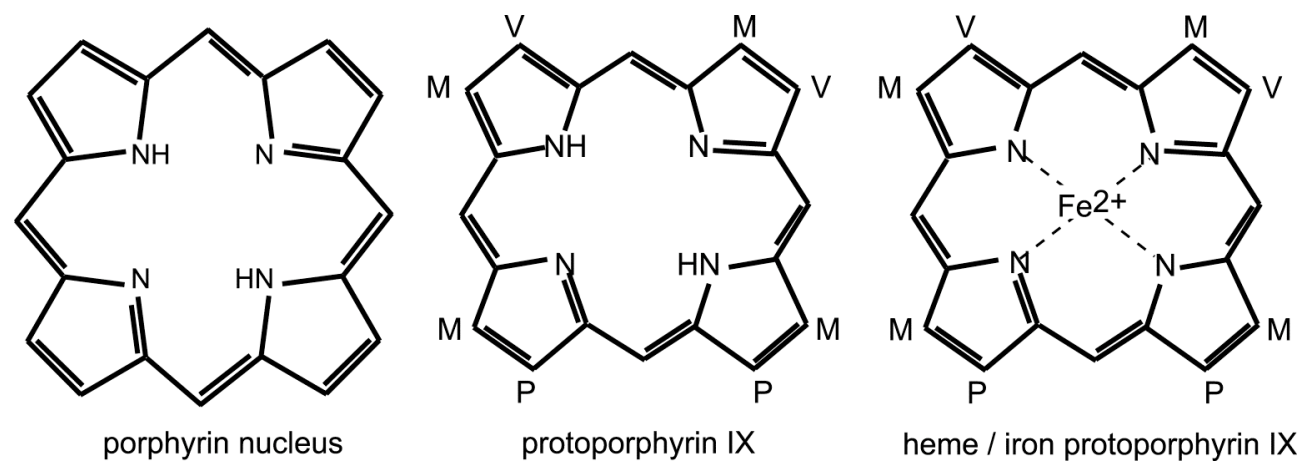

Figure 10. The porphyrin nucleus is responsible for color. Protoporphyrin IX serves as substrate for synthesis of heme b and chlorophylls. Groups attached to the periphery are methyl (M), propionate (P), and vinyl (V). 


\section{Diverse biological roles for heme}

Heme is an essential molecule for most archaea, bacteria, and eukaryotes. As the prosthetic group of proteins, heme exhibits a wide variety of functions including electron transfer reactions, oxygen transport and storage, and the reduction of oxygen to peroxides (reviewed in 4,11). Heme also functions as a regulatory molecule by transient association with transcription factors and other proteins, modulating levels of transcription, translation, and protein targeting (reviewed in 20). A combination of factors is responsible for the diversity of heme function including the protein environment and the ligation state of the iron atom (4).

\section{Conservation of the heme pathway and the need for regulation}

Heme-producing organisms synthesize tetrapyrroles from 5-aminolevulinic acid (ALA), the universal precursor (reviewed in 2). Steps common in the synthesis of all tetrapyrroles constitute a linear series of reactions that begins with the substrate ALA and ends with production of uroporphyrinogen III (Fig. 11). This part of the pathway is highly conserved; the biosynthetic intermediates and enzyme-catalyzed reactions are very similar or identical in all organisms $(2,9)$. Synthesis halts at uroporphyrinogen III for those organisms that do not possess the necessary enzymes for synthesis of more complex tetrapyrroles (20). 


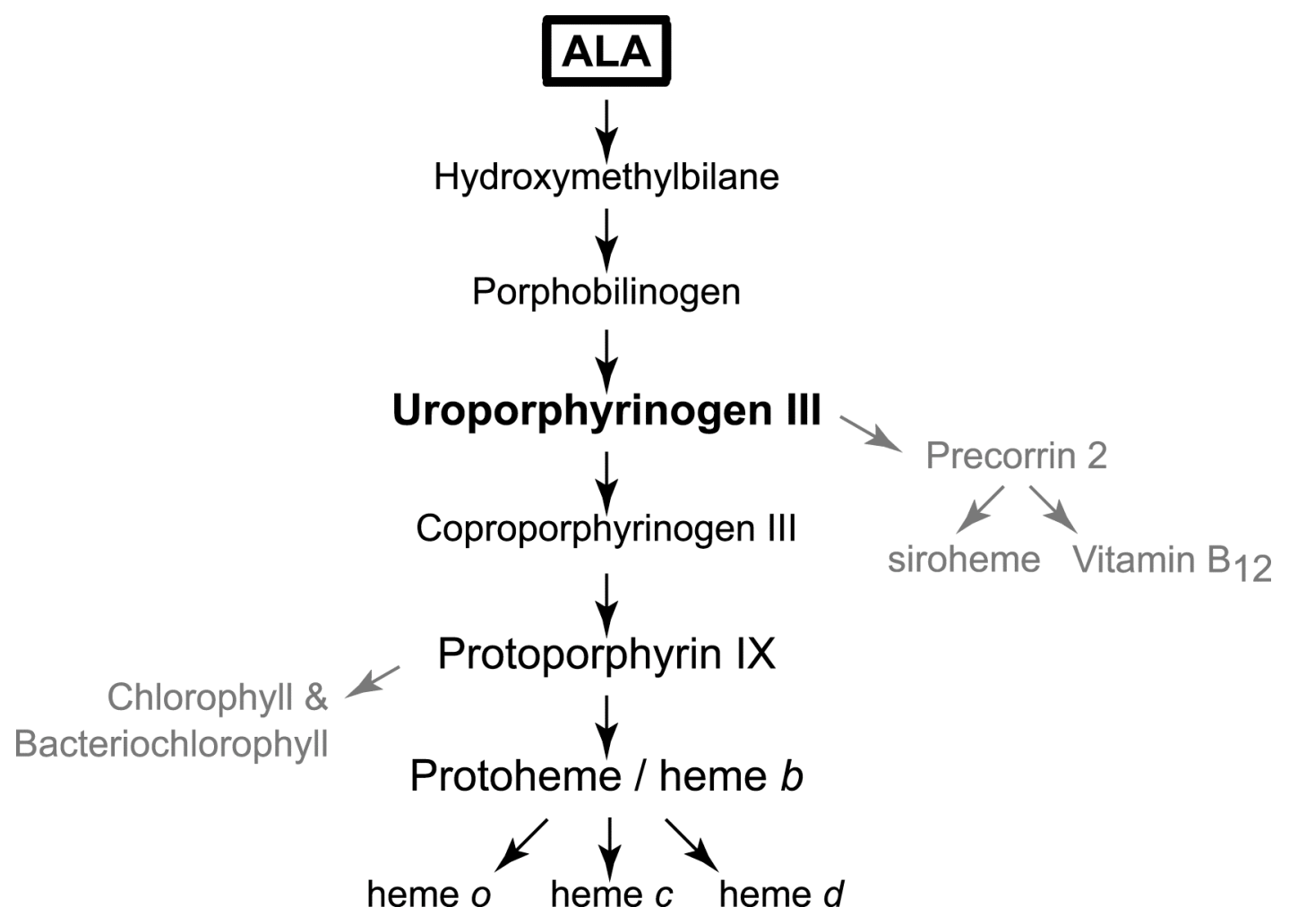

Figure 11. The heme biosynthesis pathway beginning with 5-aminolevulinic acid (ALA), the universal precursor. Uroporphyrinogen III is the first branch point in the pathway, serving as substrate for heme synthesis as well as corrinoids. Protoporphyrin IX is the direct precursor of heme b, from which other heme types are derived, and is also a substrate for chlorophyll production.

Uroporphyrinogen III is the last common intermediate in the formation of all tetrapyrroles. The heme biosynthetic pathway has multiple branches and various end products (Fig. 11), which suggests regulation is required for the timely synthesis of appropriate products. Product levels also require strict regulation since the accumulation of pathway intermediates, including porphyrins and iron, is toxic to cells due to generation of highly reactive oxygen species in the presence of light $(18,30,31)$. In humans, dysregulation of heme biosynthesis presents as porphyria, one of a group of inherited or acquired disorders that often includes photosensitivity of the skin and, in rare cases, neurological symptoms (reviewed in 23). 


\section{Two routes of ALA formation}

Two independent routes exist for the formation of ALA, the universal precursor of heme biosynthesis. The C4, or Shemin, pathway was the first to be discovered and its use is restricted to non-plant eukaryotes, including humans and other animals, as well as the $\alpha$-proteobacteria. ALA is formed from the condensation of glycine with succinyl-coenzyme A $(\mathrm{CoA})$ in a reaction catalyzed by ALA synthase (ALAS). ALAS belongs to a catalytically versatile class of enzymes that require pyridoxal 5'phosphate (PLP) as a cofactor (6).

The $\mathrm{C} 5$ route is present in plants, algae, and most bacteria including the enteric bacteria (reviewed in 2). In this route, ALA is formed from the intact five-carbon skeleton of glutamate in several steps (Fig. 12). First, in a reaction identical to that in protein synthesis, glutamate is activated by ligation to tRNA in the presence of $\mathrm{Mg}^{2+}$ and ATP. Next, glutamyl tRNA reductase (HemA) reduces the glutamyl-tRNA ${ }^{\text {Glu }}$ to an unstable intermediate, glutamate-1-semialdehyde (GSA) in a reaction that requires NADPH.

Finally, GSA aminotransferase (HemL) rearranges GSA to form ALA.

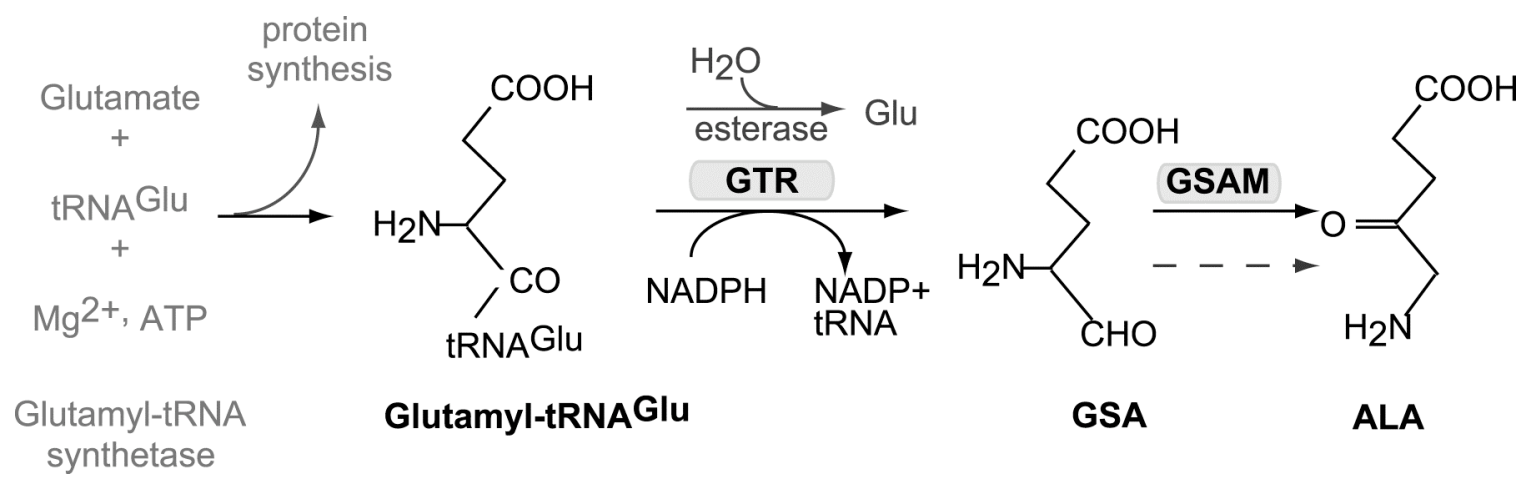

Figure 12. The C5 route of ALA production. The first reaction, catalyzed by Glutamyl-tRNA synthetase, is common to protein synthesis and heme biosynthesis, therefore the reaction catalyzed by glutamyl-tRNA reductase (GTR, HemA) is the first committed step in heme biosynthesis. In the absence of NADPH the esterase activity of GTR releases glutamate. ALA is formed at a low rate in the absence of GSAM (HemL). 


\section{The C5 pathway as a target for antimicrobials}

The enzymes and reactions following ALA formation are largely conserved among heme-producing organisms, therefore the enzymes of the C5 pathway, used by enteric and other pathogenic bacteria, provide an attractive target for development of antimicrobials $(7,9)$. The viability of this endeavor is supported by reduced infection capability of Salmonella hemA mutants (3).

\section{Formation of ALA is the rate-limiting step of heme biosynthesis in eukaryotes}

Mammals possess two ALAS isozymes, ALAS1 and ALAS2, which are regulated by heme via direct and indirect mechanisms (reviewed in 1,8). ALAS2 is expressed only in erythroid cells and provides the heme for hemoglobin. ALAS1 is expressed in all tissues and satisfies the basal heme requirement. While heme regulates the cellular expression and localization of both isozymes, it does so via different mechanisms. The regulation of ALAS2 by heme is somewhat indirect, and results from a coordination of iron levels and the end product of the pathway, heme, such that ALAS2 is synthesized only when iron is available for insertion into protoporphyrin. In contrast, ALAS1 is directly feedback-regulated by heme, inhibiting at the levels of transcription, translation, and mitochondrial import. Accumulation of pathway intermediates in cells receiving exogenous ALA identifies ALAS as the rate-limiting step in all tissues.

\section{HemA is regulated by heme availability}

Several lines of evidence suggest that HemA serves as the critical control point in regulation of heme biosynthesis. E. coli cells grown in the presence of ALA accumulate heme, indicating ALA formation is rate-limiting for heme biosynthesis (21). Strains carrying cloned hemA genes of various species excrete ALA and have a fluorescent red phenotype due to tetrapyrrole overproduction, whereas strains overproducing HemB or HemL do not have a red fluorescent phenotype (5, 33, Choi and Elliott unpublished results). These observations suggest that additional HemA enzyme increases flow through 
the heme biosynthetic pathway, whereas increased levels of HemB and HemL do not (Choi and Elliott unpublished results). Furthermore, overexpression of hemA results in the accumulation of porphyrins and ALA, suggesting HemA catalyzes the rate-controlling step in heme synthesis $(5,10)$. Strains mutant for hemH (encoding ferrochelatase) accumulate protoporphyrin IX and exhibit light-sensitivity (18).

Ferrochelatase is the final enzyme in the heme pathway, forming heme by insertion of $\mathrm{Fe}^{2+}$ into protoporphyrin. The continued production of protoporphyrin in the absence of a functional ferrochelatase enzyme suggests that the pathway's end product, heme, is required to reduce flow through the pathway.

Mutations in hemA and hemL cause ALA auxotrophy. Whereas hemA mutants exhibit a strict requirement for ALA supplementation, hemL mutants are leaky and can be adapted to growth in the absence of ALA (33). Mutations in hemD or the enzymes of subsequent steps in the pathway result in the accumulation of tetrapyrroles, which can be visualized as red fluorescence when colonies are viewed in UV light. The intensity of fluorescence increases as cells become starved for heme (33). Collectively, these observations provide compelling, but indirect, evidence that heme biosynthesis is regulated in response to heme availability and that regulation converges at the rate-limiting enzyme, HemA.

\section{Direct evidence for heme-mediated regulation of HemA}

Experimentally, heme limitation can be imposed by adaptation of a bradytrophic hemL deletion mutant to growth in the absence of ALA or starvation of mutants blocked at various steps of the heme biosynthesis pathway after ALA formation (33). Glutamyl-tRNA reductase (GTR) activity in S. enterica extracts from starved hemB, hemE, and hemH mutants is 15- to 25-fold greater than wild type. Similar increases in HemA activity were measured in extracts from ALA-adapted hemL mutants. The increased HemA activity correlates with an increase in HemA protein levels in starved cultures as determined by 
Western blot. In E. coli, Western blot analysis revealed similar increases in HemA levels in response to heme-limitation suggesting regulation is conserved between S. enterica and E. coli (33).

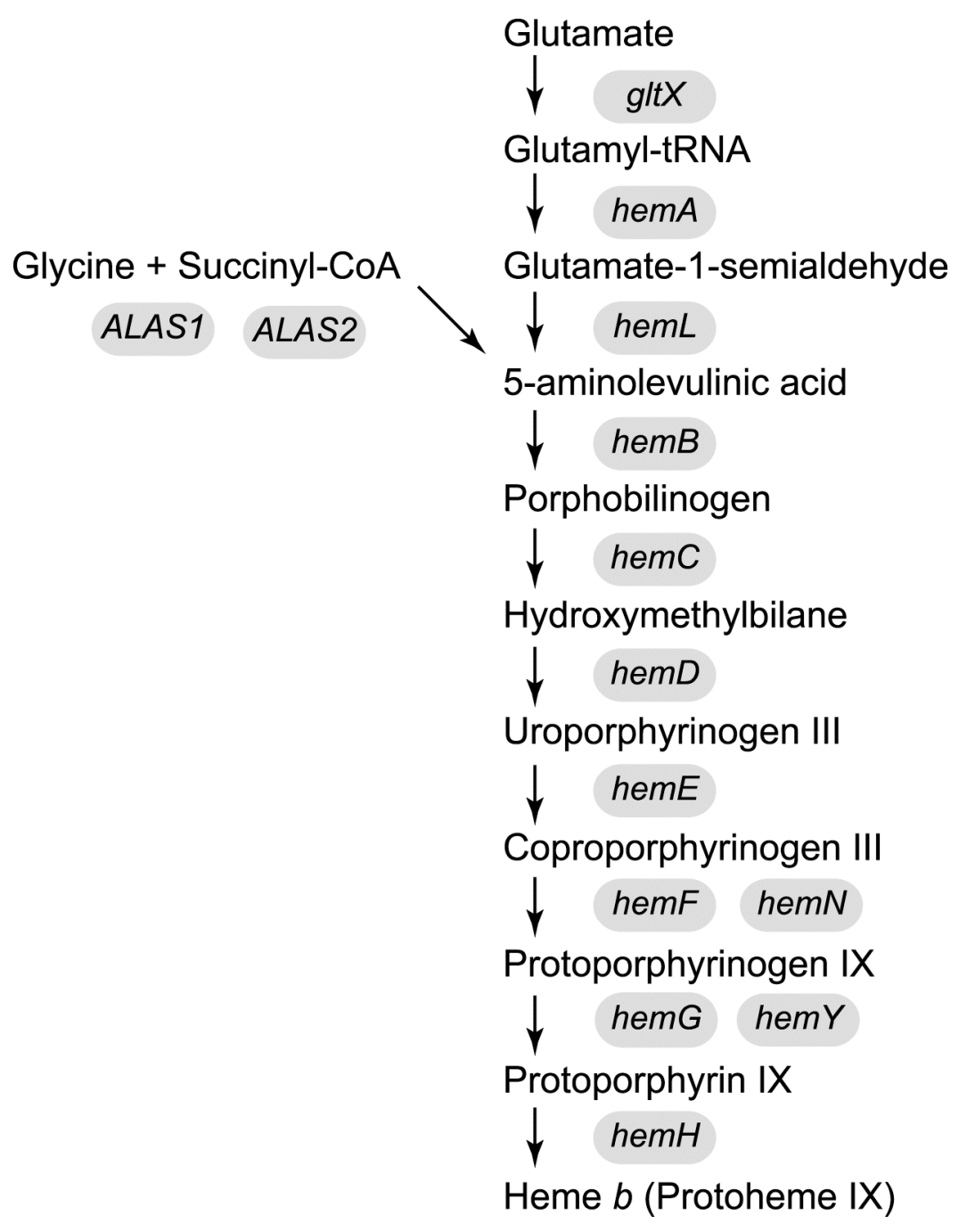

Figure 13. The heme biosynthesis pathway and genes encoding the enzymes (shaded in gray). Mutant phenotypes are discussed in the text. 


\section{Conditional stability of HemA in response to heme}

In S. enterica, a minimal (<2-fold) increase in the activity of a hemA-lac transcriptional fusion was observed concomitant with the increase in HemA enzyme and protein levels, demonstrating that regulation is primarily post-transcriptional (33). The synthesis and turnover of HemA was assessed in an S. enterica hemL mutant that had been either adapted (heme-limited) or supplemented with ALA and therefore not limited for heme. Pulse-chase and co-immunoprecipitation revealed a slight increase $(\approx 2$ fold) in protein synthesis in response to heme-limitation that could not account for the $\approx 20$-fold increase in activity $(33,35)$. The half-life of HemA in an S. enterica hemL mutant strain is 10 -fold greater in adapted (heme-limited) cultures compared to unrestricted cultures supplemented with ALA. HemA is therefore primarily regulated by conditional stability, becoming more stable in response to heme limitation (35).

\section{Identification of a potential degradation signal in the HemA N-terminus}

Analysis of HemA stability was extended to include an assessment of HemA-LacZ hybrid proteins, containing amino acids 1-416 $\left(\mathrm{HemA}_{1-416^{-}} \mathrm{LacZ}\right)$ or 1-18 (HemA $\left.\mathrm{A}_{1-18}-\mathrm{LacZ}\right)$. The stability of HemA $\mathrm{A}_{1-}$ 416-LacZ mirrors that of native HemA. In contrast, HemA $1-18$-LacZ is unstable; however, its short halflife is not conditional on heme limitation. HemA is degraded by the proteases Lon and ClpAP and turnover of both hybrid proteins was blocked in a lon clpP double mutant of E. coli (35). The same proteases are required for turnover of both HemA-LacZ fusion proteins and native HemA, suggesting that the N-terminal 18 amino acids, or a subset of them, may constitute a degradation tag, which confers sensitivity to proteolysis. However, the element that confers responsiveness to heme limitation requires

sequences further downstream. Further probing of the HemA N-terminus revealed that a mutant HemA 
construct, $\operatorname{Hem} \mathrm{A}[\mathrm{KK}]$, containing two added lysine residues between positions 2 and 3 , is stable when expressed from the $S$. enterica chromosome and is also defective in heme-mediated regulation (34).

\section{HemA: properties of the purified protein}

HemA has been purified from several sources (Table 1 and references). Purified HemA from some sources contains bound heme. The in vitro catalytic activity of some HemA enzymes is inhibited by exogenous heme, although in some cases inhibition occurs only when cell extract is added to the reaction. A correlation between the heme content of the purified enzyme and catalytic activity has been demonstrated only for Chlorobium vibrioforme, with greater sensitivity to heme inhibition exhibited by enzymes with lower heme content (29). The mechanism by which heme inhibits HemA enzyme activity is unknown. The conditional inhibition exhibited by several enzymes suggests the mechanism varies with the organism. 
Table 2. Heme content of purified HemA and heme inhibition of catalytic activity.

\begin{tabular}{|c|c|c|c|c|c|}
\hline \multirow[b]{2}{*}{ Domain } & \multirow[b]{2}{*}{ Organism } & & \multicolumn{2}{|c|}{ Heme } & \multirow[b]{2}{*}{ Reference } \\
\hline & & & Bound & $\begin{array}{l}\text { Inhibition } \\
\text { of enzyme } \\
\text { activity }\end{array}$ & \\
\hline \multirow[t]{6}{*}{ Bacteria } & Escherichia coli & $\gamma$-proteobacteria & No & No & 25,26 \\
\hline & Salmonella enterica & $\gamma$-proteobacteria & Yes & & $\begin{array}{l}\text { Unpublished } \\
\text { results }\end{array}$ \\
\hline & Bacillus subtilis & & No & & \\
\hline & $\begin{array}{l}\text { Acidothiobacillus } \\
\text { ferrooxidans }\end{array}$ & $\begin{array}{l}\text { Acidophilic } \\
\gamma \text {-proteobacteria }\end{array}$ & - & Yes & 13 \\
\hline & $\begin{array}{l}\text { Chlorobium } \\
\text { vibrioforme }\end{array}$ & Green sulfur bacterium & Yes & Yes $^{\mathrm{b}}$ & 29 \\
\hline & $\begin{array}{l}\text { Synechocystis sp. } \\
\text { PCC } 6803\end{array}$ & Cyanobacterium & No & Yes & 23 \\
\hline Archaea & $\begin{array}{l}\text { Methanopyrus } \\
\text { kandleri }\end{array}$ & Thermophilic archaeon & No & Yes & 16 \\
\hline \multirow[t]{2}{*}{ Eukaryota } & $\begin{array}{l}\text { Chlamydomonas } \\
\text { reinhardtii }\end{array}$ & Unicellular green algae & Yes & Yes $^{\mathrm{a}}$. & 28 \\
\hline & $\begin{array}{l}\text { Hordeum vulgare } \\
\text { (Barley) }\end{array}$ & Plant & Yes & Yes & 22,32 \\
\hline
\end{tabular}

a requires cell extract

$\mathrm{b}$ inhibition requires lowered heme content of purified enzyme

\section{Catalytic mechanism of glutamyl-tRNA reductase}

The crystal structure has been solved for HemA from Methanopyrus kandleri, a thermophilic archaeon (16). An N-terminal catalytic domain contains an essential conserved cysteine residue (C50 in 
S. enterica), a second domain binds NADPH, and the C-terminus is implicated in dimer formation (14,

19). The dimer forms an extended V-shaped cleft that can accommodate docking of GSA

aminotransferase. Formation of this complex would allow direct channeling of the unstable GSA substrate from HemA to HemL (14).

The catalytic cysteine residue, C48 in M. kandleri, is completely conserved and mutation of this residue results in an inactive enzyme $(25,27)$. The reactive thiol group of $\mathrm{C} 48$ acts as a nucleophile and attacks the $\alpha$-carbonyl group of tRNA-bound glutamate, forming an enzyme-localized thioester with concomitant release of tRNA. Direct hydride transfer from NADPH leads to GSA formation (17). In the absence of NADPH the esterase activity of GTR hydrolyzes the thioester releasing glutamate $(15,17)$.

\section{A HemA C170A mutant in S. enterica is stable}

In addition to the catalytic $\mathrm{C} 48$ (C50 in S. enterica and E. coli), HemA has additional non-conserved cysteines. Of the characterized HemA proteins, only S. enterica and E. coli contain a cysteine at position 170. Purified, nearly wild type S. enterica HemA contains heme, which is non-convalently attached. In S. enterica, mutation of $\mathrm{C} 170$ to alanine results in a purified protein lacking bound heme and which exhibits increased stability in vivo, suggesting heme binding acts as a proteolytic tag for HemA (12).

\section{Discussion}

HemA of $S$. enterica is regulated by conditional stability, becoming more stable when heme is limiting and subject to rapid turnover under non-limiting conditions $(33,35)$. Although the first 18 amino acids of HemA are sufficient for degradation by Lon and ClpAP, other regions of the protein are required for correct regulation in response to heme (35). The discovery of a mutant, $\mathrm{C} 170 \mathrm{~A}$, that lacks bound heme and is stable in vivo, suggests that heme binding to HemA targets the enzyme for proteolysis (12). 
Most HemA proteins have been characterized by analysis of in vitro enzyme activity. Little is known about in vivo regulation for organisms other than S. enterica. In vitro analysis of the wild type and C170A mutant proteins and their sensitivity to heme inhibition would help clarify the role of heme in regulating S. enterica HemA. It is tempting to speculate that heme inhibition of the wild type protein would demonstrate a requirement for additional factors, such as proteases, whereas the C170A mutant retains insensitivity.

\section{Literature cited}

1. Ajioka, R. S., J. D. Phillips, and J. P. Kushner. 2006. Biosynthesis of heme in mammals. Biochim Biophys Acta 1763:723-36.

2. Beale, S. I. 1990. Biosynthesis of the Tetrapyrrole Pigment Precursor, delta-Aminolevulinic Acid, from Glutamate. Plant Physiol 93:1273-1279.

3. Benjamin, W. H., Jr., P. Hall, and D. E. Briles. 1991. A hemA mutation renders Salmonella typhimurium avirulent in mice, yet capable of eliciting protection against intravenous infection with S. typhimurium. Microb Pathog 11:289-95.

4. Chapman, S. K., Daff, S., and Munro, A.W. 1997. Heme: The most versatile redox centre in biology? Structure and Bonding 88:40-66.

5. Chen, W., C. S. Russell, Y. Murooka, and S. D. Cosloy. 1994. 5-Aminolevulinic acid synthesis in Escherichia coli requires expression of hemA. J Bacteriol 176:2743-6.

6. Ferreira, G. C., and J. Gong. 1995. 5-Aminolevulinate synthase and the first step of heme biosynthesis. J Bioenerg Biomembr 27:151-9. 
7. Frankenberg, N., J. Moser, and D. Jahn. 2003. Bacterial heme biosynthesis and its biotechnological application. Appl Microbiol Biotechnol 63:115-27.

8. Furuyama, K., K. Kaneko, and P. D. Vargas. 2007. Heme as a magnificent molecule with multiple missions: heme determines its own fate and governs cellular homeostasis. Tohoku J Exp Med 213:1-16.

9. Heinemann, I. U., M. Jahn, and D. Jahn. 2008. The biochemistry of heme biosynthesis. Arch Biochem Biophys 474:238-51.

10. Higuchi, M., and L. Bogorad. 1975. The purification and properties of uroporphyrinogen I synthases and uroporphyrinogen III cosynthase. Interactions between the enzymes. Ann N Y Acad Sci 244:401-18.

11. Hou, S., M. F. Reynolds, F. T. Horrigan, S. H. Heinemann, and T. Hoshi. 2006. Reversible binding of heme to proteins in cellular signal transduction. Acc Chem Res 39:918-24.

12. Jones, A. M., Thomas Elliott. 2009. A purified mutant HemA protein from Salmonella enterica serovar Typhimurium lacks bound heme and is defective for heme-mediated regulation in vivo. unpublished manuscript.

13. Levican, G., A. Katz, M. de Armas, H. Nunez, and O. Orellana. 2007. Regulation of a glutamyl-tRNA synthetase by the heme status. Proc Natl Acad Sci U S A 104:3135-40.

\section{Luer, C., S. Schauer, K. Mobius, J. Schulze, W. D. Schubert, D. W. Heinz, D. Jahn, and J.} Moser. 2005. Complex formation between glutamyl-tRNA reductase and glutamate-1-semialdehyde 2,1aminomutase in Escherichia coli during the initial reactions of porphyrin biosynthesis. J Biol Chem 280:18568-72. 
15. Luer, C., S. Schauer, S. Virus, W. D. Schubert, D. W. Heinz, J. Moser, and D. Jahn. 2007. Glutamate recognition and hydride transfer by Escherichia coli glutamyl-tRNA reductase. Febs J 274:4609-14.

16. Moser, J., W. D. Schubert, V. Beier, I. Bringemeier, D. Jahn, and D. W. Heinz. 2001. Vshaped structure of glutamyl-tRNA reductase, the first enzyme of tRNA-dependent tetrapyrrole biosynthesis. Embo J 20:6583-90.

17. Moser, J., W. D. Schubert, D. W. Heinz, and D. Jahn. 2002. Structure and function of glutamyl-tRNA reductase involved in 5-aminolaevulinic acid formation. Biochem Soc Trans 30:579-84.

18. Nakahigashi, K., K. Nishimura, K. Miyamoto, and H. Inokuchi. 1991. Photosensitivity of a protoporphyrin-accumulating, light-sensitive mutant (visA) of Escherichia coli K-12. Proc Natl Acad Sci U S A 88:10520-4.

19. Nogaj, L. A., and S. I. Beale. 2005. Physical and kinetic interactions between glutamyl-tRNA reductase and glutamate-1-semialdehyde aminotransferase of Chlamydomonas reinhardtii. J Biol Chem 280:24301-7.

20. Panek, H., and M. R. O'Brian. 2002. A whole genome view of prokaryotic haem biosynthesis. Microbiology 148:2273-82.

21. Philipp-Dormston, W. K., and M. Doss. 1975. Over-production of porphyrins and heme in heterotrophic bacteria. Z Naturforsch C 30:425-6.

22. Pontoppidan, B., and C. G. Kannangara. 1994. Purification and partial characterisation of barley glutamyl-tRNA(Glu) reductase, the enzyme that directs glutamate to chlorophyll biosynthesis. Eur J Biochem 225:529-37.

75 
23. Rieble, S., and S. I. Beale. 1991. Purification of glutamyl-tRNA reductase from Synechocystis sp. PCC 6803. J Biol Chem 266:9740-5.

24. Sarkany, R. P. 2008. Making sense of the porphyrias. Photodermatol Photoimmunol Photomed $24: 102-8$

25. Schauer, S., S. Chaturvedi, L. Randau, J. Moser, M. Kitabatake, S. Lorenz, E. Verkamp, W. D. Schubert, T. Nakayashiki, M. Murai, K. Wall, H. U. Thomann, D. W. Heinz, H. Inokuchi, D. Soll, and D. Jahn. 2002. Escherichia coli glutamyl-tRNA reductase. Trapping the thioester intermediate. J Biol Chem 277:48657-63.

26. Schauer, S., C. Luer, and J. Moser. 2003. Large scale production of biologically active Escherichia coli glutamyl-tRNA reductase from inclusion bodies. Protein Expr Purif 31:271-5.

27. Schubert, W. D., J. Moser, S. Schauer, D. W. Heinz, and D. Jahn. 2002. Structure and function of glutamyl-tRNA reductase, the first enzyme of tetrapyrrole biosynthesis in plants and prokaryotes. Photosynth Res 74:205-15.

28. Srivastava, A., V. Lake, L. A. Nogaj, S. M. Mayer, R. D. Willows, and S. I. Beale. 2005. The Chlamydomonas reinhardtii gtr gene encoding the tetrapyrrole biosynthetic enzyme glutamyl-trna reductase: structure of the gene and properties of the expressed enzyme. Plant Mol Biol 58:643-58.

29. Srivastava, A., and S. I. Beale. 2005. Glutamyl-tRNA reductase of Chlorobium vibrioforme is a dissociable homodimer that contains one tightly bound heme per subunit. J Bacteriol 187:4444-50.

30. Storz, G., and J. A. Imlay. 1999. Oxidative stress. Curr Opin Microbiol 2:188-94.

31. Touati, D. 2000. Iron and oxidative stress in bacteria. Arch Biochem Biophys 373:1-6. 
32. Vothknecht, U. C., C. G. Kannangara, and D. von Wettstein. 1996. Expression of catalytically active barley glutamyl tRNAGlu reductase in Escherichia coli as a fusion protein with glutathione Stransferase. Proc Natl Acad Sci U S A 93:9287-91.

33. Wang, L. Y., L. Brown, M. Elliott, and T. Elliott. 1997. Regulation of heme biosynthesis in Salmonella typhimurium: activity of glutamyl-tRNA reductase (HemA) is greatly elevated during heme limitation by a mechanism which increases abundance of the protein. J Bacteriol 179:2907-14.

34. Wang, L., S. Wilson, and T. Elliott. 1999. A mutant HemA protein with positive charge close to the $\mathrm{N}$ terminus is stabilized against heme-regulated proteolysis in Salmonella typhimurium. J Bacteriol $181: 6033-41$.

35. Wang, L., M. Elliott, and T. Elliott. 1999. Conditional stability of the HemA protein (glutamyltRNA reductase) regulates heme biosynthesis in Salmonella typhimurium. J Bacteriol 181:1211-9. 


\title{
Chapter 4: A purified mutant HemA protein from Salmonella enterica serovar Typhimurium lacks bound heme and is defective for heme- mediated regulation in vivo
}

\author{
Amy M. Jones and Thomas Elliott* \\ Department of Microbiology, Immunology and Cell Biology \\ West Virginia University Health Sciences Center \\ Morgantown, WV 26506 \\ Running title: Salmonella HemA mutant protein lacking heme is stable \\ * corresponding author
}

Phone: 304-293-2676

Fax: 304-293-7823

telliott@hsc.wvu.edu

\section{Abstract}

In Salmonella enterica serovar Typhimurium and Escherichia coli, as well as many other bacteria, the hemA gene encodes the enzyme glutamyl-tRNA reductase (HemA, GluTR), which catalyzes the first committed step in heme biosynthesis. Regulation of the heme pathway in these bacteria occurs by stabilization of HemA protein in response to limitation for heme. Several groups including our own have reported difficulties in overexpressing native HemA protein. We found that by removing as few as six residues from the C-terminus, HemA can be expressed at high levels, and this form of the protein is still regulated normally. The purified, truncated but otherwise wild type protein was found to contain bound 78 
heme, identified as heme $b$ from the spectrum. Heme is released from the protein by treatment with thiol reagents. Additionally, mutation of a single cysteine residue $(\mathrm{C} 170)$ results in a protein that is both more abundant and more stable than wild type when expressed from the chromosome in single copy, indicating that $\mathrm{C} 170$ is required for normal regulation. When the mutant $\mathrm{C} 170 \mathrm{~A}$ protein was purified, it was found not to contain detectable heme. These results suggest a model in which heme association with the enzyme targets it for degradation in vivo.

\section{Introduction}

Glutamyl-tRNA reductase (HemA) catalyzes the first committed step of the heme biosynthetic pathway. The substrate of this reaction is charged glutamyl-tRNA ${ }^{\text {Glu }}$, identical to the form used for protein synthesis, which is first cleaved from the tRNA and then reduced using NADPH to form glutamate-1-semialdehyde (GSA). The unstable semialdehyde is subsequently converted to 5aminolevulinic acid (ALA) by GSA aminotransferase, the product of the hemL gene (reviewed in references 1 and 8). The latter reaction can also proceed slowly in vitro in the absence of an enzyme catalyst (7).

HemA has been shown to be the target of heme-specific regulation in S. typhimurium and E. coli. Previously, our laboratory described regulation of the HemA enzyme by a mechanism that involves stabilization of the protein in response to heme limitation $(26,27)$. Experimentally, heme limitation can be imposed by adaptation of a bradytrophic hemL deletion mutant to growth in the absence of ALA. The growth rate of adapted hemL cells is approximately $80 \%$ of that of ALA-supplemented hemL or wild-type cells. It is not yet clear how bacteria experience heme limitation in nature, but some possibilities include the secretion of heme pathway inhibitors by competitor species, limitation for iron, or recovery from nongrowing states. 
HemA is regulated by conditional stability, becoming more stable and thus more abundant under heme-limiting conditions. In cells that are unrestricted for heme, HemA is subject to rapid turnover by the proteases Lon and ClpAP (25). One striking observation was that just the N-terminal 18 amino acids of HemA are sufficient for degradation by the same two proteases, as demonstrated in the context of a $\mathrm{Hem}_{1-18}$-LacZ protein fusion. This construct was as stable as the nearly full-length $\mathrm{HemA}_{1-416}$-LacZ in a lon clpP double mutant. However, the HemA $\mathrm{A}_{1-18}$-LacZ hybrid protein was not correctly regulated by heme (26). Clearly, although a key determinant of HemA proteolysis resides within the first 18 amino acids of HemA, other regions of the protein are also involved in stabilization in response to heme limitation. In the same study, we reported that insertion of two lysine residues between the second and third amino acids from the N-terminus resulted in complete stabilization and increased abundance of HemA under all growth conditions tested (27). This mutant (referred to as HemA[KK]) has been used in the current work as a positive control for stabilized HemA.

Hem A disulfide bond:

Formation of an intramolecular disulfide bond exposes the protease-sensitive tag resulting in degradation of HemA.

\section{HemA binds heme:}

Results in the protease-sensitive conformation, in which a degradation tag is exposed and HemA is degraded.
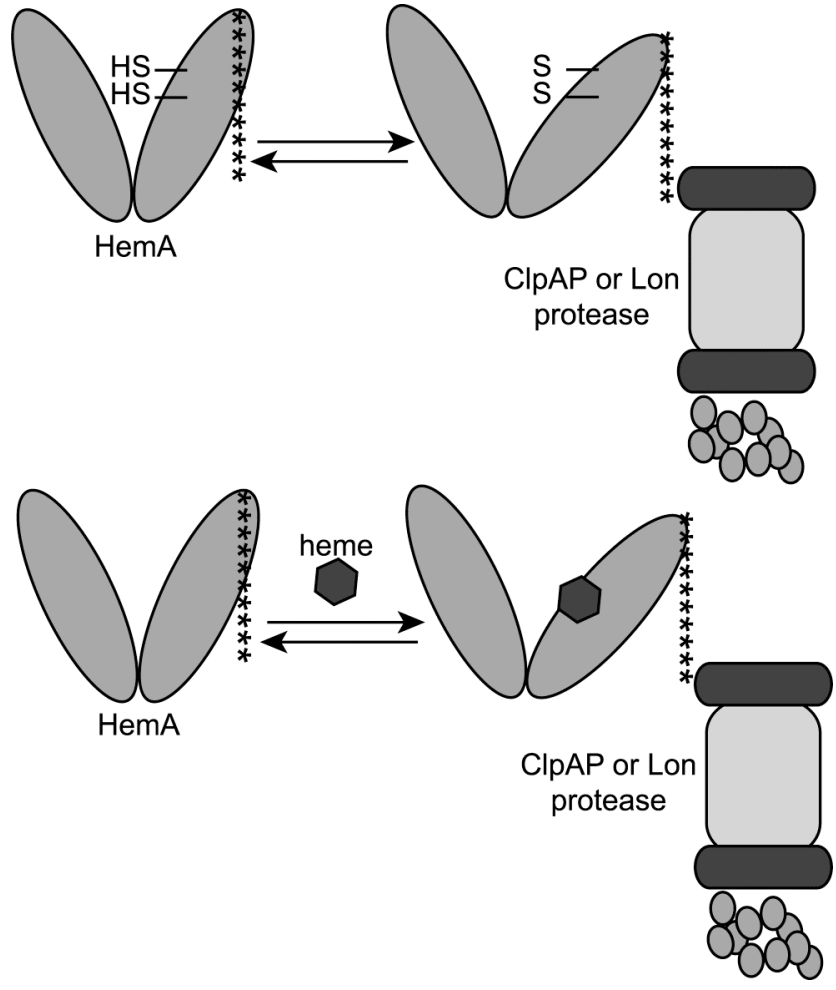
Figure 14. Two models for regulation of HemA turnover by heme limitation (adapted from 27). Asterisks indicate a putative protease recognition site located within the N-terminus of HemA. The models postulate that HemA exists in alternative conformations and that the protease-sensitive conformation can be stabilized in response to either heme availability or intracellular redox potential.

We previously suggested a model in which HemA exists in two alternative conformations, proteasesensitive or protease-resistant, and that when heme is not limiting HemA exists in the protease-sensitive conformation, in which it is targeted for degradation and thereby flow through the heme biosynthetic pathway is reduced (Fig. 14). We proposed two specific models for how this might work: in one, cellular redox status would be reflected in formation of a disulfide bond involving one of three cysteine residues. In the second model, heme would bind directly to the enzyme. At the time, there was evidence that heme could be associated with the HemA protein of some species (24), and this has been extended more recently $(20,21)$. Our results support the second model and extend the previous work, by showing that the $\mathrm{C} 170 \mathrm{~A}$ mutant of HemA is stabilized and more abundant than the wild type protein. Furthermore, we show that over-expressed and purified (nearly wild type) protein contains bound heme, whereas its C170A derivative does not.

\section{Materials and Methods}

Bacterial strains. The strains used in this study are listed in Table 1; all S. typhimurium strains are derived from LT2.

Growth of cultures. Cultures were grown in either Luria-Bertani medium (4), modified minimal MOPS (morpholinepropanesulfonic acid) medium $(3,13)$ containing $0.2 \%$ glycerol as the carbon source, or NCE medium with $0.2 \%$ glycerol as the carbon source (2). Plates were prepared with nutrient agar (Difco) and $5 \mathrm{~g}$ of $\mathrm{NaCl}$ per liter or with NCE medium. ALA was used at $2 \mu \mathrm{M}$ in minimal medium and 
at $150 \mu \mathrm{M}$ in rich medium. Adaptation of hemL mutant strains to growth in the absence of ALA supplementation has been described previously (25).

Plasmid construction. Techniques for plasmid construction followed standard methods (10). Mutations and C-terminal truncations were made by PCR and verified by sequencing. Plasmids are listed in Table 1. Primer sequences are available upon request.

Purification of expressed proteins. Cultures were grown overnight in LB containing ampicillin $(100 \mu \mathrm{g} / \mathrm{ml})$ and chloramphenicol $(20 \mu \mathrm{g} / \mathrm{ml})$, diluted 1:10 into fresh medium, and incubated at $30^{\circ} \mathrm{C}$ for 2 hours prior to induction with IPTG at a final concentration of $1 \mathrm{mM}$. Following an additional 3 hours of incubation, cells were harvested by centrifugation. The cell pellet was resuspended in $10 \mathrm{ml}$ of lysis buffer (20 mM Tris pH 8.0, $250 \mathrm{mM} \mathrm{NaCl}, 10 \mathrm{mM}$ imidazole, and 1:100 dilution of Sigma protease inhibitor cocktail) then passed through a French press 2-3 times. The extracts were then clarified by centrifugation at $24,000 \mathrm{x}$ g for 30 minutes. Supernatants were mixed with $2.5 \mathrm{ml}$ nickel-nitrilotriacetic acid (Ni-NTA) resin (Qiagen) on a rocker at $4{ }^{\circ} \mathrm{C}$ for 1 hour. Ni-NTA was washed twice in batches using the above buffer, but containing $5 \mathrm{mM}$ imidazole (wash 1) and $15 \mathrm{mM}$ imidazole (wash 2), then poured into polypropylene columns. Protein was eluted from the column in $5 \mathrm{ml}$ of elution buffer $(0.5 \mathrm{M}$ imidazole). Purified protein preparations were de-salted using PD-10 columns (GE Healthcare).

Immunological detection of proteins. Detection of HemA protein by Western blot has been described in detail previously (25). With the exception of Figure 16, the primary antibody was antiHemA (H23), a mouse monoclonal antibody of the $\gamma 1$ isotype (25). The monoclonal anti-FLAG antibody was purchased from Sigma and used according to the manufacturer's protocol. 
Spectrophotometry. The UV-Visible spectra shown in Figure 17 were recorded using a DW-2000 UV-Visible spectrophotometer (SLM-Aminco) using the split beam mode, $9.0 \mathrm{~nm}$ slit width, and a scan rate of $1.0 \mathrm{~nm} \mathrm{~min}{ }^{-1}$. The spectra shown in Figure 20 were recorded using a Synergy HT Plate Reader (BioTek) with absorption measured at $10 \mathrm{~nm}$ intervals from 300-650 nm. Cytochrome $c$ (Sigma C7752) or hemin (Sigma H2375) standards were included in each 96-well plate used for determination of purified HemA spectra. Three different conditions were measured per plate; the first measured $100 \mu \mathrm{l}$ of undiluted protein, the second measured proteins diluted in $100 \mu \mathrm{l}$ alkaline pyridine solution (oxidized), and the third followed addition of a few grains of sodium dithionite then mixing (reduced). The plate was read at least twice following sodium dithionite addition to ensure complete reduction.

Heme content. The heme content of purified HemA was determined by the pyridine hemochromogen assay (6). Purified proteins were diluted $1: 1$ in alkaline pyridine solution $(0.2 \mathrm{M} \mathrm{NaOH}$, 4.2 M pyridine). A few grains of sodium dithionite were added as a reducing agent. The difference in absorption at $556 \mathrm{~nm}$ and $536 \mathrm{~nm}$ of the reduced protein in alkaline pyridine solution was used to calculate the heme concentration using $\boldsymbol{E}_{\mathrm{mM}} \mathrm{M}_{56-\mathrm{A} 537}$ value of 23.4 . The predicted $\boldsymbol{E}_{\mathrm{mM}_{280}}$ for both HemA and HemA $1-412-\mathrm{His}_{6}$ is $30,940 \mathrm{M}^{-1} \mathrm{~cm}^{-1}$ (14).

Heme binding assay. Purified $\mathrm{HemA}_{1-412}-\mathrm{His}_{6}(100 \mu \mathrm{l})$ was diluted 1:10 in lysis buffer (see above) then the absorbance at $280 \mathrm{~nm}$ and $420 \mathrm{~nm}$ was recorded. The diluted protein was mixed with Ni-NTA resin that had been equilibrated with buffer. The mixture was incubated at $4^{\circ} \mathrm{C}$ on a rocker for $1 \mathrm{hr}$, then poured into a polypropylene column. The flow-through was collected upon loading as well as for each subsequent wash and the $\mathrm{A}_{420}$ measured. The column was washed three times with $5 \mathrm{ml}$ buffer followed 
by three washes with $6 \mathrm{M}$ guanidine- $\mathrm{HCl}(1 \mathrm{ml}$ ea), and finally eluted with buffer containing $0.5 \mathrm{M}$ imidazole. In addition to the $\mathrm{A}_{420}$, the $\mathrm{A}_{280}$ of the eluate was also measured to estimate recovered protein.

Detection of heme-catalyzed peroxidase activity. Proteins were diluted in duplicate into standard protein sample buffer lacking DTT, and $\beta$-ME was added to one. Samples containing $\beta$-ME were boiled for 10 minutes prior to loading onto 8\% SDS-PAGE gels. Duplicate gels were loaded with $20 \mu \mathrm{g}$ of purified protein and $0.5 \mu \mathrm{g}$ cytochrome $c$. Following SDS-PAGE, one gel was stained for total protein using Coomassie blue and proteins in the second gel were transferred to a PVDF membrane for subsequent detection of peroxidase activity. After transfer, the membrane was rinsed with $\sim 10 \mathrm{ml}$ PBS for $1 \mathrm{~min}$. Peroxidase activity was detected by covering the membrane with $1 \mathrm{ml}$ each of SuperSignal West Pico (Pierce) reagents for 4-5 min, then exposing to film.

Transfer of C170A mutation to the chromosome. PCR was performed using the plasmid pTE762 as the template. Integration into the S. typhimurium chromosome was achieved via linear transformation using a previously published protocol (27) and results verified by sequencing.

HemA stability. Cultures grown overnight in MOPS $0.2 \%$ glycerol at $37^{\circ} \mathrm{C}$ were diluted 1:50 into the same pre-warmed medium and incubated at $37^{\circ} \mathrm{C}$. Protein synthesis was inhibited by addition of chloramphenicol $(200 \mathrm{ug} / \mathrm{ml})$ at $\mathrm{OD}_{600}=0.40$. Aliquots were taken at 0,30 , and 60 minutes following inhibition and prepared for SDS-PAGE and immunoblot using anti-HemA antibody.

\section{Results}

\section{Overexpression of HemA}


Initial attempts to over-express either native or His-tagged HemA protein using the standard T7 system were unsuccessful (unpublished data, but see below). Other groups, working with various organisms, have also reported difficulties including low yield, enzyme instability, and aggregation (4, 15, $18,23,24)$. Pointing to a possible solution of these difficulties, we observed that constructs bearing a sequenced amber mutant allele of hemA (Q369Am) did allow over-expression of the truncated protein, at a high level similar to that observed for other proteins we have purified (e.g. HemL, RpoS). This encouraged us to test whether relatively short C-terminal truncations could be overexpressed at high levels as well.

The hemA gene from Salmonella typhimurium was inserted into a plasmid derived from pET3 (22) under the control of a T7 promoter. Various constructs encoded either full-length HemA (amino acids 1418) or one of several small C-terminal truncations; all bearing a C-terminal His 6 tag in addition. Protein overexpression was induced by a standard protocol in E. coli BL21(DE3)/pLysS (22). Analysis of whole cell lysates from induced cultures showed that while the full-length HemA construct could not be significantly over-expressed, a truncated form of HemA lacking six amino acids from the C-terminus gave a strong visible band by Coomassie stain (Fig. 15A), and was at least 20 -fold more abundant than the native protein when analyzed by Western blot (Fig. 15B).

For the truncated proteins, degradation products are apparent below the HemA band, but these were not observed for the full-length protein. Truncated proteins are often more susceptible to degradation than native forms. Although we have not determined the level at which over-expression of full-length HemA fails, the absence of degradation products suggests that proteolytic attack is probably not significant. Models for HemA interaction with the tRNA substrate have been proposed in which the interaction involves the C-terminus of the protein (12). Titration of tRNA ${ }^{\text {Glu }}$ is a possible mechanism limiting over-expression. 

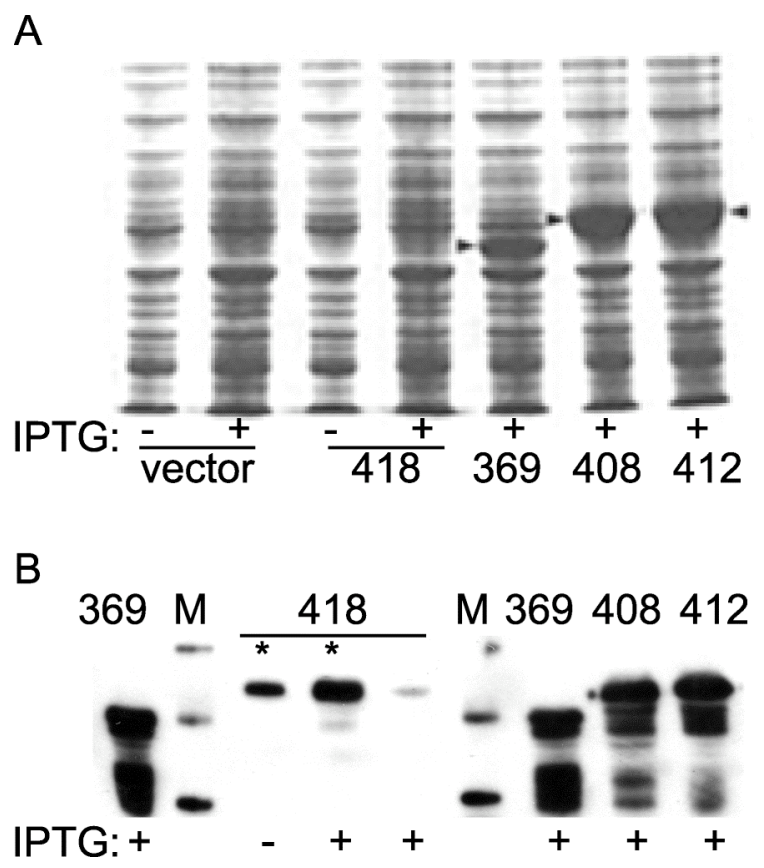

Figure 15. Truncated HemA can be overexpressed. E. coli BL21(DE3) carrying plasmids that express either full-length (amino acids 1-418) or C-terminally truncated Salmonella serovar Typhimurium HemA bearing a C-terminal His ${ }_{6}$ tag were grown in LB medium containing ampicillin $(100 \mu \mathrm{g}$ per $\mathrm{ml})$ and chloramphenicol $(20 \mu \mathrm{g}$ per ml) and induced with IPTG (1 mM) 2 hrs prior to harvesting cells. In both A and B, numbers correspond to the position of the final amino acid of HemA encoded by that construct. (A) Coomassie-stained gel. Arrows indicate the position of HemA in the lanes containing the truncated forms. (B) Western blot of HemA. HemA was detected using anti-HemA H23 primary antibody. An asterisk (*) indicates a 1:10 dilution in sample buffer alone; whereas the other samples were diluted 1:100 with lysate from the uninduced vector control strain. Strains analyzed: TE7771, TE7772, TE7875, TE7876, and TE7877.

HemA is composed of three domains: an N-terminal catalytic domain, an NADPH-binding domain, and an extended C-terminal region required for dimerization (12). Purified E. coli HemA lacking its entire C-terminal dimerization domain was reported to retain less than $5 \%$ of the enzymatic activity of the wild-type protein (9). Therefore it was important to verify that truncated HemA is both functional and correctly regulated by heme. Strains mutant for hemA require ALA supplementation for growth. 
Plasmid-encoded truncated and tagged Salmonella serovar Typhimurium hemA complemented an E. coli hemA mutant and restored growth in the absence of ALA. Correct regulation in response to heme was tested by Western blot (Fig. 16). To eliminate the possibility that a partial defect in enzyme activity of the truncated proteins could affect results of the test, an E. coli host that is wild type for hemA was used, and the plasmid-encoded proteins were specifically detected by an additional C-terminal FLAG tag. The truncated HemA proteins demonstrated correct regulation in response to heme.

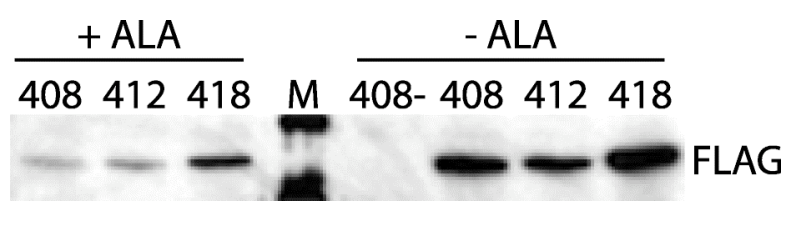

Figure 16 Truncated and FLAG-tagged HemA is correctly regulated by heme. Salmonella serovar Typhimurium HemA was expressed from plasmids pTE764 (hemAp lac o hem A FLAG His 6 ) and its truncated derivatives in an $E$. coli hem $A^{+}$hemL mutant host strain. Cultures were grown in MOPS minimal medium containing ampicillin (50 $\mu \mathrm{g} / \mathrm{ml})$, IPTG $(35 \mu \mathrm{g} / \mathrm{ml})$, and $0.2 \%$ glycerol as the carbon source in the presence of $10 \mu \mathrm{M}$ ALA or else adapted to growth in the absence of ALA. HemA levels were detected by Western blot using anti-FLAG antibody. A strain with plasmid encoding HemA truncated at position 408 and lacking the FLAG tag (408-) was included as a negative control. Strains analyzed: TE7910, TE7911, TE7927, and TE7937.

\section{Purification and characterization of HemA 1-412-His $_{6}$}

His-tagged C-terminally-truncated HemA was purified by Ni-NTA affinity chromatography. The purified protein was red in color, suggesting the presence of bound heme. This was surprising since in previous studies purified E. coli HemA (which is $94 \%$ identical to S. typhimurium HemA) did not contain heme or indeed any prosthetic group $(16,17)$. We suggest this difference may be related to the methods used for over-expression of the E. coli protein, one of which resulted in its sequestration in inclusion bodies (17). Additionally, in an earlier report it was demonstrated that E. coli HemA was soluble when overexpressed from the $\mathrm{T} 7$ promoter in conjunction with chaperone proteins, yet the purified protein 
lacked heme (16). The tight association of chaperones with the purified HemA obtained by this method could potentially block a tagging system.

\section{Purified HemA contains bound heme}

The absorption spectrum of purified HemA protein (Fig. 17) contains features characteristic of heme, including a prominent peak at $424 \mathrm{~nm}$ (the Soret band). Upon reduction with Na-dithionite the peak at $424 \mathrm{~nm}$ became sharper and shifted toward a longer wavelength $(426 \mathrm{~nm})$, and two other peaks appeared, one at $530 \mathrm{~nm}$ and another at $560 \mathrm{~nm}$. The spectrum of reduced heme (hemin), which was used as a control, was very similar to that of the purified protein (data not shown).

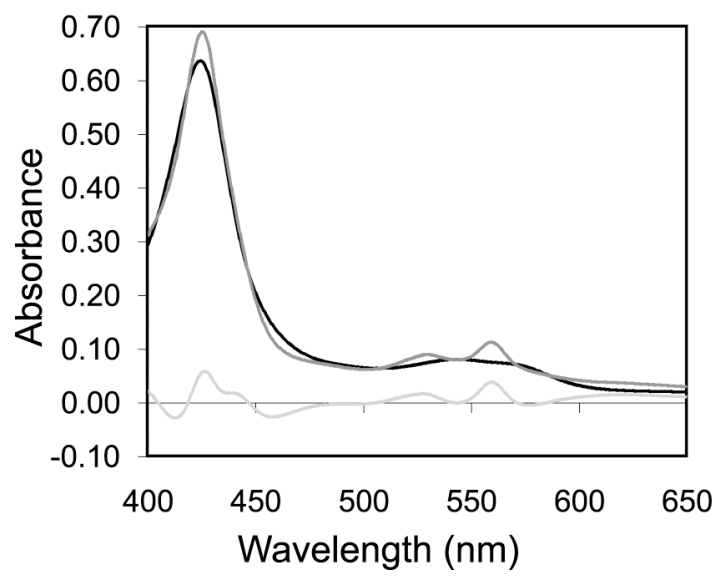

Figure 17 Purified HemA1-412-His 6 has a heme $b$ type spectrum. The absorption spectra of purified $\mathrm{HemA}_{1-}$

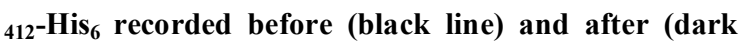
gray line) dithionite addition. The difference spectra (light gray) is also shown.

The heme concentration in the purified protein was determined by pyridine hemochromogen assay (6). Three separate protein preparations averaged $0.055 \mathrm{~mol}$ heme per mol protein monomer. This ratio is lower than the heme:peptide ratio reported for HemA in other organisms. Purified HemA from Chlorobium vibrioforme contained $1 \mathrm{~mol}$ heme per mol polypeptide (21), whereas HemA from Chlamydomonas reinhardtii contained $\leq 0.2$ mol heme per mol protein subunit (20). 


\section{HemA Cys $\rightarrow$ Ala mutants}


The HemA protein of S. typhimurium contains three cysteines, C50, C74, and C170, all conserved in E. coli. Of these, only C50, which is essential for catalysis $(11,16)$, is conserved among all organisms. The presence of cysteine residues suggested the possibility that redox status or disulfide bond formation may be important in HemA regulation. Each of the three cysteines of HemA was individually changed to alanine resulting in the mutants $\mathrm{C} 50 \mathrm{~A}, \mathrm{C} 74 \mathrm{~A}$, and C170A. These were expressed in E. coli from a plasmid bearing the native hemA promoter, but controlled by the lac operator and repressor. Both C74A and $\mathrm{C} 170 \mathrm{~A}$ were capable of complementing an E. coli hemA mutant when expressed at normal levels, thereby demonstrating that they encode functional proteins. As expected, plasmids encoding the Q369
Figure 18 Western blot analysis of HemA Cys $\rightarrow$ Ala strain (TE5812) carrying plasmid pTE740 (hemAp lac o amber mutant and C50A mutant proteins were unable to complement in the same test.
overnight in NCE containing $0.2 \%$ glycerol, ampicillin (50 $\mu \mathrm{g} / \mathrm{ml})$, and ALA $(10 \mu \mathrm{M})$, then diluted 1:50 into the same medium plus IPTG $(35 \mu \mathrm{M})$. After 24 hrs of incubation, samples were prepared for Western blot using anti-HemA (H23) antibody. Strains analyzed: TE7764, TE7767, TE8219, TE8220, TE7929, and TE7884.

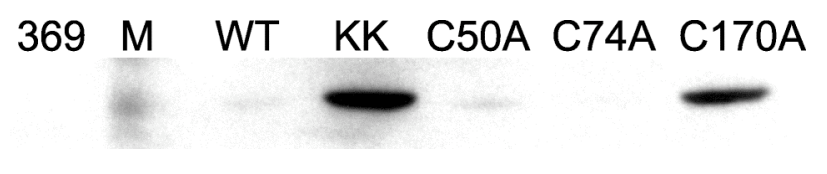

In a previous report we observed that HemA protein is undetectable by Western blot in wild-type cultures grown overnight whereas the HemA[KK] mutant is maintained at easily detectable levels (27). As a first assessment of the regulatory phenotype of the HemA Cys mutants, HemA was analyzed by Western blot of lysates prepared from overnight cultures (Fig. 18). HemA C170A was nearly as abundant as $\mathrm{HemA}[\mathrm{KK}]$, whereas HemA levels in the other mutants and wild-type were at or below the limit of 
detection, suggesting that of the three mutants, $\mathrm{C} 170 \mathrm{~A}$ alone displays a regulatory defect. To verify this, the Cys mutants were assessed for correct regulation in response to heme by comparison of HemA levels in adapted (-ALA) and supplemented (+ ALA) cultures (Fig. 19). In ALA-supplemented cultures, HemA levels were greater in the C170A mutant compared to the wild-type strain and C74 mutant (Fig. 19A), and slightly greater than HemA[KK] in a similar test (Fig. 19B). We conclude that HemA[C170A] is a heme regulatory mutant.

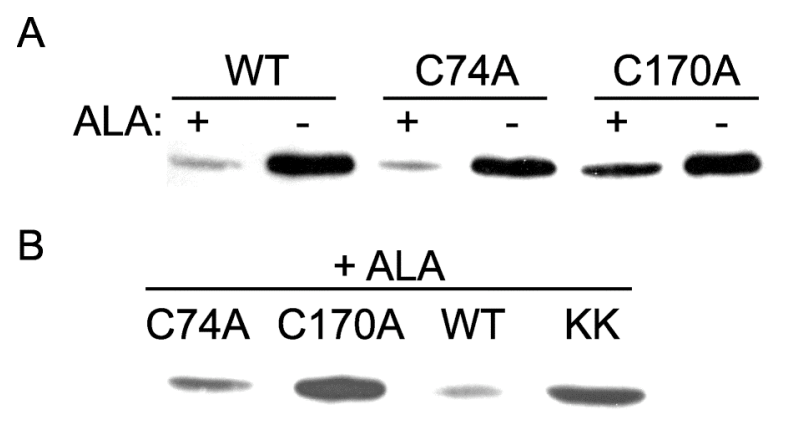

Figure 19. Hem $A[C 170 A]$ is a regulatory mutant. HemA was expressed from plasmid pTE740 and its derivatives in an E. coli host strain mutant for hemA and hemL. Cultures were grown as described in the legend to Fig. 16. (A) Western blot of HemA levels in adapted (- ALA) and supplemented (+ ALA) cultures. (B) Western blot of HemA levels in cultures supplemented with ALA including the HemA[KK] mutant as a control for stability. Strains analyzed: TE7823, TE7824, TE7849, TE7850.

\section{Purification and characterization of His-tagged HemA C170A}

HemA $[\mathrm{C} 170 \mathrm{~A}]_{1-412}-\mathrm{His}_{6}$ was purified according to the same protocol used for $\mathrm{HemA}_{1-412}-\mathrm{His}_{6}$. The C170A mutant protein was colorless, suggesting that it is does not contain bound heme. The absence of heme in purified $\mathrm{C} 170 \mathrm{~A}$ protein is also demonstrated by its absorption spectrum, which lacks the peaks characteristic of heme-containing proteins (Fig. 20). 


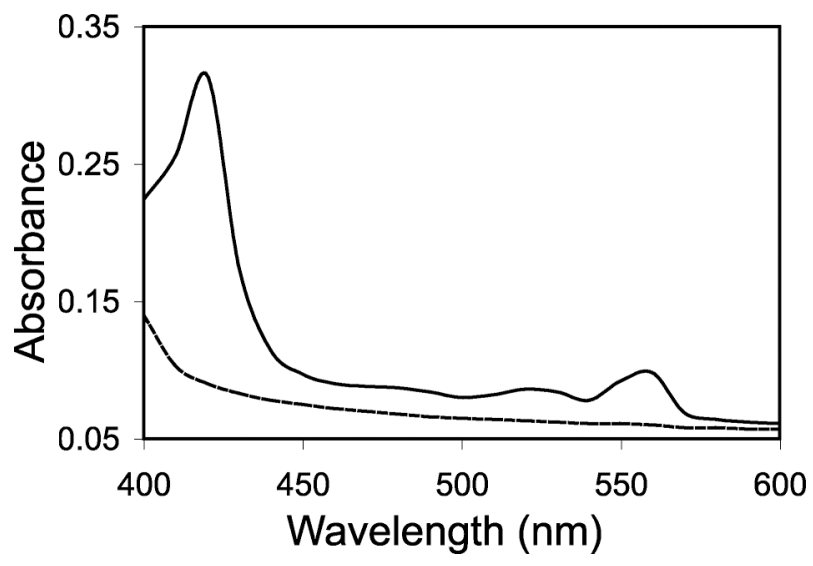

Figure 20. Characteristic heme b peaks are absent from the Hem $A[C 170 A]$ spectrum. The spectra of purified HemA1-412-His6 (solid line) and HemA[C170A]1-412-His6 (dashed line).

\section{Testing heme-protein association}

The lack of heme in purified $\mathrm{C} 170 \mathrm{~A}$ prompted us to investigate the nature of the association between heme and wild-type HemA. The HemA spectrum is that of a $b$-type heme; this class of molecules is attached non-covalently. To test whether heme can be dissociated from HemA, we attempted to remove it from the purified protein using the strong denaturant, $6 \mathrm{M}$ guanidine- $\mathrm{HCl}$. Purified $\mathrm{HemA}_{1-412}-\mathrm{His}_{6}$ protein samples were re-bound to Ni-NTA resin and poured into a column. Removal of heme from the enzyme was followed by measuring the $A_{420}$ of column eluates. Columns were washed three times with 6 $\mathrm{M}$ guanidine-HCl. A maximum of $7 \%$ of the heme was removed by this treatment, and in two trials failed to remove any of the bound heme (data not shown). These results demonstrate a strong association between heme and HemA. Despite the above results, which indicate very tight binding, thiol reagents, which have been used to distinguish covalent heme-protein bonds, are incompatible with Ni-NTA. Therefore, the nature of the association between heme and HemA was further examined by different method.

\section{Detection of heme-associated peroxidase activity}


The second method used for detection of heme-binding proteins (such as cytochrome $c$ ) takes advantage of the heme-associated peroxidase activity, which can be measured by standard ECL reagents (a Western blot without the antibody; 5). Furthermore, if attachment of heme to HemA is covalent then the peroxidase activity should be detected at the appropriate molecular mass following SDS-PAGE. (In the following results, purified $\mathrm{HemA}_{1-412}-\mathrm{His}_{6}$ is referred to as 'wild-type').

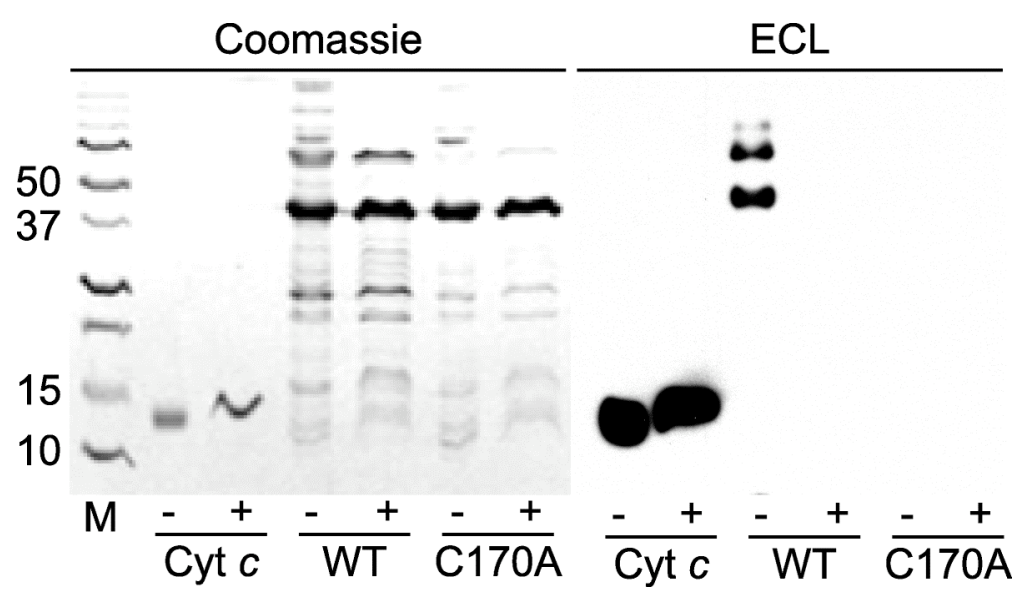

Figure 21. ECL detection of heme-associated peroxidase activity in purified HemA. Purified proteins $(\approx 20 \mu g)$ and cytochrome $c(0.5 \mu \mathrm{g})$ were run on duplicate 8\% SDS-PAGE gels; one was stained with Coomassie Blue (left panel) and the other was processed for detection of heme-associated peroxidase activity (right panel) as described in the methods section. Samples in the lanes marked "+" were prepared in sample buffer containing $\beta$-ME and boiled, while those marked "_." were unheated and prepared in buffer lacking $\beta$-ME. Lane M contains Precision Plus Protein Standards (Bio-Rad), and the molecular masses (kDa) for several of its component proteins are given for reference.

Purified wild type and C170A mutant proteins were assessed for heme-associated peroxidase activity and duplicate gels were stained for protein with Coomassie Blue (Fig. 21). Cytochrome $c$ was included as a positive control for covalent attachment of heme, and its heme-associated peroxidase activity was detected at the molecular mass of the protein, $\sim 13 \mathrm{kDa}$. The calculated molecular mass of monomeric 
HemA is approximately $46 \mathrm{kDa}$. Both the wild type and C170A proteins were detected in Coomassiestained gels at the predicted molecular mass (Fig. 21, left lanes), however peroxidase activity was detected only for the wild-type protein and then only in unheated samples lacking both DTT and $\beta$-ME. Any one of three treatments (DTT, $\beta$-ME, boiling) abolished the signal from HemA (Fig. 21, and data not shown) indicating that heme is not covalently bound. No signal was observed for the C170A mutant under any of the conditions tested. Three bands are observed for the untreated wild-type sample. The smallest and most abundant band corresponds to HemA protein. The bands above it are probably aggregates as observed in other studies $(16,18,23)$.

Figure 22 HemA C170A is stable. Native and mutant HemA proteins were expressed from the Salmonella chromosome in single copy. Cultures were grown in MOPS minimal medium containing $0.2 \%$ glycerol to an $\mathrm{OD}_{600}=0.40$. Protein synthesis was inhibited by addition of chloramphenicol $(200 \mu \mathrm{g} / \mathrm{ml})$. (A) Western blot of HemA levels at 0,30 , and 60 minutes following inhibition of protein synthesis. (B) Densitometry analysis (ImageJ). HemA was unstable in the wild-type strain (closed circles) and nearly stable over the time course for $\operatorname{HemA}[\mathrm{KK}]$ (closed squares) and $\mathrm{HemA}[\mathrm{C170A}]$ (open circles). Strains analyzed: TE6825, TE7700, and TE9287.

A
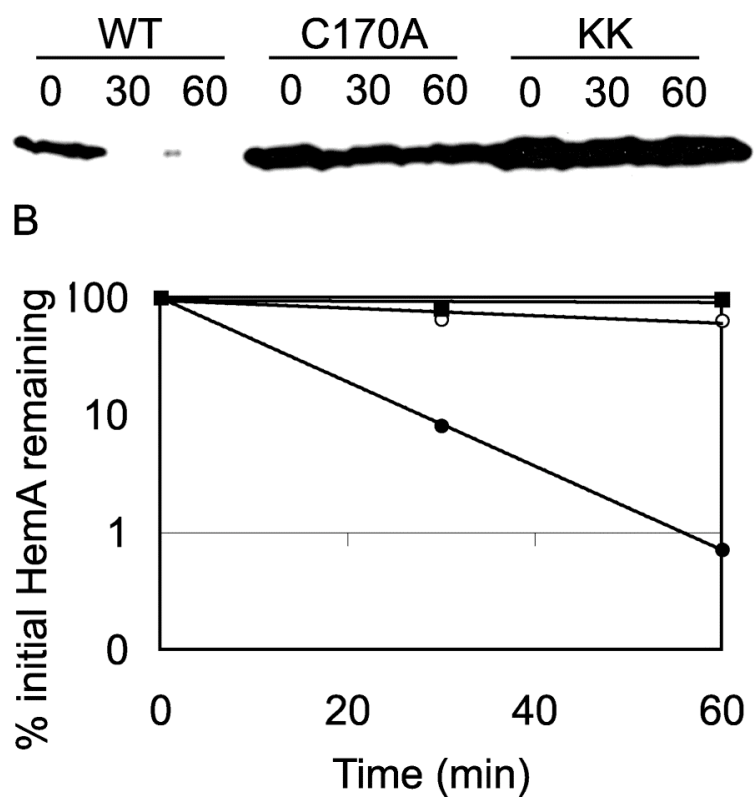

\section{HemA stability by immunoblot}

According to the models in Fig. 14, heme binding to HemA acts as a tag that leads to proteolytic attack. The absence of bound heme in purified C170A led us to predict that the mutant would exhibit increased stability over wild-type HemA. The stability of native and C170A mutant HemA, expressed in 
single copy from the Salmonella serovar Typhimurium chromosome, was analyzed by Western blot after inhibition of protein synthesis (Fig. 22). HemA[KK], included as a positive control, remained stable over the time course of the experiment. Wild-type HemA was present at lower levels than the mutants and was detectable only at the initial time point. In support of the model, the C170A mutant was nearly as stable as $\mathrm{HemA}[\mathrm{KK}]$.

\section{Discussion}

In the present work we have shown that truncated HemA protein, lacking only six C-terminal amino acids, is functional, exhibits correct regulation in response to heme availability, and can be efficiently overexpressed and purified. A fraction of purified $\mathrm{HemA}_{1-412}-\mathrm{His}_{6}$ contained heme, which is noncovalently attached. In a previously posited model, we suggested that heme binding to HemA serves as a tag for HemA proteolysis. In support of this model, we identified a mutation, C170A, which both abrogates heme binding and increases protein stability.

HemA purified from Chlorobium vibrioform (21), Chlamydomonas reinhardtii (20), and barley (24) contains heme, whereas the purified proteins from E. coli $(16,17)$ and Methanopyrus kandleri $(11)$ do not. Among these organisms, only S. typhimurium and E. coli possess a cysteine at position 170; a valine occupies the equivalent position in the others. While we have shown that $\mathrm{C} 170$ is necessary for HemA to bind heme in Salmonella serovar Typhimurium, it is not conserved among the organisms in which heme is known to associate with HemA. This finding further supports a non-covalent association between heme and HemA. 
Based on the crystal structure of HemA from Methanopyrus kandleri (12) and a structure-based sequence alignment with E. coli HemA (16), C170 is located within the NADPH binding domain. The C170A Salmonella mutant protein complemented an E. coli hemA mutant thereby demonstrating that the enzyme is functional. This suggested that the mutation did not affect the enzyme's ability to bind NADPH, a hypothesis further supported by the work of Schauer and coworkers who reported that a purified mutant HemA protein from E. coli, C170S, retained nearly wild-type reductase and esterase activity (16). Because E. coli wild-type HemA lacks associated heme, which we suggested may be due to the purification protocols employed (see text), mutation of C170 in E. coli has no reported phenotype.

Because such a small fraction of purified $\mathrm{HemA}_{1-412}-\mathrm{His}_{6}$ contained heme, we were unable to identify the exact site of heme attachment, however C170 is clearly important in this capacity as shown by the lack of bound heme in the purified C170A mutant protein. Due to the non-covalent association of heme with HemA, as well as the lack of conservation of $\mathrm{C} 170$, it seems unlikely that this residue is directly involved in heme binding. The simplest explanation is that mutation of $\mathrm{C} 170$ results in a structural change that abrogates heme binding, possibly by disrupting the shape or chemistry of the heme pocket or altering the region recognized by a tagging system.

\section{Acknowledgements}

This work was supported by Public Health Service grants 6M40403 and GM63616.

The authors thank Andrew Shiemke and Courtney Williamson for their assistance with absorption spectrophotometry. 
Table 3. Bacterial strains

Strain Genotype

Salmonella

TE6285 LT2

TE7700 zde-1858::Tn10d-Tet hemA [KK]

TE9287 zde-1858::Tn10d-Tet hemA [C170A]

E. coli

TE5812 MC4100 hemA8

TE6160 MC4100 hemL::Kan (EcoRI)

TE7764 MC4100 hemA8/pTE740

TE7767 MC4100 hemA8/pTE741 [KK]

TE7771 BL21(DE3)/pLysS/pET3a

TE7772 BL21(DE3)/pLysS/pTE700

TE7806 hemA8 hemL::kan

TE7823 MC4100 hemA8 hemL::kan (EcoRI)/pTE740

TE7824 MC4100 hemA8 hemL::kan (EcoRI)/pTE741

97 


\begin{tabular}{|c|c|}
\hline TE7849 & MC4100 hemA8 hemL::kan (EcoRI)/pTE761 \\
\hline TE7850 & MC4100 hemA8 hemL::kan (EcoRI)/pTE762 \\
\hline TE7875 & BL21(DE3)/pLysS/pTE603 \\
\hline TE7876 & BL21(DE3)/pLysS/pTE751 \\
\hline TE7877 & BL21(DE3)/pLysS/pTE752 \\
\hline TE7884 & MC4100 hemA8/pTE748 \\
\hline TE7910 & MC4100 hemL::Kan (EcoRI)/pTE749 \\
\hline TE7911 & MC4100 hemL::Kan (EcoRI)/pTE753 \\
\hline TE7927 & MC4100 hemL::Kan (EcoRI)/pTE763 \\
\hline TE7929 & MC4100 hemA8/pTE760 \\
\hline TE7937 & MC4100 hemL::Kan (EcoRI)/pTE764 \\
\hline TE8219 & MC4100 hemA8/pTE761 \\
\hline TE8220 & MC4100 hemA8/pTE762 \\
\hline TE9510 & BL21(DE3)/pLysS/pTE752 \\
\hline TE9511 & BL21(DE3)/pLysS/pTE778 \\
\hline
\end{tabular}


Plasmids

pTE603 PT7 hemA Q369 Am-His6

pTE700 PT7 hem $A_{1-418-\text { His }_{6}}$

pTE740 hemAp lac o NdeI hemA $A^{+}$prfA (codon 6)

pTE741 hemAp lac o NdeI hem ${ }^{+}[\mathrm{KK}]$ prfA (codon 6)

pTE749 hemAp lac o hemA RBS NdeI hemA (codon 408) XhoI His 6 BamHI

pTE751 PT7 hemA 1 -408-His6

pTE752 PT7 hemA 1 -412-His 6

pTE753 hemAp la co hemA RBS NdeI hemA codon 408 XhoI FLAG His 6 BamHI

pTE761 hemAp la co NdeI hemA ${ }^{+}[\mathrm{C} 74 \mathrm{~A}]$ prfA (codon 6)

pTE762 hemAp lac o NdeI hem $A^{+}[\mathrm{C} 170 \mathrm{~A}] \operatorname{prfA}(\operatorname{codon} 6)$

pTE763 hemAp la co hemA RBS NdeI hem $A_{1-412}$ XhoI FLAG His 6 BamHI

pTE764 hemAp la co hemA RBS NdeI hem $A_{1-418}$ XhoI FLAG His ${ }_{6}$ BamHI

99 
This page is intentionally blank. 


\section{Literature cited}

1. Beale, S. I. 1996. Biosynthesis of hemes, p. 731-748. In F. C. Neidhardt, R. Curtiss III, J. L, Ingraham, E. C. C. Lin, K. B. Low, B. Magasanik, W. S. Reznikoff, M. Riley, M. Schaechter, and H. E. Umbarger (ed.), Escherichia coli and Salmonella: cellular and molecular biology, 2 ed. American Society for Microbiology, Washington, D.C.

2. Berkowitz, D., J. M. Hushon, H. J. Whitfield, Jr., J. Roth, and B. N. Ames. 1968. Procedure for identifying nonsense mutations. J. Bacteriol. 96:215-20.

3. Bochner, B. R., and B. N. Ames. 1982. Complete analysis of cellular nucleotides by twodimensional thin layer chromatography. J. Biol. Chem. 257:9759-69.

4. Chen, W., L. Wright, S. Li, S. D. Cosloy, and C. S. Russell. 1996. Expression of glutamyltRNA reductase in Escherichia coli. Biochim. Biophys. Acta. 1309:109-21.

5. Dorward, D. W. 1993. Detection and quantitation of heme-containing proteins by chemiluminescence. Anal. Biochem. 209:219-23.

6. Fuhrhop J. H., S. K. 1975. Hemes: determination as pyridine hemochromes, p. 804-807. In S. KM (ed.), Porphyrins and metalloporphyrins. Elsevier Science Inc., New York, NY.

7. Hoober, J. K., A. Kahn, D. E. Ash, S. Gough, and C. G. Kannangara. 1988. Biosynthesis of delta-aminolevulinate in greening barley leaves. IX. Structure of the substrate, mode of gabaculine inhibition, and the catalytic mechanism of glutamate 1-semialdehyde aminotransferase. Carlsberg Res. Commun. 53:11-25. 
8. Jahn, D., E. Verkamp, and D. Soll. 1992. Glutamyl-transfer RNA: a precursor of heme and chlorophyll biosynthesis. Trends Biochem. Sci. 17:215-8.

9. Luer, C., S. Schauer, K. Mobius, J. Schulze, W. D. Schubert, D. W. Heinz, D. Jahn, and J. Moser. 2005. Complex formation between glutamyl-tRNA reductase and glutamate-1-semialdehyde 2,1aminomutase in Escherichia coli during the initial reactions of porphyrin biosynthesis. J. Biol. Chem. 280:18568-72.

10. Maniatis, T., E. F. Fritsch, and J. Sambrook. 1982. Molecular cloning: a laboratory manual. Cold Spring Harbor Laboratory, Cold Spring Harbor, N.Y.

11. Moser, J., S. Lorenz, C. Hubschwerlen, A. Rompf, and D. Jahn. 1999. Methanopyrus kandleri glutamyl-tRNA reductase. J. Biol. Chem. 274:30679-85.

12. Moser, J., W. D. Schubert, V. Beier, I. Bringemeier, D. Jahn, and D. W. Heinz. 2001. Vshaped structure of glutamyl-tRNA reductase, the first enzyme of tRNA-dependent tetrapyrrole biosynthesis. EMBO J. 20:6583-90.

13. Neidhardt, F. C., P. L. Bloch, and D. F. Smith. 1974. Culture medium for enterobacteria. J. Bacteriol. 119:736-47.

14. Pace, C. N. and Schmid, F.X. 1997. How to determine the molar absorbance coefficient of a protein. p. 253-259 In Protein structure: A Practical Approach. T.E. Creighton (ed.) IRL Press, Oxford, U.K. 
15. Rieble, S., and S. I. Beale. 1991. Purification of glutamyl-tRNA reductase from Synechocystis sp. PCC 6803. J. Biol. Chem. 266:9740-5.

16. Schauer, S., S. Chaturvedi, L. Randau, J. Moser, M. Kitabatake, S. Lorenz, E. Verkamp, W. D. Schubert, T. Nakayashiki, M. Murai, K. Wall, H. U. Thomann, D. W. Heinz, H. Inokuchi, D. Soll, and D. Jahn. 2002. Escherichia coli glutamyl-tRNA reductase. Trapping the thioester intermediate. J. Biol. Chem. 277:48657-63.

17. Schauer, S., C. Luer, and J. Moser. 2003. Large scale production of biologically active Escherichia coli glutamyl-tRNA reductase from inclusion bodies. Protein Expr. Purif. 31:271-5.

18. Schroder, I., L. Hederstedt, C. G. Kannangara, and P. Gough. 1992. Glutamyl-tRNA reductase activity in Bacillus subtilis is dependent on the hemA gene product. Biochem. J. 281(Pt 3):84350.

19. Silhavy, T. J., M. L. Berman, and L. W. Enquist. 1984. Experiments with gene fusions. Cold Spring Harbor Laboratory, Cold Spring Harbor, N.Y.

20. Srivastava, A., V. Lake, L. A. Nogaj, S. M. Mayer, R. D. Willows, and S. I. Beale. 2005. The Chlamydomonas reinhardtii gtr gene encoding the tetrapyrrole biosynthetic enzyme glutamyl-tRNA reductase: structure of the gene and properties of the expressed enzyme. Plant Mol. Biol. 58:643-58.

21. Srivastava, A., and S. I. Beale. 2005. Glutamyl-tRNA reductase of Chlorobium vibrioforme is a dissociable homodimer that contains one tightly bound heme per subunit. J. Bacteriol. 187:4444-50. 
22. Studier, F. W., and B. A. Moffatt. 1986. Use of bacteriophage T7 RNA polymerase to direct selective high-level expression of cloned genes. J. Mol. Biol. 189:113-30.

23. Verkamp, E., M. Jahn, D. Jahn, A. M. Kumar, and D. Soll. 1992. Glutamyl-tRNA reductase from Escherichia coli and Synechocystis 6803. Gene structure and expression. J. Biol. Chem. 267:827580.

24. Vothknecht, U. C., C. G. Kannangara, and D. von Wettstein. 1996. Expression of catalytically active barley glutamyl tRNAGlu reductase in Escherichia coli as a fusion protein with glutathione Stransferase. Proc. Natl. Acad. Sci. U S A 93:9287-91.

25. Wang, L. Y., L. Brown, M. Elliott, and T. Elliott. 1997. Regulation of heme biosynthesis in Salmonella typhimurium: activity of glutamyl-tRNA reductase (HemA) is greatly elevated during heme limitation by a mechanism which increases abundance of the protein. J. Bacteriol. 179:2907-14.

26. Wang, L., M. Elliott, and T. Elliott. 1999. Conditional stability of the HemA protein (glutamyltRNA reductase) regulates heme biosynthesis in Salmonella typhimurium. J. Bacteriol. 181:1211-9.

27. Wang, L., S. Wilson, and T. Elliott. 1999. A mutant HemA protein with positive charge close to the $\mathrm{N}$ terminus is stabilized against heme-regulated proteolysis in Salmonella typhimurium. J. Bacteriol. $181: 6033-41$. 